\title{
Dynamics of the B-A Transition of DNA Double Helices
}

\author{
Dissertation \\ zur Erlangung des Doktorgrades \\ der Mathematisch-Naturwissenschaftlichen Fakultäten \\ der Georg-August-Universität zu Göttingen
}

\author{
vorgelegt von \\ Davis Jose \\ aus \\ Palai (Indien)
}

Göttingen 2005 
D 7

Referent:

Prof. Dr. Jurgen Troe

Korreferent:

Prof. Dr. Axel Zeeck

Tag der mündlichen Prüfung:

26-04-05 
Dedicated to my parents 


\section{Table of contents}

\section{Chapter 1 Introduction}

1.1 Introduction.....................................................

1.2 The structure of double stranded DNA ........................2

1.3 Different forms of DNA ......................................2

1.3.1 B-form DNA..............................................

1.3.2. A-form DNA......................................... 4

1.4 The B-A transition of DNA double helices......................... .5

1.4.1 Inducing the B-A transition in solution......................5

1.4.2 Sequence dependence of B-A transition .....................8

1.4.3 B-A transition is cooperative............................ 8

1.4.4 B-A transition in DNA and Transcription.......................11

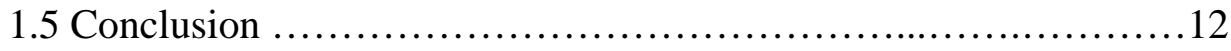

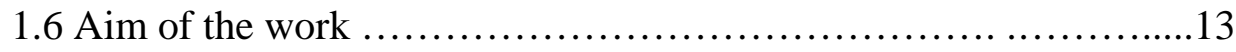

\section{Chapter 2 Materials}

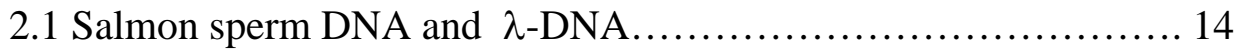

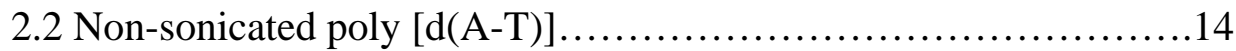

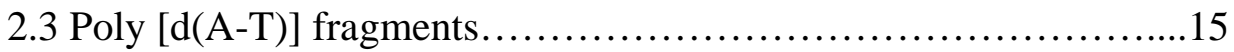

2.4859 bp DNA and plasmid DNA.................................15

2.5 Materials for stopped flow......................................16

2.6 Materials for field jump................................... 16

\section{Chapter 3 Methods}

3.1 Analytical ultra centrifugation.................................17

3.2 Gel electrophoresis .......................................18

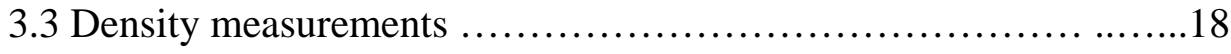


3.4 Viscosity measurements............................................. 19

3.4.1 Determination of the cell constant for the viscometer...........20

3.5 Melting temperature measurements ................................20

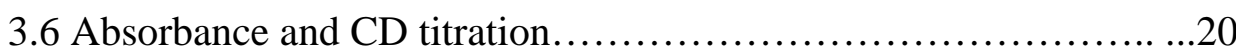

3.7 Stopped flow experiments ............................................

3.7.1 The stopped-flow instrument ................................. 21

3.7.2 Performance of the instrument.................................23

3.8 Relaxation Kinetics and field jump experiments......................24

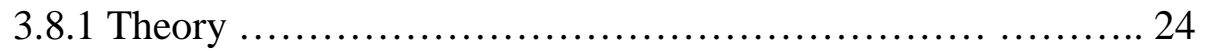

3.8.2 Field jump experiments .................................... 25

3.8.2.1 Dichroism amplitude...................................26

3.8.2.2 Dichroism decay ................................... 28

3.8.2.3 Magic angle measurements.............................29

3.8.2.4 Field jump instrument.................................... 30

3.8.2.5 Measuring cell........................................

3.8.2.6 Spectrophotometric detection..............................32

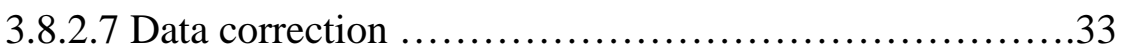

\section{Chapter 4 Results}

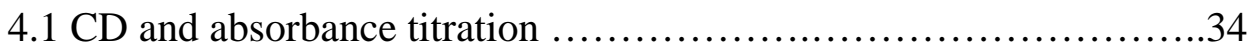

4.1.1 Transitions effected by ethanol...................................35

4.1.2 Transitions effected by multivalent cations......................39

4.1.3 Transitions effected by TFE...................................41

4.1.4 Selection of optimal probe and conditions .....................42

4.1.4.1 Denaturation Spectra ..................................43

4.1.4.2 Melting temperature measurements ...................44

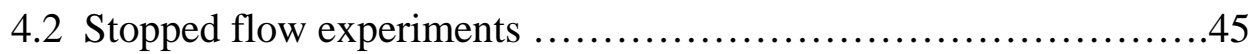

4.2.1 technical problems occurred in stopped flow experiments ..... 47

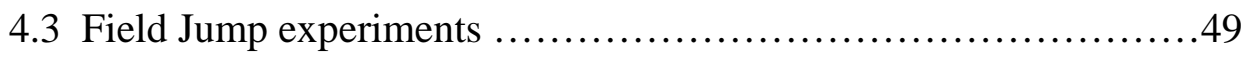

4.3.1 Experiments with poly [d(A-T)] and ethanol ................. 49 
4.3.2 Chain length dependence in B-A transition.......................56

4.3.2.1. Experiments with 70 bp poly d(A-T) fragment............56

4.3.2.2. Experiments with 120 bp poly d(A-T) fragment ...........59

4.3.3 Ionic strength dependence in B-A transition.....................61

4.3.4 Experiments with poly $[\mathrm{d}(\mathrm{A}-\mathrm{T})]$ and TFE....................62

4.3.5 Experiments with natural DNA ............................. 65

4.3.5.1 Experiments with 859 bp DNA .......................66

4.3.5.2 Experiments with 2629 bp plasmid DNA................72

4.3.5.3 Experiments with 7160 bp plasmid DNA................75

4.3.5.4 Experiments with $\lambda$-DNA........................76

4.3.6 Field dependence of B-A transition ........................... 83

Chapter $5 \quad$ Discussion............................................91

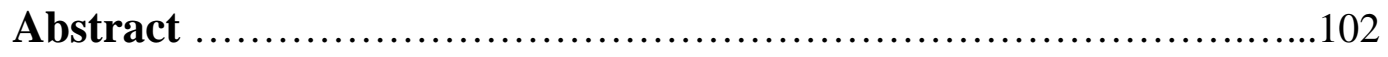

Abbreviations....................................................... 105

Specifications................................................................

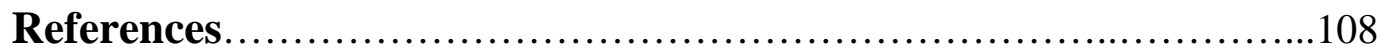




\section{CHAPTER 1}

\section{INTRODUCTION}

\subsection{Introduction}

Nucleic acids occupy a position of central importance in biological systems. Remarkably, even though based on relatively simple nucleotide monomers, these biopolymers participate in an impressive array of complex cellular functions. Nucleic acids are central molecules in the transmission, expression and conservation of genetic information. For example, from the deoxyribonucleic acid (DNA) duplex structure, genetic information is stored, accessed, and replicated as a linear nucleotide code. In partnership with DNA, ribonucleic acid (RNA) is an essential biopolymer, which among other functions transport genetic information from DNA to the site of protein manufacturing, the ribosome.

The classic example of how biological function follows from biomolecular structure comes from the elucidation by Watson and Crick (1953) of the structure of DNA as a double helix, using the X-ray fiber diffraction patterns generated by Franklin, Wilkins, and their associates (Franklin and Gosling, 1953; Wilkins et al., 1953) and the chemical evidence on base complementarity of Chargaff (1950). It was immediately obvious how information could be passed from one generation to the next by synthesizing a complementary strand for each of the parent strands and pairing with the parental complement. Meselson and Stahl (1957) used the technique of density gradient ultracentrifugation to verify this mode of semi conservative replication.

As one might expect, the study of nucleic acids has become a broad area spanning many diverse fields of science. Primary research aims include not only an understanding of the fundamental nature of nucleic acids, but also many more focused endeavours. Yet some of the basic factors remain undiscovered. 


\subsection{The structure of Double-Stranded DNA}

Watson and Crick first described the structure of the DNA double helix in 1953. Duplex DNA is a right-handed helix formed by two individual DNA strands aligned in an antiparallel direction. The two strands are held together by hydrogen bonds between individual bases. The bases are stacked near the center of the cylindrical helix. The base stacking provides considerable stability to the double helix. The sugar and phosphate groups are on the outside of the helix and form a backbone for the helix.

Differences between the characteristics of base stacking and hydrogen bonding energies contribute to the heterogeneity of the DNA helix structure. The overall energy of hydrogen bonding depends predominantly on base composition whereas base stacking energies depend on the sequence of the DNA. Once the DNA double helix is formed, it is remarkably stable. The individual interactions stabilizing the helix are weak, but the sum of all interactions makes a very stable helix.

It is significant biologically that the genetic information exists as a double stranded DNA molecule. First, the two complementary strands provide templates that can be copied by DNA polymerase, producing two exact copies of the genetic information. Second, the double stranded structure is also of critical importance when either strand is damaged by genotoxic chemicals or ionizing or ultraviolet radiation. By having two complementary copies of the genetic information, the undamaged strand can serve as a template for repair of the damaged strand. Third, the B-form helix is designed to protect the chemical identity of the genetic information. Hydrogen bonding, base stacking interactions, and hydration of the helix stabilize and chemically insulate the Watson-Crick informational coding surfaces from the environment.

\subsection{Different forms of DNA}

Currently many different helical geometries of DNA are known. Even though they share a number of common properties, the known helical structures of double stranded nucleic acids differ in a number of important features. These include the sense of the helix, number of base pairs per turn, the tilt of the base pairs, the twist of the base pairs, the diameter of the helix and the nature of the grooves of the helix. B-, 
A- and Z-form forms are the most important and widely studied forms of DNA. Numerous other subtle variations in the shape of the DNA double helix, in specialized situations, may have some biological relevance (Saenger, 1984).

The structure of DNA can be described by a number of parameters that define the helix (Dickerson et al., 1989; Saenger, 1984). Table 1 shows the difference in the important helix parameters of B and A forms of DNA double helix.

\begin{tabular}{|l|c|c|}
\hline Parameter & A-DNA & B-DNA \\
\hline Helix sense & Right & Right \\
\hline Residue per turn & 11 & $10(10.5)^{\mathrm{a}}$ \\
\hline Axial rise $(\AA)$ & 2.55 & 3.4 \\
\hline Helix pitch $\left(^{\circ}\right)$ & 28 & 34 \\
\hline Base pair tilt $\left(^{\circ}\right)$ & 20 & -6 \\
\hline Rotation per residue $\left(^{\circ}\right)$ & 33 & $36(34.3)^{\mathrm{a}}$ \\
\hline Diameter of the helix $(\AA)$ & 23 & 20 \\
\hline Major groove & narrow and deep & wide and deep \\
\hline Minor groove & wide and shallow & narrow and deep \\
\hline $\begin{array}{l}\text { Deoxyribose } \\
\text { ring conformation }\end{array}$ & C3`endo & C2`endo $^{`}$ \\
\hline
\end{tabular}

${ }^{a}$ Values in parenthesis are the residues per turn and rotation per residue for B-form DNA as it exists in solution of physiological ionic strength. Other values are taken from $X$-ray diffraction data (Sinden, 1994).

Table 1.1 Helix parameters

\subsubsection{B-form DNA}

The structure of B-form DNA, the most common form, was originally deduced from X-ray diffraction analysis of the sodium salt of DNA fibers at $92 \%$ relative humidity (Franklin and Gosling, 1953; Wilkins et al., 1953; Langridge et al., $1960 \mathrm{a}, \mathrm{b})$. A dominant feature of B-form DNA is the presence of two distinct grooves, a major and a minor groove. These two grooves obviously provide very distinct surfaces with which proteins can interact. Different DNA binding proteins have 
domains that interact with either the major or the minor groove. Different functional groups on the purine and pyrimidine bases are accessible from the major or the minor groove. The Watson-Crick hydrogen bonding surfaces are not available to solvent or proteins, since the functional groups involved in hydrogen bonding are interacting with each other at the center of the double helix.

\subsubsection{A-form DNA}

A-form DNA was originally identified by X-ray diffraction analysis of DNA fibers at 75\% relative humidity (Franklin and Gosling, 1953; Fuller et al., 1965). The grooves of A-DNA are not as deep as in B-DNA and the bases are much more tilted. The significant difference between A-form DNA and B-form DNA is that the sugar pucker in A-form DNA is C3'endo compared with C2'endo for B-DNA. Structures of the B-and A-form of the double helix are shown in figure 1.1. Another major structural distinction between A and B forms of DNA is a large hole in the Aform helix center. The hole diameter is $9 \AA$, almost a half of the total helix parameter. It should be noted that in spite of such a great difference between the two conformations, the $\mathrm{A}$ and $\mathrm{B}$ forms have almost equal diameters. The A-form central hole is the result of substantial base-pair displacement from the center to the periphery. The factor, which is responsible for this displacement, is the different sugar ring configuration in the B and A forms (Dickerson, 1992). The pentose ring is not flat but puckered, and this puckering is characterized by two discrete types of conformation, C2'-endo and C3'endo. C2'-endo correlates with B-form, whereas C3'-endo sugar puckering is characteristic of A-form. If the sugar conformation is switched from C2'-endo to C3'endo, the DNA is converted from B-form to A-form, then the direction glycoside bonds joining the sugars with bases is changed in the space approximately by $60^{\circ}$, and just this causes a large $(\sim 4 \AA)$ base pair shift from the center to the periphery. 


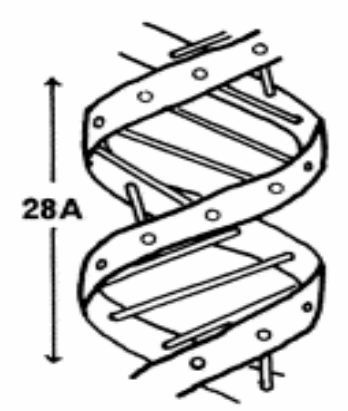

A.

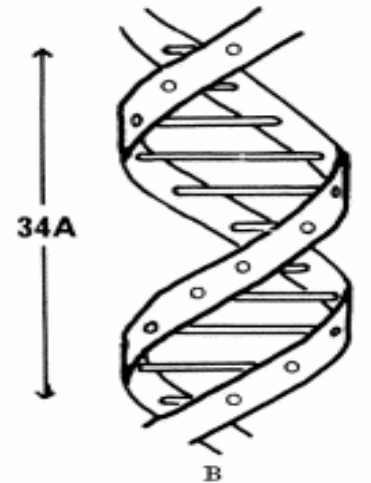

Figure 1.1 Schematic representation of the A and B forms of DNA

\subsection{The B-A transition of DNA double helices}

\subsubsection{Inducing B-A transition in solution}

The conformation of DNA in solution is a function of temperature, $\mathrm{pH}$, salt concentration, and solvent. Linear unconstrained DNAs mostly adopt variants of the Bform in low and moderate salt aqueous solutions, but there are solvents or agents that promote their non-B conformers. The transition between the standard B-form of DNA double helices and the A-form has been observed already during the first x-ray studies (Watson and Crick, 1953; Wilkins et al., 1953; Franklin and Gosling, 1953). The B to A transition of DNA in solution is induced by the reduction of water activity by addition of ethanol or trifluroethanol (Brahms et al., 1964; Ivanov et al., 1974; Ivanov et al., 1985). In X-ray fiber diffraction studies on natural DNAs, A, B and C forms were found on changing the humidity and salt conditions (Cooper, 1966; Arnott et al., 1972; Arnott et al., 1975). Now it is known that multivalent cations also play a major role in 
stabilizing different conformations of DNA (Bloomfield, 1991; Minyat et al., 1979)

Circular dichroism is a convenient method for tracing the shift of B-form to A-form or vice versa, which allows one to obtain the transition curve as a function of ethanol/TFE content (Brahms et al., 1964; Ivanov et al., 1974). There is a significant increase in magnitude of the first band of CD spectrum of natural DNA in $80 \%(\mathrm{v} / \mathrm{v})$ ethanol-water when compared to that of DNA in water alone. Thus while DNA assumes the well known B form in water, the CD spectrum in $80 \%$ ethanol resembles what one might expect for A-form DNA. Films of DNA in the A form have a similar large first CD band (Tunis-schnieder et al., 1970) as does double stranded RNA (Samejima et al., 1968; Gratzer et al., 1971).

DNA is a polyelectrolyte with a very high linear charge density, with one negative charge per phosphate. Therefore, DNA strongly interacts with ions, particularly cations, in the intracellular environment. Three major types of ionic interaction exist in nucleic acid solutions. They are 1) specific ion binding to a specific site on a DNA molecule 2) interactions of the Debye-Hückel type involving the diffuse ion atmosphere and 3) territorial binding of condensed counter ions. The interactions between a polyion and its counter ions are explained by the polyelectrolyte theory based on counter ion condensation by Manning (1977 a, 1979). Here, the polyelectrolyte was treated as a continuous line charge and the charge density parameter was defined. In the Poisson-Boltzmann theory, DNA was considered as a cylinder with a finite radius (Anderson and Record, 1982,1990). Recently the polyelectrolyte theory was extended from the standard line charge model to helical and double helical charge arrays (Manning, 2002). It is known that B-DNA has a lower charge density than A-DNA. The High charge density of A-form suggests that the A-form should be stabilized relative to the B-form with an increase in salt concentration. Therefore it is expected that cations will induce the B to A transition under proper conditions.

Spermine and spermidine are known to promote transcription and translation in vivo (Cohen et al., 1967; Young et al., 1974) and in vitro (Fuchs et al., 1967; Morris et al., 1973). Because of the cationic nature of these compounds they directly interact with nucleic acids. Minyat et al., showed that polyamines such as spermine and spermidine can induce the B- to A- transition of DNA in water/ethanol solution (Minyat et al., 1979). But puterscine and $\mathrm{Mg}^{2+}$ were found to stabilize the Bform (Ivanov et al., 1974, Minyat et al., 1979, Xu et al., 1993). This is in contrast to the proposed polyelectrolyte theory. One possible reason for this disagreement might be the 
specific site binding nature of these cations.

It is known that ethanol at high salt concentrations will induce aggregation of DNA. All the studies on B-A transition of DNA were done at a low salt concentration. Ivanov and coworkers described the dependence of B-A transition on salt concentration in detail (Ivanov, et al., 1974). Synthetic DNAs also undergo B-Atransition under suitable conditions. Conformational transitions were detected in poly [d(A-T)] (Vorlickova et al., 1982,1985$)$ and other synthetic nucleic acids. A summary of all literature on B-A transition in solution under different conditions is given in table 1.2.

\begin{tabular}{|c|c|c|c|c|}
\hline & DNA sample & Solvent & Salt concentration & Reference \\
\hline 1 & $\begin{array}{l}\text { Calf thymus } \\
\text { E.coli }\end{array}$ & Ethanol & $\begin{array}{l}\text { 1mM NaCl, } \\
1 \mathrm{mM} \text { Tris } \\
0.1 \mathrm{mM} \text { EDTA }\end{array}$ & Girod et.al (1973) \\
\hline 2 & $\begin{array}{l}\text { Calf thymus } \\
\text { M.luteus }\end{array}$ & Ethanol & $0.5 \mathrm{mM} \mathrm{NaCl}$ & Ivanov et.al (1974) \\
\hline 3 & $\begin{array}{l}\text { Calf thymus } \\
\text { E.coli } \\
\text { C.perfringens } \\
\end{array}$ & TFE & $\begin{array}{l}0.667 \mathrm{mM} \mathrm{Na}_{3 / 2} \mathrm{H}_{3 / 2} \\
\mathrm{PO}_{4},\end{array}$ & $\begin{array}{l}\text { Sprecher et.al } \\
(1979)\end{array}$ \\
\hline 4 & Calf thymus & $\begin{array}{l}\text { Ethanol/spermine } \\
\text { Ethanol/spermidine } \\
\text { Ethanol/putrecine }\end{array}$ & $0.5 \mathrm{mM} \mathrm{NaCl}$ & $\begin{array}{l}\text { Minayat et.al } \\
\text { (1979) }\end{array}$ \\
\hline 5 & $\begin{array}{l}\text { E.coli restriction } \\
\text { fragments }\end{array}$ & Ethanol & $\begin{array}{l}0.4 \mathrm{mM} \mathrm{NaPO}_{4} \\
0.02 \mathrm{mM} \mathrm{EDTA}\end{array}$ & $\begin{array}{l}\text { Hillen and Wells } \\
\text { (1980) }\end{array}$ \\
\hline 6 & $\begin{array}{l}\text { Calf thymus } \\
\text { E.coli } \\
\text { C.perfringens } \\
\end{array}$ & Ethanol & $\begin{array}{l}0.4 \mathrm{mM} \mathrm{NaPO}_{4} \\
0.02 \mathrm{mM} \mathrm{EDTA}\end{array}$ & $\begin{array}{l}\text { Nara-Inui,H et.al., } \\
\text { (1985) }\end{array}$ \\
\hline 7 & $\begin{array}{l}\text { Calf thymus } \\
\text { E.coli } \\
\text { C.perfringens }\end{array}$ & Ethanol & $0.3 \mathrm{mM} \mathrm{NaCl}_{4}$, & $\begin{array}{l}\text { Nara-Inui,H et.al., } \\
\text { (1985) }\end{array}$ \\
\hline 8 & $\begin{array}{l}4 \text { different self } \\
\text { complementary } \\
\text { dodecanucleotides }\end{array}$ & TFE & $\begin{array}{l}2 \mathrm{mM} \mathrm{NaCl}, \\
0.1 \mathrm{mM} \text { EDTA }\end{array}$ & $\begin{array}{l}\text { Minchenkova et.al } \\
\text { (1986) }\end{array}$ \\
\hline 9 & Poly [d(A-T)] & ethanol & $\begin{array}{l}0.15 \mathrm{mM} \mathrm{NaPO}_{4}, \\
0.02 \mathrm{mM} \text { EDTA }\end{array}$ & $\begin{array}{l}\text { Vorlickova et.al., } \\
(1982,1985)\end{array}$ \\
\hline
\end{tabular}

Table 1.2 Literature survey on B-A transition induced by alcohol 


\subsubsection{Sequence dependence of B-A transition}

The ability of DNA to undergo B-A-transition in solution with an increase of ethanol/TFE concentration depends only slightly on the GC-content. For example, on comparing the midpoint of transition of calf thymus DNA (42\% GC), and poly [d(A-T)] (Ivanov et al., 1985), the transition occurs nearly at the same ethanol content. But nucleic acids with high GC content undergo B-A- transition at lower ethanol content than those with very low GC content. The transition of M.lysodeicticus DNA (72\% GC) lies at an ethanol content lower by 3-4\% than for C.perfringens DNA (31\%) (Ivanov et al., 1983; Ivanov et al., 1985). In addition, a striking contrast is observed in the behaviour of the polynucleotides poly[dA-dT] and poly[dG-dC]. The former does not transit into A form under normal condition, whereas the latter retained its A-form under those conditions in which DNA exist in the B-form (Arnott et al., 1974). Minchenkova et al (1986) studied the sequence dependence of B-A-transition using four different self-complementary decadeoxynucleotides with defined nucleotide sequences. The results showed that the width of the B-A transition depends on the specific sequence of the base pairs. All these observations points towards the conclusion that it is the specific sequence rather than the general GC content that governs the ability of a sample to shift into an A conformation.

\subsubsection{B-A transition is cooperative}

Cooperative processes are observed in polymers. If a process consists of a series of equivalent reaction steps, it can undergo a cooperative process. A process is referred as cooperative, if it is carried out at once by a group of reaction steps rather than by individual reactions. Cooperative conformational transitions are of great importance in the understanding of biological processes such as enzyme regulation, synthesis and denaturation of nucleic acids and proteins etc. The formation of an $\alpha$ helix from a disordered polypeptide, which is a cooperative transition, is one of the most studied transitions in polypeptides. Depending on various factors such as temperature, solvent, $\mathrm{pH}$ and salt concentration, polypeptides exist in a state of either 
random coils or of the more highly ordered $\alpha$ - helix. The transitions between the two conformations are usually quite sharp, which is characteristic of a cooperative phenomenon. Moreover, the rate of forming a helix from the random coil state is very fast, generally occurring within $10^{-5}$ to $10^{-7} \mathrm{sec}$, and is independent of the length of the polypeptide chain. In contrast, the rate of unravelling is strongly size dependent (Creighton, 1983).

A cooperative transition is reflected by a sharp transition curve. If the transition is a non-cooperative one or if the chain length is below the cooperative length, a broad transition curve will be obtained. The B-A transition is found to have a relatively narrow transition curve, which indicates that this transition might be cooperative. If the B-A transition is cooperative, the base pairs will take part as a group. For this reason within a transition interval, a long DNA molecule is subdivided into alternating parts of B- and A- conformations (Krylov et al., 1990). Then there will be two types of junction points $A / B$ or $B / A$, which are specific boundary conformation, probably different from both A-and B-conformations. The boundary concentration is maximal at a half transition point, i.e., at an alcohol content where there are equal A- and B-fractions. At this point the difference between the A- and Bform free energies is equal to zero. Hence the relative concentration of boundaries is determined solely by the free energy of boundary Fj.

$[\mathrm{A} / \mathrm{B}] /[\mathrm{DNA}]=\exp (-\mathrm{Fj} / \mathrm{RT})$

where, $[\mathrm{A} / \mathrm{B}]$ is the concentration of $\mathrm{A} / \mathrm{B}$ junction, [DNA] is the concentration of DNA, $\mathrm{R}$ is the universal gas constant and $\mathrm{T}$ is the temperature.

The inverse value, evidently an average distance between neighbouring boundaries at the transition point is called the cooperativity length $v$ :

$v=\exp (\mathrm{Fj} / \mathrm{RT})$ or $\mathrm{Fj}=\mathrm{RT} \ln v$

So the higher is the boundary energy, the more cooperative the transition is, and the transition curve will have less width.

Ivanov and Krylov (1992) described three independent methods to show the cooperative character of B-A transition and determined the cooperative length of this transition. In the first method, ligands, which binds specifically with either B for or A form is used. The theory of co-operative transitions in the presence of ligands, developed by Frank-Kamenetskii and Karapetyan (1972) for helix - coil transition, was used to determine the cooperativity length. According to this theory, the 
cooperative length $v_{0}$ can be determined using the formula,

$v_{0}=(4 / \Delta \mathrm{a})_{c} \underline{\lim }_{0}\left(\delta \mathrm{a}_{\mathrm{t}}\right)^{2} /(c \delta \Delta \mathrm{a})$

where, $\Delta \mathrm{a}$ is the width of the transition curve without ligands, $\delta \mathrm{a}_{\mathrm{t}}$ is the shift of the mid point of transition in the presence of a concentration of ligands, $c$, expressed as the number of ligands per base pair and $\delta \Delta \mathrm{a}$ is the change in the width of the transition. The condition for the selection of ligands is that the ligand binding constant of one of the DNA forms is at least 10 times higher than that of the other one or the widening between the two curves should be two times larger than the shift of the transition point. Netropsin, which stabilizes B-form, and spermine which stabilizes Aform, were used as the ligand. Using these ligands, the cooperative length was found to be 10-30 base pairs (Ivanov et al., 1974; Minyat et al., 1979).

The second method was based on the phase diagram of A, B, and coil forms. Poly $[\mathrm{d}(\mathrm{A}-\mathrm{T})]$ was used as the model system and the change in enthalpy of the polynucleotide melting was determined by calorimetry. The slope of the A-coil and B-coil branches in the vicinity of the triple point was obtained from the phase diagram. Using these parameters and the width of the B-A transition for poly [d(A$\mathrm{T}$ )], a cooperative length of 30 base pair for B-A transition was obtained. (Ivanov et al., 1983,1985).

The drawback of the first method was the use of a foreign compound, whose size is comparable to the cooperativity length of the B-A transition. This problem was overcame by doing experiments with short fragments, where the length of the fragment is equal to or less than that of the cooperative length. Here the duplex will undergo the transition in an all-or-none principle, that is, without B-A junctions. B-A transition was followed in four self-complementary decadeoxyduplexes and found that all transitions have the same width of about $6 \%$ in terms of relative humidity. Using this transition width and the free energy parameters obtained from phase diagrams a cooperative length B-A transition was found to be approximately 16 base pairs.

The accuracy of these independent determinations is not very high. But all of them provided similar values and this confirms that the cooperative length of B-A transition is in the range of 10-30 base pairs. For comparison, helix to coil transition in DNA is characterized by a cooperativity length $v=10^{2}$ pairs (Frank-Kamenetskii, 1974), for B to $Z$ transition $v=10-25$ base pairs (Ivanov and Minyat, 1981; Ivanov et 
al., 1983).

But molecular dynamics simulation studies showing the B-A transition occurring within a few nanoseconds and the absence of any significant activation barrier suggested by Dickerson et al (2001) using a continuum of X-ray structures between B and A forms speaks against the cooperativity of B-A transition. Therefore, there is an ambiguity about the cooperative nature of B-A transition. To arrive at a conclusion about the cooperativity of B-A transition, the width of the transition for different chain lengths should be followed. For chain lengths above the cooperative length, a narrow transition range will be observed. Reasonable awareness about the time constants of this transition can reveal some idea about the cooperative nature of the B-A transition. It is expected that chain lengths above the cooperative length will undergo the transition at the same rate, whereas for those below the cooperative length, a noticeable retardation will be observed.

\subsubsection{B-A transition in DNA and Transcription}

It has been known for a long time now that double stranded RNA regions are present in A-conformation independently of the environment (Arnott, 1970). The 2'-OH group of the ribose sugar does not fit in the B-form sugar-phosphate backbone. But in A-conformation this hydroxyl group is directed outside without any steric barriers. For this reason the hybrid ribose-deoxyribose duplex prefers A-like conformation, since the DNA strand can acquire both conformations whereas only Aconformation is possible to the RNA one (Arnott et al., 1968; Lane et al., 1993). This fact led to the idea about the A-form involvement in transcription.

For confirming the involvement of A-form in transcription, RNA polymerase operation was closely followed (Beabealashvily et al., 1972; Ivanov et al., 1995). Specific RNA polymerase binding sites occupy only a small fraction of natural DNA. Treatment with DNAase gave DNA fragments, which are firmly bound with RNA polymerase. These nucleoprotein complexes were isolated and their CD spectra were registered to answer the question about the DNA form: A or B. It was shown that the polymerase bound DNA within the complex does not contain any noticeable amount of A-form (Ivanov et al., 1995). Thus RNA polymerase binding with promoter does not create A-conformation. The nucleoprotein complexes were capable of both synthesis initiation and synthesis of short RNA about 15 nucleotides. A CD 
spectrum recorded at specific intervals of this reaction showed the A-form arising at these steps. A simple calculation showed that the formed RNA is not large enough to explain the observed A-form amplitude. This means that the DNA template contributes to the A-form CD spectrum. The same result was also obtained without DNAase treatment (Wachsman et al., 1980). But these works did not firmly say whether the observed A-form belongs to a DNA-RNA hybrid or a part of the double stranded template itself is converted into A-form. The fact that polymerases are able to convert a part of DNA into A-conformation was found in the structural studies of a transcribing T7 RNA polymerase initiation complex (Cheatham and Steitz, 1999) and also in crystalline structure studies of the HIV reverse transcriptase complex with DNA ( Jacobo-Molina et al 1993). A number of other studies further confirmed the occurrence of B-A transition as an essential step for the processing of genetic information. (Jones, et al., 1999; Lu, et al., 2000; Keifer, et al., 1998).

\subsection{Conclusion}

The key roles played by nucleic acids in the molecular processes associated with life, especially the storage and transfer of genetic information, have focused the attention on these molecules. They have been studied over the years with every available technique, and a wealth of information has been obtained. Not only is the amount of information accumulated enormous, but the rate of acquisition of information is also increasing, with the major thrust being placed on genome projects.

DNA does not exist as the monotonously uniform helix. The conformation of DNA is not static, but dynamic. It depends upon the environment where it exists and is able to transform among them under suitable conditions. These different conformations may have some significant effect in the biological processes.

The transition between the standard B-form of DNA double helices and the A-form was observed during the first x-ray studies. This conformation may be biologically important. First it is a stable form of double helical fragments of RNA and thereby DNA-RNA hybrid duplexes. Second the local B to A transition of DNA has been repeatedly suggested to occur during transcription. Third proteins exist that transform DNA into A form when complexed (Mohr et al., 1991).

Ivanov and co-workers suggested that A-DNA is a high-energy 
conformation of the double helix under physiological conditions (Ivanov and Krylov, 1992). But Dickerson et al. showed X-ray structures, which were interpreted to represent a continuum of structures between B and A forms (Dickerson and Ng, 2001; Vargason et al., 2001, Ng and Dickerson, 2002). This suggests that there is no serious energy barrier between these two conformations and also points towards the absence of any significant activation barrier. In order to have an explicit insight into the B-A transition this contradiction should be explained.

Even though a lot of information about the different helical forms of nucleic acids is known, the dynamics of the transition between these different forms has not been characterized. To have an unambiguous understanding about the involvement of these different forms in the functioning of a living cell, it is necessary to have a precise idea about the dynamics of these transitions.

\subsection{Aim of the work}

The transition between the standard B-form of DNA double helices and the A-form was observed during the first X-ray studies. Fifty years on and the dynamics of this transition have still not been characterized, despite the fact that the B-A transition is known to be essential for the processing of genetic information. Molecular dynamics simulations have predicted the transition to proceed within a few nanoseconds (Yang et al., 1996; Cheatham et al., 1996; Sporus et al., 1998; Stefl et al., 2000; Dornberger et al., 2001) and the absence of any significant activation barrier has been suggested from a comparison of crystal structures (Dickerson and Ng, 2001; Vargason et al., 2001). This seems to be in contrast with the clear cooperativity of the B-A transition. The B-A transition was first detected by Franklin and Gosling, who characterized the change of the helix structure as 'a substantial rearrangement of the molecule'. This might be an indication for a substantial activation barrier. The aim of the present work was to experimentally determine the dynamics of B-A-transition. An unambiguous experimental determination of the rate of B-A transition will throw light into the internal dynamics of the DNA double helices. 


\section{CHAPTER 2}

\section{MATERIALS}

\subsection{Salmon sperm DNA and $\lambda$-DNA}

Salmon sperm DNA was purchased from sigma and $\lambda$-DNA was from Fermentas. Salmon sperm DNA was then dissolved in $0.1 \mathrm{M} \mathrm{NaCl}, 1 \mathrm{mM} \mathrm{Na}-$ cacodylate $\mathrm{pH} 7,0.2 \mathrm{mM}$ EDTA and the sample was agitated overnight. Part of the sample was then sonicated using a Branson sonifier B-12 under nitrogen atmosphere. $25 \mathrm{ml}$ of the stock solution was sonicated for 20 minutes. After 2 minutes of sonication one-minute pause was given to compensate for the heating up of sample during sonication. $\lambda$-DNA was dissolved in $0.2 \mathrm{M} \mathrm{NaCl}, 15 \mathrm{mM}$ Na-cacodylate $\mathrm{pH}$ 7, $3 \mathrm{mM}$ EDTA and was allowed to get completely dissolved by leaving it there for 2 hours. All samples were first dialyzed extensively against $0.2 \mathrm{M} \mathrm{NaCl}, 15 \mathrm{mM} \mathrm{Na}-$ cacodylate $\mathrm{pH} 7,3 \mathrm{mM}$ EDTA, and then against $0.25 \mathrm{mM} \mathrm{NaCl}, 0.25 \mathrm{mM} \mathrm{Na}-$ cacodylate $\mathrm{pH}$ 7, $0.05 \mathrm{mM}$ EDTA. Using analytical ultra centrifugation and gel electrophoresis non-sonicated Salmon sperm DNA was found to be with an average chain length of 4600 bp and sonicated Salmon sperm DNA was with an average chain length of $400 \mathrm{bp}$. For $\lambda$-DNA, the determined chain length was 48,502 bp.

\subsection{Non-sonicated poly[d(A-T)]}

Poly[d(A-T)] sodium salt (Sigma) was dialyzed extensively against $0.2 \mathrm{M}$ $\mathrm{NaCl}, 15 \mathrm{mM} \mathrm{Na}$-cacodylate $\mathrm{pH}$ 7, $3 \mathrm{mM}$ EDTA and then against $0.25 \mathrm{mM} \mathrm{NaCl}$, 0.25 mM Na-cacodylate pH 7, 0.05 mM EDTA. Using analytical ultracentrifugation and gel electrophoresis the chain length of the sample was determined to be $\sim 1500 \mathrm{bp}$ in $0.1 \mathrm{M} \mathrm{NaCl}, 10 \mathrm{mM}$ Na-Cacodylate pH 7, 2 mM EDTA. 


\subsection{Poly $[d(A-T)]$ fragments}

Poly $[\mathrm{d}(\mathrm{A}-\mathrm{T})]$ sodium salt, purchased from Sigma was dissolved in $0.1 \mathrm{M}$ $\mathrm{NaCl}, 1 \mathrm{mM}$ Na-cacodylate $\mathrm{pH}$ 7, $0.2 \mathrm{mM}$ EDTA. The sample was then sonicated using a Branson sonifier B-12 under nitrogen atmosphere at $0^{\circ} \mathrm{C} .3 \mathrm{ml}$ of the stock solution was sonicated for 14 minutes. After 2 minutes of sonication one-minute pause was given to compensate for the heating up of sample during sonication. The sonicated sample was then separated into different fractions by sephacryl S500 column chromatography. To get a more narrow distribution of chain lengths, these fractions were subjected to preparative polyacrylamide gel electrophoresis and subsequently to biotrap elution. The eluted sample was then dialyzed extensively against $0.2 \mathrm{M} \mathrm{NaCl}, 15 \mathrm{mM}$ Na-cacodylate $\mathrm{pH}$ 7, $3 \mathrm{mM}$ EDTA and then against 0.25 $\mathrm{mM} \mathrm{NaCl}, 0.25$ mM Na-cacodylate pH 7, 0.05 mM EDTA. The average chain lengths were determined by gel electrophoresis.

\subsection{9 bp DNA and plasmid DNAs}

The 859 bp DNA restriction fragment, 2629 bp plasmid DNA and 7160 bp plasmid DNA were kindly provided from the lab. The 859 bp DNA restriction fragment was prepared in the lab and used after dialyzing extensively against $1 \mathrm{M}$ $\mathrm{NaCl}, 1 \mathrm{mM}$ Na-cacodylate pH 7, $1 \mathrm{mM}$ EDTA and then against $0.25 \mathrm{mM} \mathrm{NaCl}, 0.25$ mM Na-cacodylate pH 7, 0.05 mM EDTA. 2629 bp plasmid DNA was prepared in the lab, linearized and used after dialyzing extensively against $1 \mathrm{M} \mathrm{NaCl}, 1 \mathrm{mM} \mathrm{Na}-$ cacodylate $\mathrm{pH}$ 7, $1 \mathrm{mM}$ EDTA and then against $0.25 \mathrm{mM} \mathrm{NaCl}, 0.25 \mathrm{mM}$ Nacacodylate $\mathrm{pH}$ 7, $0.05 \mathrm{mM}$ EDTA. The 7160 bp plasmid DNA was purchased from Plasmid Factory and was linearized by EcoR1. The sample was then dialyzed extensively against $1 \mathrm{M} \mathrm{NaCl}, 1 \mathrm{mM}$ Na-cacodylate $\mathrm{pH}$ 7, $1 \mathrm{mM}$ EDTA and then against $0.25 \mathrm{mM} \mathrm{NaCl}, 0.25 \mathrm{mM}$ Na-cacodylate pH 7, 0.05 mM EDTA. 


\subsection{Materials for stopped flow}

The concentration of the nucleic acid was adjusted so that the absorbance of the sample after mixing should be around 1. Nucleic acid samples and ethanol are degassed separately. Appropriate solutions were taken in each syringe, without any air bubble. The exact volume percentages of ethanol after mixing were determined from the corresponding densities.

\subsection{Materials for field jump}

The concentration of the nucleic acid was adjusted such that the dichroism amplitude does not exceed $10 \%$ of the total light intensity. The nucleic acid solution and ethanol were degassed separately and then calculated amount of ethanol was added to the nucleic acid solution and mixed well. The measuring cell was first degassed with buffer and then sample was transferred to it. Degassing of the sample inside the measuring cell was done for $\sim 25$ seconds and an absorbance spectrum of the sample was recorded. It was then subjected to field jump after making sure that no air bubbles are present in it. The state of the sample after experiment was checked by recording an absorbance spectrum and comparing it with the one recorded before experiment. The sample was then transferred to a density meter and density of the solution was determined at $20^{\circ} \mathrm{C}$. 


\section{CHAPTER 3}

\section{METHODS}

\subsection{Analytical ultra centrifugation}

Analytical ultra centrifugation was used to determine the exact molecular weight of the nucleic acids used in the experiments. Sedimentation velocity studies were carried out with nucleic acids samples and sedimentation coefficient of the samples was determined by Beckman XL-A optima analytical ultracentrifuge. The rotor used was $A n-60 \mathrm{Ti}$ and the change in absorbance was monitored at $250 \mathrm{~nm}$. The determination of the sedimentation coefficient was done at $8^{\circ} \mathrm{C}$ and the conversion of the observed sedimentation coefficient to the standard value was done using the formula;

$$
\begin{array}{rl}
S_{20, \mathrm{w}}= & S *(1-\mathrm{v} \rho)_{20, \mathrm{w}} * \eta_{\mathrm{T}, \mathrm{b}} \\
(1-\mathrm{v} \rho)_{\mathrm{T}, \mathrm{b}} & * \eta_{20, \mathrm{w}}
\end{array}
$$

where,

$\mathrm{S}^{*}=$ observed sedimentation coefficient

$\mathrm{v}_{20, \mathrm{w}}=$ specific volume of water at $20^{\circ} \mathrm{C}$

$\rho_{20, \mathrm{w}}=$ density of water at $20^{\circ} \mathrm{C}$

$\eta_{20, w}=$ coefficient viscosity of water at $20^{\circ} \mathrm{C}$

$\mathrm{v}_{\mathrm{T}, \mathrm{b}}=$ specific volume of solution at temperature $\mathrm{T}$

$\rho_{\mathrm{T}, \mathrm{b}}=$ density of solution at temperature $\mathrm{T}$

$\eta_{\mathrm{T}, \mathrm{b}}=$ coefficient viscosity of solution at temperature $\mathrm{T}$

The molecular weight of the sample was calculated using the equation (Yamakawa et al., 1973);

$\mathrm{S}_{20, \mathrm{w}}=\left[\mathrm{M}_{\mathrm{L}}(1-\mathrm{v} \rho) / \mathrm{N}_{\mathrm{A}} 3 \pi \eta\right]\left[\mathrm{C}_{1} \ln (\mathrm{L} / \mathrm{d})+\mathrm{C}_{2}+\mathrm{C}_{3} \mathrm{~L}+\mathrm{C}_{4} \mathrm{~L}^{2}+\mathrm{C}_{5} \mathrm{~L}^{3}\right]$

where, $\left\{\mathrm{L}=\lambda \mathrm{M} / \mathrm{M}_{\mathrm{L}}\right\}$ 
$\mathrm{M}_{\mathrm{L}}=$ Molecular weight per unit length of the cylinder axis, which is known to be 195 daltons/Å for DNA.

$\mathrm{N}_{\mathrm{A}}=$ Avagadro number

$\lambda^{-1}=$ Kuhn statistical segment length $=1000 \AA \AA$ in $0.1 \mathrm{M} \mathrm{NaCl}$

$\mathrm{d}=$ diameter $=25 \AA$

and $\mathrm{C}_{1}, \mathrm{C}_{2}$ etc are values which depends on the diameter

\subsection{Gel electrophoresis}

The molecular weight of samples used was further confirmed by gel electrophoresis. 5\% standard polyacrylamide gel was prepared using the following components:

$6.67 \mathrm{ml}$ rotiphorese gel 30

$4 \mathrm{ml} 10 \mathrm{X}$ TBE II

$29.11 \mathrm{ml} \mathrm{H}_{2} \mathrm{O}$

$200 \mu \mathrm{l}$ 10\% Ammoniumperoxodisulphate

$20 \mu \mathrm{l}$ TEMED as polymerisation catalyzer

A $2 \mathrm{~mm}$ spacer was used and the gel was allowed to polymerise for 45

minutes. Once the electrophoresis was over, the gel was stained with ethidium bromide solution and photograph was taken.

\subsection{Density Measurement}

Density of an aqueous solution is dependent on the percentage of the components and the temperature at which the measurement was done. The B-A transition has a strong dependence on the percentage of ethanol. The boiling point of ethanol is $70^{\circ} \mathrm{C}$ and that of TFE is $72-74^{\circ} \mathrm{C}$. Therefore on degassing an aqueous solution of ethanol or TFE, a change in the percentage of components will occur. For an exact determination of the percentage of components, density measurement of the sample was used. The density was then converted to weight percentage of the components and finally to volume percentages.

The density measurements of all samples were carried out on a DMA60 Density meter in combination with a DMA602 remote cell at $20^{\circ} \mathrm{C}$. The remote cell 
consists of a $U$ tube to which the sample is injected. The instrument directly measures the period of oscillation, T. The instrument was calibrated at various temperatures using water and heptane as standard solutions. Measured periods and corresponding density values of water at various temperatures were used for the determination of densities of other samples. The measured period of the sample was converted to density using the following equation;

$\rho_{\mathrm{x}}=\rho_{\mathrm{w}}-\mathrm{K}\left(\mathrm{T}_{\mathrm{w}}{ }^{2}-\mathrm{T}_{\mathrm{x}}{ }^{2}\right)$

where $\rho_{\mathrm{x}}$ and $\rho_{\mathrm{w}}$ are the densities of the sample and water, $T_{\mathrm{x}}, \mathrm{T}_{\mathrm{w}}$ are the period of oscillation of sample and water at the measuring temperature and $\mathrm{K}$ is the calibration constant. Performance of the instrument was checked with water and ethanol and it showed that the density of a sample could be measured up to an accuracy of $10^{-5} \pm$ $10^{-6} \mathrm{~g} \mathrm{~cm}^{-3}$.

\subsection{Viscosity Measurement}

In order to have a standard criterion for evaluation of the dichroism decay time constants, the time constants should be corrected to the state of water at $20^{\circ} \mathrm{C}$. To apply viscosity corrections, the viscosity of ethanol-water mixture and TFE-water mixture should be known. Viscosity of ethanol-water mixture was available from literature. But adequate data, which shows the relationship between percentage of components and their coefficient of viscosity for TFE-water mixture, was not available. Therefore, experiments were done to determine the coefficient of viscosity of water-TFE mixture at $8^{\circ} \mathrm{C}$.

KPG Ubbelohde micro-viscometer with capillary number I (colour code blue) was used for the measurement. Proper thermostating was done by a water bath and temperature was maintained exactly at $8 \pm 0.5^{\circ} \mathrm{C}$ throughout the experiment. The solution was mixed thoroughly and centrifugation for 2 minutes at $12000 \mathrm{rev} / \mathrm{min}$ in an eppendorf centrifuge 5415C was done. It was then degassed for 40 seconds and then the solution was transferred to the viscometer. The apparatus was set at $8^{\circ} \mathrm{C}$, the viscometer was kept inside the chamber for about 20 minutes for temperature equilibration, and efflux time was determined. The measurement was repeated till reproducible results were obtained. 


\subsubsection{Determination of the cell constant for the viscometer}

Kinematic viscosity of water at $8^{\circ} \mathrm{C}$ was calculated using its coefficient of viscosity and density at $8^{\circ} \mathrm{C}$ and the value is $1.3862 \mathrm{~mm}^{2} / \mathrm{sec}$. The efflux time of water at $8^{\circ} \mathrm{C}$ was determined and using these values, the cell constant for the viscometer was calculated using the equation,

$\mathrm{K}=\mathrm{v} /(\mathrm{t}-\tau)$

Where $v$ is the kinematic viscosity, $t$ is the efflux time and $\tau$ is the Hagenbach correction which is 0.0135 seconds for the current set-up and the obtained cell constant was 0.01069 .

The kinematic viscosity at various percentages of TFE was calculated using the following equation $v=K(t-\tau)$ and the coefficient of viscosities were determined using the density of the solution at that particular TFE percentage using the formula, $\eta=v \rho$

where $\eta$ is the coefficient of viscosity and $\rho$ is the density of the solution.

\subsection{Melting temperature measurement}

The exact state of each sample was confirmed by checking its melting temperature. The change in absorbance as a function of temperature was followed at $260 \mathrm{~nm}$ in a Cary 219 spectrophotometer. An increase in temperature of $0.1^{\circ} \mathrm{C}$ per minute was applied to the sample.

\subsection{Absorbance and CD titration}

Ultraviolet absorption (UV) and circular dichroism (CD) spectroscopes that probe electronic properties of the bases are very useful and general tools for characterizing nucleic acids, although they do not provide the atomic level detail of crystallography or NMR. Native states of nucleic acids can be distinguished from denatured states by measurement of the absorbance of unpolarized light. The UV 
absorbance of a double stranded polynucleotide can be $20-30 \%$ less than that of the single strands. CD gives even more information about nucleic acid helical structures. CD spectroscopy is sensitive to the asymmetry of a molecule. In the case of DNA, the chromophores for the CD transitions are the four bases. The bases themselves have a plane of symmetry, but a CD is induced in their electronic transition by interactions with the asymmetric environment of the DNA. Since the circular dichroism of a base is determined primarily by its immediate environment, the measurement is particularly sensitive to the secondary structure of DNA.

The B-A-transition can be easily followed by the change in absorbance of the sample. A Cary $4 \mathrm{UV}$-Visible spectrophotometer was used for recording the spectrum. Titration with poly $[\mathrm{d}(\mathrm{A}-\mathrm{T})]$ was conducted at $0^{\circ} \mathrm{C}$, under nitrogen atmosphere, whereas experiments with natural DNA was done at $20^{\circ} \mathrm{C}$. The baseline was first set by recording air against air. Cuvettes with a path length of $2 \mathrm{~cm}$ were used in which one contains the sample and the other buffer alone. Calculated amount of ethanol was added to both cuvettes each time and absorbance spectrum was recorded. This was then converted to extinction coefficient and spectrum of clean $\mathrm{B}$ form (either at $0 \%$ Ethanol or at $50 \%$ ethanol) was subtracted from all other spectra and a difference spectrum, which shows clearly the change in extinction coefficients occurring on B-A- transition was obtained.

All CD experiments were carried out on a JASCO J-720 spectrophotometer. A strain free cuvette of $1 \mathrm{~cm}$ path length was used for the measurement. Experiments with natural DNAs were done at room temperature, while that with poly $[\mathrm{d}(\mathrm{A}-\mathrm{T})]$ was performed at $0^{\circ} \mathrm{C}$. For experiments at $0^{\circ} \mathrm{C}$, condensation of moisture on the surface of the cuvettes were avoided by providing nitrogen atmosphere in the chamber.

\subsection{Stopped flow experiments}

\subsubsection{The stopped-flow instrument}

A stopped flow spectrophotometer is essentially a conventional spectrophotometer with the addition of a system for rapid mixing- the stopped-flow block. The block diagram (fig. 3.1) of the stopped-flow instrument shows the main 
parts and their assembly: the two syringes, the mixing chamber, the observation cell and the stop-syringe. By applying pressure on the drive plate, the flow was initiated. The solutions from the two syringes then flow into the mixing chamber and then to the observation cell. A special type of quartz cuvette prepared by Hellma GmbH and Co (Müllheim, Germany) was used as the observation cell. The optical detection system was constructed from the following main components: a 200W mercury-xenon lamp, a Bausch \& Lomb high-intensity gating monochromator, and a photomultiplier with amplifier. The solution from the observation cell then flows into the stop syringe. The system also contains a trigger switch, which initiates the recording of the signal with time. The measured signals are digitised by a Tektronix DSA 602 and are transmitted to a PC. A more detailed description of the instrument and its components can be found elsewhere. (Porschke, 1998).

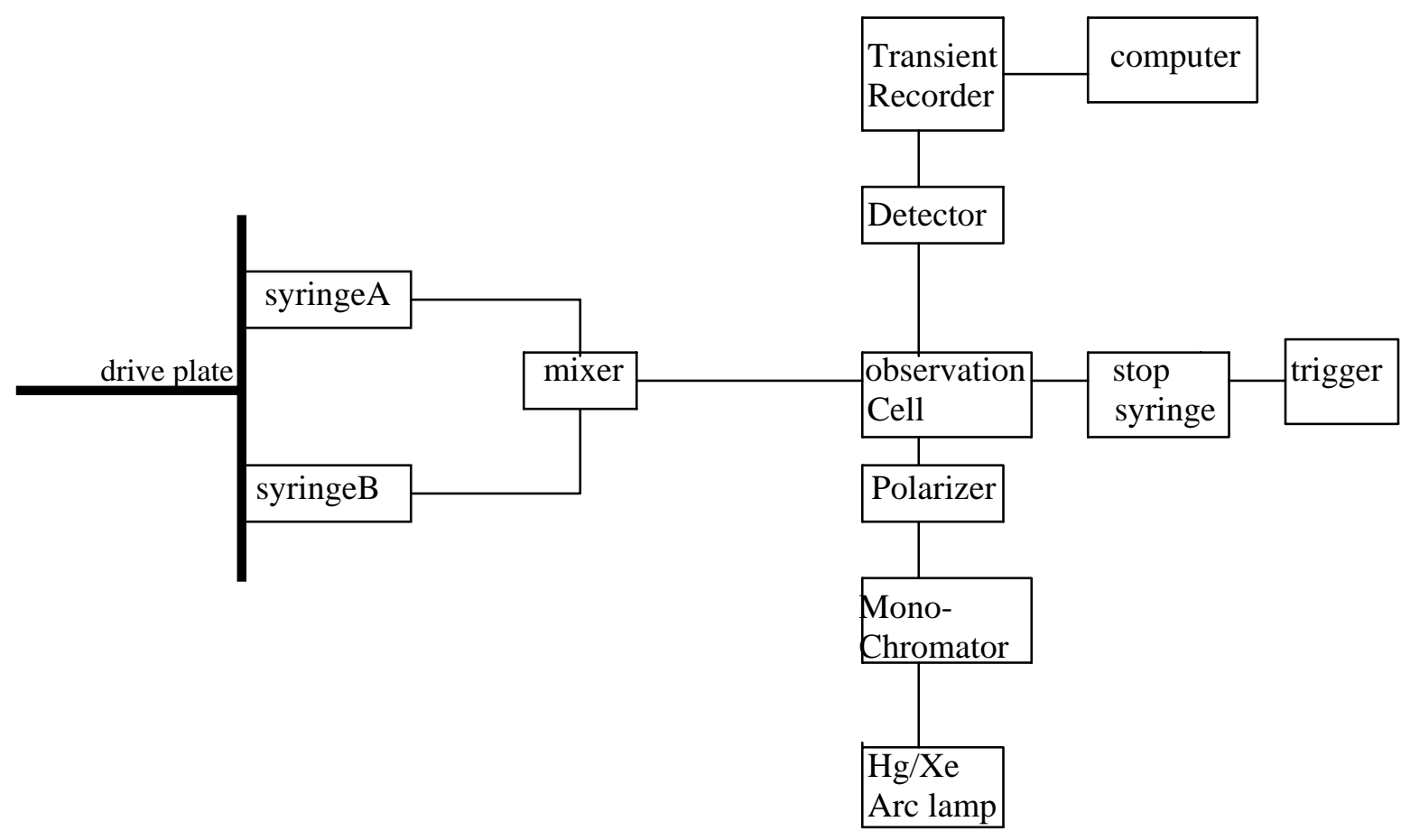

Figure 3.1 Block diagram of the stopped-flow instrument 


\subsubsection{Performance of the instrument}

The two most important criteria for the quality of a stopped-flow instrument are the homogeneity of mixing and the "dead time" of the flow. Mixing of a solution of zero absorbance with a solution of high absorbance did not lead to transients in the record signal: this result demonstrates that mixing into the measuring cell is completely homogenous.

The dead time of stopped-flow instrument is the time, which elapses between mixing and observation. Reactions occurring faster than the dead time of the instrument cannot be measured. This precise theoretical definition of dead time, however, does not hold in practice since the points of mixing and observation are not uniquely defined. Although the two solutions come into contact with each other in a definite point, complete mixing occurs during the turbulent flow of the solution from the mixer to the observation cell. Similarly, the solution is not observed at a single point in this cell but over a finite distance and therefore at a finite range of times. Since both points in the theoretical definition of dead time are floating, the best can be done is to experimentally determine the effective dead time of the instrument. The effective dead time is the average age of the solution in the observation chamber when flow stops. The dead time was measured by the reaction of 2,6dichlorophenolindophenol with ascorbic acid (Tonomura et al., 1978). By an excess of ascorbic acid the reaction was forced to be pseudo-first-order; the reduction reaction of 2,6-dichlorophenolindophenol was recorded at $580 \mathrm{~nm}$. Measurements with ascorbic acid concentrations in the range of 10 to $50 \mathrm{mM}$ showed that the dead time of the instrument under the standard conditions of operation is $0.2 \mathrm{~ms}$. 


\subsection{Relaxation kinetics}

\subsubsection{Theory}

Mixing techniques are limited in time resolution to about $10^{-4} \mathrm{sec}$ because of the physical problem of rapidly combining two solutions. Relaxation methods circumvent this difficulty. One special feature of relaxation kinetics is that one deals with rate process of systems that are close to equilibrium. So all rate equations, regardless of order, are reduced to linear relationships and thus allow the treatment of complex systems in a relatively straightforward fashion (Eigen and DeMaeyer, 1963; Bernasconi, 1976).

A chemical equilibrium, and thus the equilibrium concentrations of the species involved, is dependent on external parameters such as temperature, pressure or electric field strength according to

$\delta \ln \mathrm{K}=(\delta \ln K / \delta \mathrm{T})_{\mathrm{P}, \mathrm{E}} \delta \mathrm{T}+(\delta \ln \mathrm{K} / \delta \mathrm{P})_{\mathrm{T}, \mathrm{E}} \delta \mathrm{P}+(\delta \ln \mathrm{K} / \delta \mathrm{E})_{\mathrm{P}, \mathrm{T}} \delta \mathrm{E}$

where $\mathrm{K}$ is the equilibrium constant, $\mathrm{T}$ is the temperature, $\mathrm{P}$ is the pressure and $\mathrm{E}$ is the electric field. In chemical relaxation technique, the equilibrium is rapidly changed by perturbing one of these parameters. The reestablishment of equilibrium requires a certain amount of time depending upon the rate constants of the system. If the external parameter is changed within a very short time $t$, it is possible to observe reactions with time constants very close to $t$. The time resolution is determined by the rate of change in the external parameter and, of course, also by the response time of the detector used for the measurements.

In most relaxation experiments the chemical equilibrium is perturbed only to a relatively small degree. A single reaction step is reflected by one relaxation process

$$
\mathrm{c}(\mathrm{t})=\mathrm{c} 1+(\mathrm{c} 2-\mathrm{c} 1) *\left(1-\mathrm{e}^{(-\mathrm{t} / \tau)}\right)
$$

with a time constant $\tau$, which depends upon the rate constants and the concentrations. When several reactions are coupled to each other, one relaxation effect is expected for each independent reaction step. In addition to the time constants the relaxation curves contain another very useful information: the amplitudes directly depend upon 
thermodynamic parameters and thus can be used for the determination of equilibrium constants.

\subsubsection{Field jump Experiments}

Two different types of reactions are known to be sensitive to electric fields and thus may show field induced relaxation effects (Eigen and DeMaeyer, 1963; Demaeyer, 1969; Demaeyer, 1974). The first type of reaction is associated with a change in the dipole moment. It can be calculated that rather high changes in the dipole moment are required for any appreciable changes in the equilibrium at the field strengths, which are accessible in the usual instruments. Reactions of this type with sufficiently high changes in the dipole moment are quite rare. The second type of reaction, which may be perturbed by field pulses, is associated with some change in the state of ionization. As calculated by Onsager (Onsager, 1934) and found experimentally, this type of reaction is quite sensitive to electric fields. A simple $\mathrm{A}^{+}+$ $\mathrm{B}^{-} \leftrightarrow \mathrm{AB}$ reaction may be perturbed by electric fields of moderate strength to considerable degree, such that the relaxation can be easily characterized. Much larger amplitudes are found for reactions with higher changes in the number of charges. Since most biopolymers are polyelectrolytes, their reactions can be analysed with the aid of field jump instruments.

A system containing free charges cannot be in true thermodynamic equilibrium in the presence of an electric field, since the latter implies a steady flow of charges. But in the absence of free charges, in a solution containing permanent dipoles or polarizable molecules, a thermodynamic approach to the problem of chemical coupling is suitable. A thermodynamic derivation of the effect of a homogenous electric field upon a chemical reaction equilibrium leads to the following expression:

$$
\left(\delta \ln K_{\mathrm{c}} / \delta \mathrm{E}\right)_{\mathrm{T}, \mathrm{P}}=(\Delta \mathrm{M} / \mathrm{RT})
$$

where $\mathrm{E}$ is the field strength, $\mathrm{K}$ is the equilibrium constant of the chemical reaction, $\mathrm{R}$ is the gas constant and $\mathrm{T}$ is the temperature. The quantity $\Delta \mathrm{M}$ is the change in the macroscopic electric moment of the system per mole equivalent transformation of reaction partners:

$$
\Delta \mathrm{M}=(\delta \mathrm{M} / \delta \xi)_{\mathrm{T}, \mathrm{P}, \mathrm{E}}
$$


the variable $\xi$ is the extent of reaction, expressed by the number of mole equivalents transformed.

\subsubsection{Dichroism amplitude}

Almost all macromolecules have some electric dipole and when short pulses of electric fields are applied to solutions of macromolecules, the field pulses induce alignment of the molecules along the direction of the field vector. This molecular alignment can be recorded: 1) by measurements of the absorbance of polarized light 2) by measurements of the anisotropy of the refractive index 3) by any other optical technique like fluorescence or light scattering.

During application of an electric field pulse the change of the optical parameter approaches a limiting value, which is characteristic of a stationary state with partially aligned molecules. The change of the optical parameter, reflecting the degree of alignment, increases with increasing field strength.

The orientation of molecules in the presence of an external electric field results from the interaction of their dipole moments with the field. In the case of induced dipoles with a preferential polarizability $\alpha$ along one axis of the molecule, the energy of interaction is given by:

$$
\mathrm{U}_{\mathrm{i}}=-(1 / 2) \alpha \mathrm{E}^{2} \cos ^{2} \theta
$$

where $E$ is the electric field strength and $\theta$ is the angle between the induced dipole and the electric field vector. In the case of permanent dipoles with a dipole moment $\mu_{\mathrm{p}}$ the energy of interaction is given by

$$
\mathrm{U}_{\mathrm{p}}=-\mu_{\mathrm{p}} \mathrm{E} \cos \theta
$$

The distribution of molecular orientations is determined by the interaction energy with respect to the thermal energy $k T, k$ is the Boltzmann constant, $\mathrm{T}=$ absolute temperature and is described by the Boltzmann function:

$$
f(\theta)=\frac{\exp (-\mathrm{U} / k \mathrm{~T})}{\int_{0}^{\pi}(\exp (-\mathrm{U} / k \mathrm{~T}) 2 \pi \sin \theta \mathrm{d} \theta)}
$$

where $\mathrm{U}=\mathrm{U}_{\mathrm{i}}+\mathrm{U}_{\mathrm{p}}$

When the molecules are aligned in the direction of the electric field, the 
absorbance of light is changed relative to the natural state, where the molecules are in the usual random spatial distribution. The change of the absorbance of light polarized parallel to the field vector $\Delta \mathrm{A}_{l l}$ is a measure of the degree of orientation. The theory predicts that the change of the absorbance of light polarized perpendicular to the field vector $\Delta \mathrm{A}_{\perp}$ measured under the same conditions fulfils the relation:

$$
\Delta \mathrm{A}_{l l}=-2 \Delta \mathrm{A}_{\perp}
$$

the relative change of the absorbance defined by:

$$
\left(\Delta \mathrm{A}_{11}-\Delta \mathrm{A}_{\perp}\right) / \mathrm{A}=\left(1.5 * \Delta \mathrm{A}_{11}\right) / \mathrm{A}=\xi,
$$

where $\xi$ is the reduced electric dichroism, A is the isotropic absorbance measured in the absence of an electric field.

The degree of molecular orientation and thus the magnitude of electric dichroism increases with the electric field strength E. Complete orientation in the direction of electric field may be expected only in the limit of infinitely high E. The distribution of the orientational states is described quantitatively by the Boltzmann function. The dependence of the dichroism on the electric field strength requires integration of the following form of the Boltzmann function, also denoted as the 'orientation function':

$$
\phi=\frac{\int_{0}^{\pi}[\exp (-\mathrm{U} / k \mathrm{~T})]\left(3 \cos ^{2} \theta-1\right)(\pi \sin \theta \mathrm{d} \theta)}{\int_{0}^{\pi}[\exp (-\mathrm{U} / k \mathrm{~T})](2 \pi \sin \theta \mathrm{d} \theta)}
$$

and the dependence of the dichroism on the electric field strength is given by:

$$
\xi=\phi \cdot \xi_{\infty}
$$

in the case of induced dipoles the orientation function is given by:

$$
\phi=\left\{3 / 4\left[\left(\mathrm{e}^{\gamma / \sqrt{ } \gamma} \int_{0}^{\sqrt{\gamma}} \mathrm{e}^{\mathrm{x} 2} \mathrm{dx}\right)-1 / \gamma\right]-1 / 2\right\}
$$

where $\gamma=\left(\alpha E^{2}\right) /(2 k T)$.

In the case of permanent dipoles the orientation function is given by:

$$
\phi=[1-\{3[\operatorname{coth} \beta-(1 / \beta)] / \beta\}
$$

where $\beta=\mu_{\mathrm{p}} \mathrm{E} / \mathrm{kT}$ 
The orientation functions may be used to determine the limiting value of the electric dichroism corresponding to complete molecular orientation, by least squares fitting of dichroism values measured at different field strengths. The limiting value of the electric dichroism provides direct information about the orientation of the chromophores with respect to the dipole vector according to the following relation:

$$
\xi_{\infty}=(3 / 2)\left(3 \cos ^{2}(\varphi)-1\right)
$$

where $\varphi$ is the angle of the transition dipole moment of the chromophore relative to the dipole vector. When the transition dipole moment of the chromophore is oriented parallel to the dipole vector, corresponding to $\varphi=0^{\circ}$, the limiting value of dichroism is +3 . In the other limit case, where the transition dipole moment of the chromophore is in a perpendicular direction, the dipole vector $\varphi=90^{\circ}$, the liming value of dichroism is -1.5 . Thus, the limiting value of the electric dichroism can be used to calculate the angle $\varphi$ of the optical transition dipole with respect to the direction of the electric dipole. A quantitative analysis of stationary values of the dichroism measured at different field strengths using appropriate orientation functions may also be used to determine the nature and magnitude of the dipole moment. The electrostatic parameters provide information on the state of the charged residues of the macromolecule.

\subsubsection{Dichroism decay}

When the electric field is switched off, the molecules revert to their random distribution by the process of rotational diffusion. The process of rotational diffusion is very strongly dependent on the molecular size: the time required for the transition from the aligned to the random state increases with the cube of the length of rigid rod like molecules. Thus the dichroism decay time constant, which reflects the rotational diffusion process, is a very sensitive indicator of the length. Short DNA molecules up to chain lengths of $\sim 100$ bp behave like rigid rods. Rotational diffusion of these rigid rods is mainly determined by the length $l$ of the rod, whereas the width of the rod, described by the radius $r$, is of marginal influence only, except for very short rods. The dichroism decay time constants $\tau_{\mathrm{d}}{ }^{\mathrm{rr}}$ for such rods may be described by (Tirado et al., 1980; Tirado et al. 1984), 
$\tau_{\mathrm{d}}^{\mathrm{rr}}=\left(\pi \eta l^{3)} / 18 \mathrm{kT} .\left[\ln (\mathrm{q})-0.662+(0.917 / \mathrm{q})-\left(0.050 / \mathrm{q}^{2}\right)\right]\right.$

where $\mathrm{q}=l / 2 r$. This equation may be used to calculate the length $l$ of a rigid rod like molecule from its dichroism decay time constant.

\subsubsection{Magic angle measurements}

Electric field pulses induce both chemical and physical relaxation effects. The first description and analysis of chemical effects induced by electric fields has been presented by Wien (Wien, 1931). A theoretical description of the "second Wien effect” or the "dissociation field effect” has been given by Onsager (Onsager, 1934). It has been shown that this effect is particularly large for polyelectrolytes (Wissbrun et al. 1958). For a proper understanding of these two effects, they must be well separated from each other and any superimposition of these two entirely different effects will lead to misinterpretation of the observed data. The field induced reaction effects can be separated from orientation effects by using polarized light oriented at the magic angle $\left(54.7^{\circ}\right)$ with respect to the field vector.

The first application of magic angle conditions for measurements of temperature jump relaxation data has been reported by Dourlent et al. (1974). But a complete suppression of the orientation effect was not observed at $54.7^{\circ}$, instead an empirical adjustment of the polarizer for optimal suppression, which was clearly different by about $15^{\circ}$ from the expectation according to theory was used. Quartz is quite sensitive to mechanical stress and shows optical anisotropy under relatively small mechanical distortions. The optical anisotropy may lead to rather large perturbations under the conditions of temperature and field jump experiments. Usually the jumps are associated with pressure waves, which increase any residual optical anisotropy. This anisotropy lead to the observed deviation in the magic angle.

If absorbance changes resulting from orientations are to be suppressed, the quartz windows should be made as strain free as possible. A procedure developed by Porschke (Porschke, 1996) serves as the most appropriate one for the prevention of any effects induced by the strain of quartz windows. Because of the high sensitivity of quartz crystals towards any mechanical distortion, the cells used for these measurements have to be constructed with special care. First of all, the orifices in the cell bodies for the quartz windows have to be machined as accurately as possible. The 
quartz windows are then inserted into the cell body without any strain by using a layer of silicon grease of medium viscosity. If the quartz windows are inserted carefully with a sufficient quantity of grease, the windows are virtually swimming in grease, which avoids any strain and leads to damping of effects that may be induced by shock waves. The available silicon grease is inert, but during degassing of solutions in the cell usually some grease may move on to the inner surface of the quartz used for transmission of the light beam. But test experiments showed that there is not any artefact resulting from the grease.

The magic angle has to be adjusted with special care, when chemical relaxation effects are investigated in the presence of large orientation effects. The exact magic angle for a set up was precisely determined by using DNA double helices as a test system because of their high optical anisotropy.

A large optical anisotropy of the system under investigation induces changes of the polarization state of the light beam used and thus suspends the magic angle conditions. The magic angle conditions remain valid if the change of the light intensity resulting from orientation effects does not exceed $10 \%$ of the total light intensity. If changes of light intensity resulting from electric dichroism exceed $10 \%$ of the total light intensity, either wavelength used for observation should be readjusted, or the concentration of the sample should be reduced so that it is within the $10 \%$ limit. There are a number of experiments in literature in which satisfactory separation of physical and chemical relaxations are done (Porschke, 1974, 1976)

When reaction effects are small compared to orientation effects, the magic angle conditions should be controlled carefully. Such control involves measurement of the field induced amplitudes $\Delta \mathrm{A}_{0}, \Delta \mathrm{A}_{55}$ and $\Delta \mathrm{A}_{90}$ with polarized light oriented at $\varphi$ $=0^{\circ}, 55^{\circ}, 90^{\circ}$ with respect to field vector. The ratio

$\mathrm{R}=\left(\Delta \mathrm{A}_{0}-\Delta \mathrm{A}_{55}\right) /\left(\Delta \mathrm{A}_{90}-\Delta \mathrm{A}_{55}\right)$ should be -2 . Data with a deviation larger than $10 \%$ from this value were rejected.

\subsubsection{Field jump instrument}

The major parts of an instrument for electro-optical measurement comprises of a pulse generator, a system for spectrophotometric detection, a device for analog-digital conversion, and a computer for data processing. The general design 
of such an instrument is shown in figure 3.2.

High voltage pulses with short rise/decay times have been generated by the cable discharge technique (Hoffmann, 1971; Grunhagen, 1974; Porschke and Obst, 1991): coaxial cables are charged up by standard high voltage power supplies up to the range of $100 \mathrm{kV}$; the cable is then connected to the measuring cell by a spark gap, which is used as a switching device. The essential parts of spark gaps are two electrodes, usually of spherical shape, which are kept at a distance just above that allowing spontaneous discharge; the spark gap is converted into a highly conductive state within a very short time by moving the electrodes to a distance sufficient for spark discharge. The pulse may be terminated by a second spark gap, which is triggered by a helper spark.

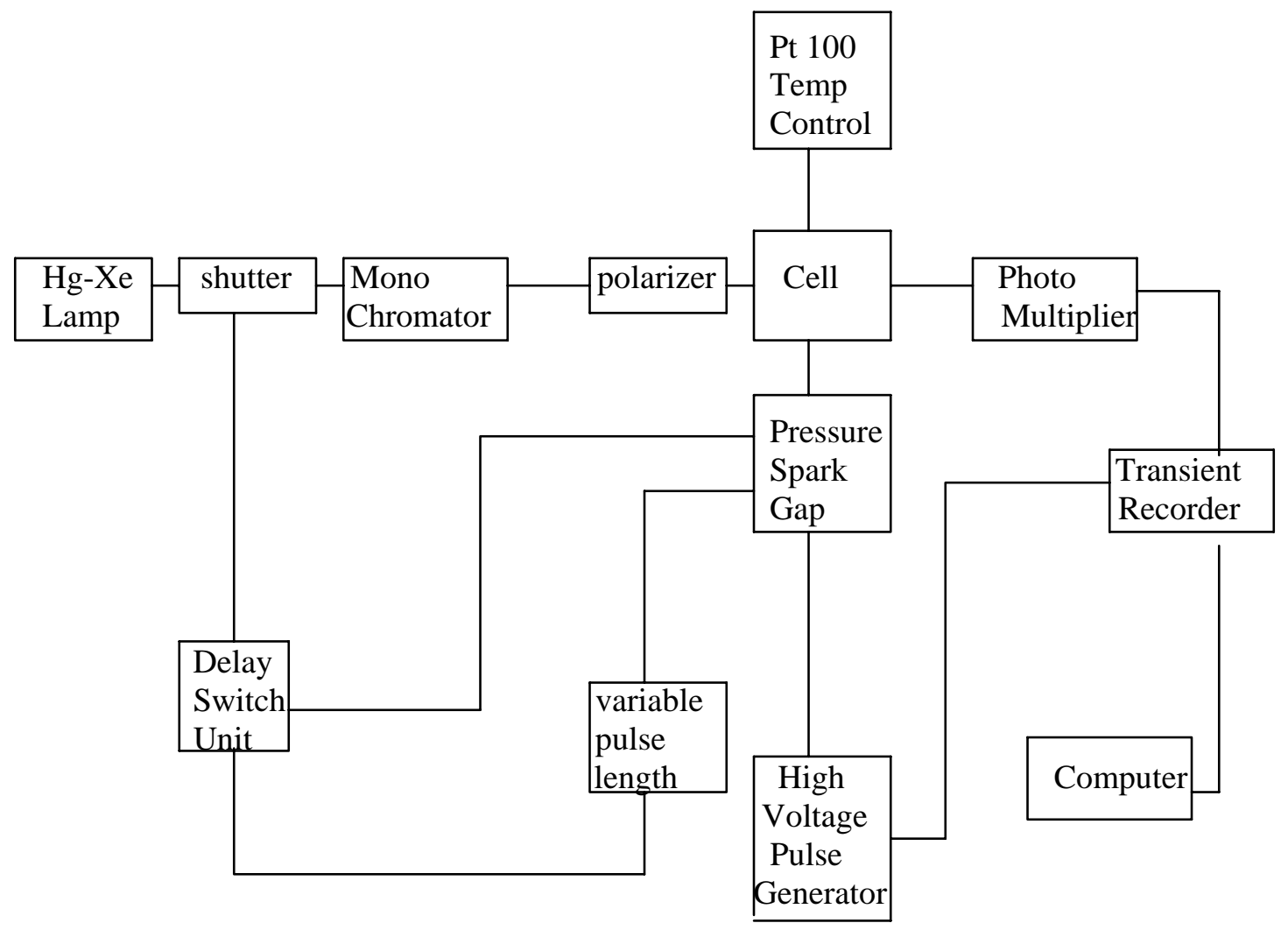

Figure 3.2 Block diagram of the field jump instrument 


\subsubsection{Measuring cell}

Special types of measuring cells, which can withstand high field pulses, are prepared. The electrodes are machined from brass and are covered by a $\sim 1 \mathrm{~mm}$ layer of Pt. The quartz windows for spectrophotometric detection are carefully inserted into the body machined from synthetic polymer (e.g macrolon) with a thin layer of silicon grease, such that the conical windows are without strain.

\subsubsection{Spectrophotometric detection}

Standard commercial spectrophotometers are not appropriate for molecular electro-optical measurements, because their time resolution is usually limited to the msec/sec time range. The light source should have as high intensity as possible in order to get a maximal signal to noise ratio. The optical path length was 20mm. The spectrophotometric system was composed of a Hamamatsu L2423 mercury/xenon arc lamp, a Schoeffel GM250 grating monochromator, a Glan air polarizer and a home made photomultiplier detector.

A major problem for molecular electro-optical measurements results form the fact that $\mathrm{mV}$ signals have to be recorded simultaneously to the application of $\mathrm{kV}$ pulses. Under these conditions, induction effects may lead to serious perturbations of measured signals. These problems can be avoided by careful shielding of the detection device. The photomultiplier may be shielded in special covers from $\mu$-metal, protecting mainly against magnetic perturbation. In addition, the multiplier head including the amplifier should be shielded in a solid metal cover for protection against electric induction effects. Finally, the connection between the multiplier head and the digitizer should be shielded as well. The electric supply lines of all instruments should be checked for earth circuits, which may lead to large perturbations and thus should be eliminated.

The photoelectric signal was stored on a Tektronix DSA 601A digitizing signal analyzer. The experimental data were analysed by a set of programs developed for quantitative characterization of chemical and physical relaxation data (Diekmann et al. 1982; Porschke and Jung, 1985). Convolution of rise or decay curves with the 
detector response curve (response time constant $0.93 \mu$ s used in all measurements) was considered by quantitative deconvolution procedures. Due to the convolution an orientation curve with $m$ components

$$
\mathrm{A}(\mathrm{t})=\sum_{K=1}^{m} \mathrm{~A}_{\mathrm{k}}\left(1-\mathrm{e}^{-\mathrm{t} / \mathrm{k}}\right)
$$

is measured in the form

$$
A^{\prime}(t)=\sum_{K=1}^{m} A_{k}\left(1+\left(\tau_{k} / \tau_{D}-\tau_{k}\right) e^{-t / \tau k}-\left(\tau_{D} / \tau_{D}-\tau_{k}\right) e^{-t / \tau D}\right)
$$

where $\tau_{\mathrm{D}}$ is the (exponential) rise time of the detector. For $m$ components $2 m+1$ parameters have to be fitted. They are $m$ relaxation times, $m$ amplitudes and the base line. The optimal parameters are calculated according to the least squares using linear variables for amplitudes and non-linear variables for time constants. The decision on the number $m$ of components contributing to the observed curve is mainly based on the magnitude of the signal to noise ratio and the plot of residuals and the autocorrelation of the residuals.

\subsubsection{Data correction}

When electric field pulses induce reaction effects, these are reflected in the transients measured at all orientations of the polarized light. Thus transients measured at $\varphi=0^{\circ}$ must be corrected by subtraction of the corresponding transients measured at $\varphi=55^{\circ}$ to get unperturbed dichroism transients. For subtraction the transients were transferred to the same level of light intensity.

Dichroism decay time constants measured at different ethanol content are affected by different viscosities. For quantitative comparison, time constants were corrected to the state of water at $20^{\circ} \mathrm{C}$ by multiplying with a factor,

$$
\left(\eta_{\mathrm{w}} * \mathrm{~T}_{\mathrm{e}}\right) /\left(\eta_{\mathrm{e}} * 293.1\right)
$$

where $\eta_{e}$ and $\eta_{w}$ are the viscosities of the solvent under the conditions of the experiment and of water at $20^{\circ} \mathrm{C}$ respectively; $\mathrm{T}_{\mathrm{e}}$ is the absolute temperature of the solvent used during experiments. 


\section{CHAPTER 4}

\section{RESULTS}

\subsection{CD and Absorbance Titration}

The fact that a reduction in water activity induces the B-A transition of DNA double helices and this transition is associated with clearly defined spectral changes is well known. Therefore, the optimal way to study the B-A transition of DNA in solution is by following the spectral changes during the transition using CD and absorbance difference spectra. The required reduction of water activity can be achieved by the addition of ethanol or triflouro-ethanol. The addition of ethanol at high salt induces aggregation and precipitation of DNA. Therefore, almost all experimental data on the B-A transition in literature were obtained at low salt concentrations.

Minchenkova et.al (1986) and Tolstorukov et.al (2001) showed that the B-A transition is dependent on the G-C content of the DNA helix. Thus, the width of the transition for homopolymers is expected to be lower than that for DNA with mixed sequence. Polymers with G-C base pairs have a stronger tendency for aggregation than those with A-T base pairs. It is known that the reduction of water activity induces a B-Z-A transition in poly $[\mathrm{d}(\mathrm{G}-\mathrm{C})]($ Pohl,1976) and Nara-inui et.al (1985) suggested that poly [dG-dC] will aggregate under the usual experimental conditions for B-A transition. Arnott et.al, (1974) showed that poly [dA-dT] would remain in the B-form even at conditions, which normally favours the A-form. Considering all these facts poly $[\mathrm{d}(\mathrm{A}-\mathrm{T})]$ was chosen as the optimal probe to study the B-A transition of DNA in solution. 


\subsubsection{Transition effected by ethanol}

The absorbance difference spectra of poly $[\mathrm{d}(\mathrm{A}-\mathrm{T})]$ (fig 4.1) and nonsonicated Salmon sperm DNA (fig 4.2) in solutions of various ethanol content shows the spectral changes observed in B-A transition. In the case of poly $[\mathrm{d}(\mathrm{A}-\mathrm{T})]$ the intensity of the $286 \mathrm{~nm}$ band increases with an increase in the ethanol content of the solution. This increase is observed at the $265 \mathrm{~nm}$ band for natural DNA. For both samples the intensity of the $248 \mathrm{~nm}$ band decreases as the ethanol content of the solution increases. For poly [d(A-T)], two clear isobestic points for B-A transition are observed at $270 \mathrm{~nm}$ and $238 \mathrm{~nm}$. The presence of isobestic points in a transition confirms that only two conformations are involved in the transition. The absorbance difference spectra of natural DNA did not reveal any isobestic point for the B-A transition. Natural DNA is a heterogeneous polymer and it is known that B-A transition is dependent on GC content (Minchenkova et.al, 1986). The variations in the percentage of GC content through helix have some effect on the transition. This explains the deviation of the transition curves from the isobestic points in natural DNA.

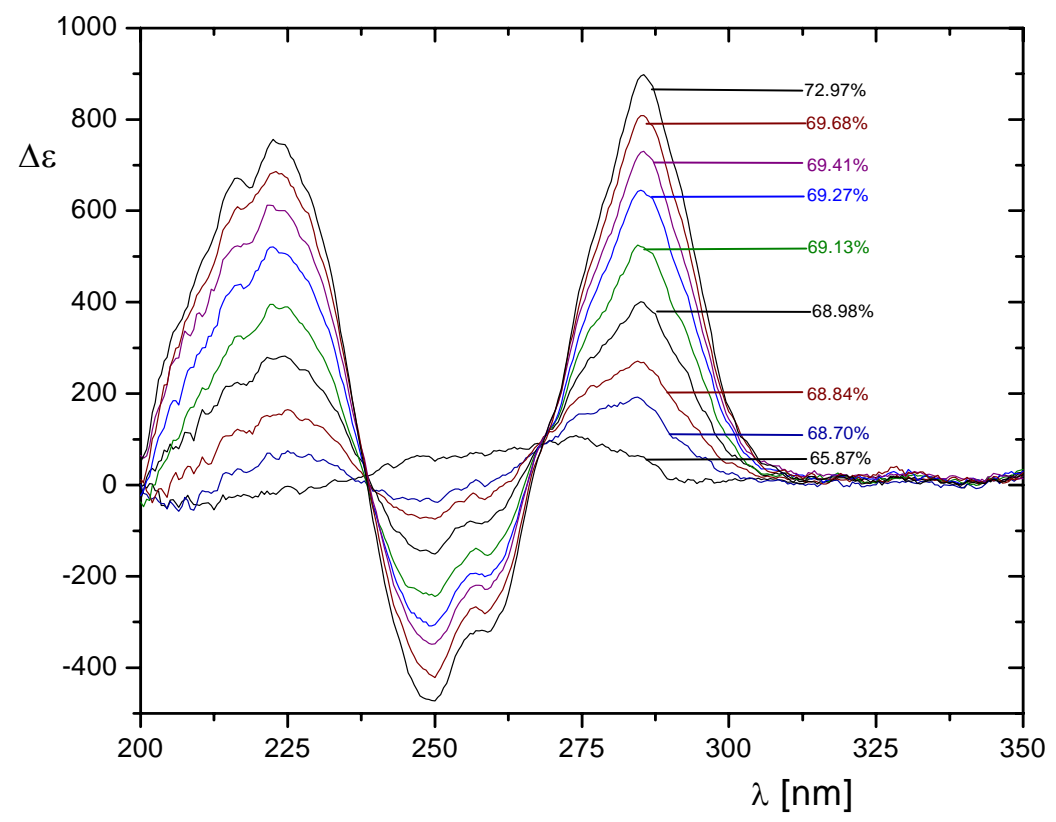

Figure 4.1 B-A-transition of poly [d(A-T)] indicated by absorption spectra at various ethanol percentages. The absorption spectrum measured at $51.68 \%$ was subtracted from the absorption spectra measured at the given ethanol percentages $\left(\Delta \varepsilon\right.$ in $\mathrm{M}^{-1} \mathrm{~cm}^{-1} ; \%$ in v/v-units; $0^{\circ} \mathrm{C}$, starting concentrations: $40 \mu \mathrm{M}$ poly [d(A-T)], $125 \mu \mathrm{M} \mathrm{NaCl}, 125 \mu \mathrm{M}$ Cacodylate $\mathrm{pH}$ 7, $25 \mu$ M EDTA). 


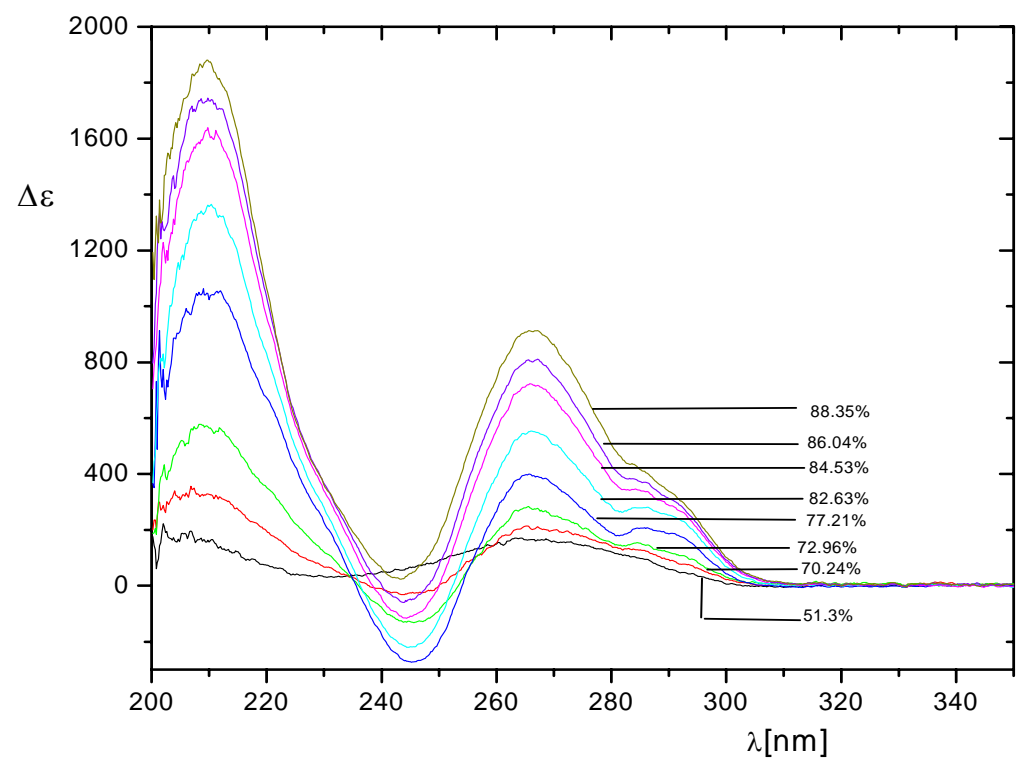

Figure 4.2 B-A-transition of non-sonicated Salmon sperm DNA indicated by absorption spectra at various ethanol percentages. The absorption spectrum measured at $0 \%$ was subtracted from the absorption spectra measured at the given ethanol percentages $\left(\Delta \varepsilon\right.$ in $\mathrm{M}^{-1}$ $\mathrm{cm}^{-1}$; \% in v/v-units; $20^{\circ} \mathrm{C}$, starting concentrations: $100 \mu \mathrm{M}$ DNA, $125 \mu \mathrm{M} \mathrm{NaCl}, 125 \mu \mathrm{M}$ Cacodylate $\mathrm{pH}$ 7, $25 \mu \mathrm{M}$ EDTA).

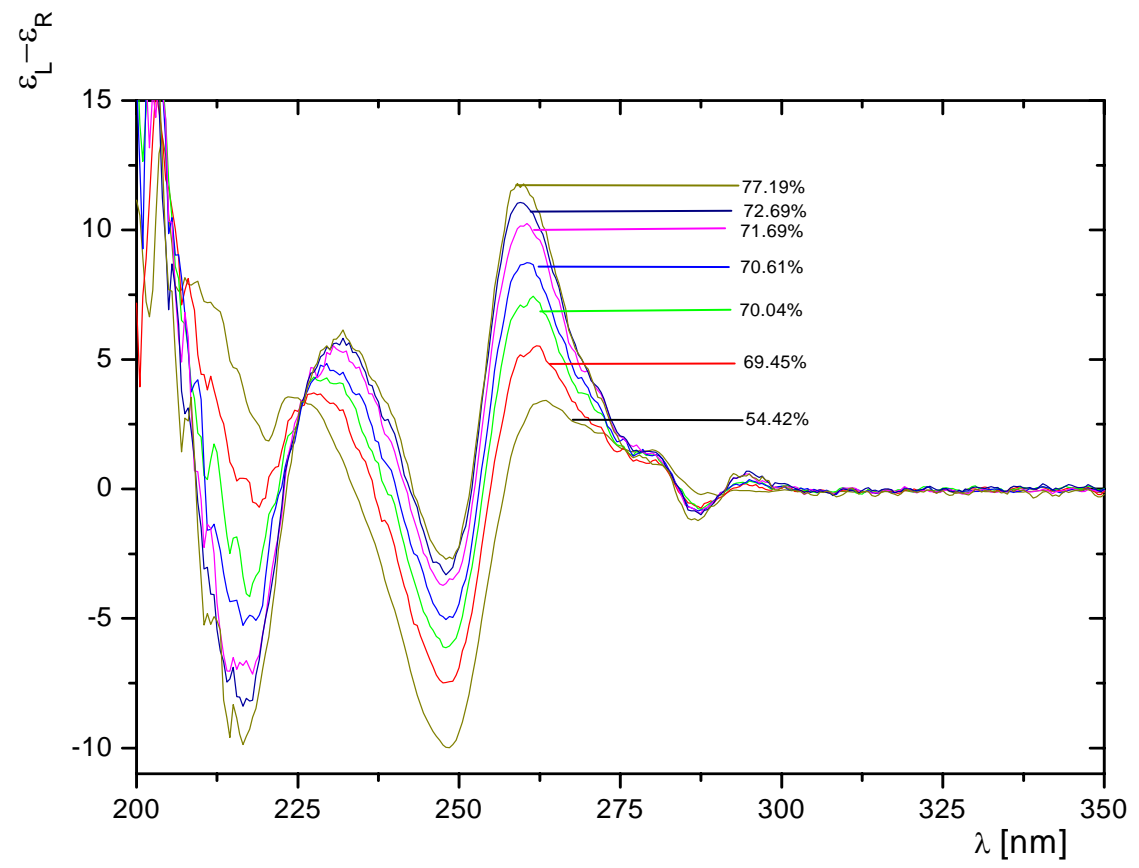


Figure 4.3 B-A-transition of 100 bp poly [d(A-T)] indicated by $C D$ spectra at various ethanol percentages. (\% in $\mathrm{v} / \mathrm{v}$-units; $0^{\circ} \mathrm{C}$, starting concentrations: $70 \mu \mathrm{M}$ poly[d(A-T)], 125 $\mu \mathrm{M} \mathrm{NaCl}, 125 \mu \mathrm{M}$ Cacodylate $\mathrm{pH}$ 7, $25 \mu \mathrm{M}$ EDTA).

To confirm the characteristic features of B-A transition, the CD spectra of poly $[\mathrm{d}(\mathrm{A}-\mathrm{T})]$ (fig. 4.3) and non-sonicated Salmon sperm DNA at various ethanol percentages were recorded. The $260 \mathrm{~nm}$ band of poly [d(A-T)] and the $267 \mathrm{~nm}$ band of natural DNA shows an increase in intensity with an increase in the ethanol content of the solution. Figure 4.4 shows the $C D$ transition curve of poly $[\mathrm{d}(\mathrm{A}-\mathrm{T})]$ as a function of percentage of ethanol.

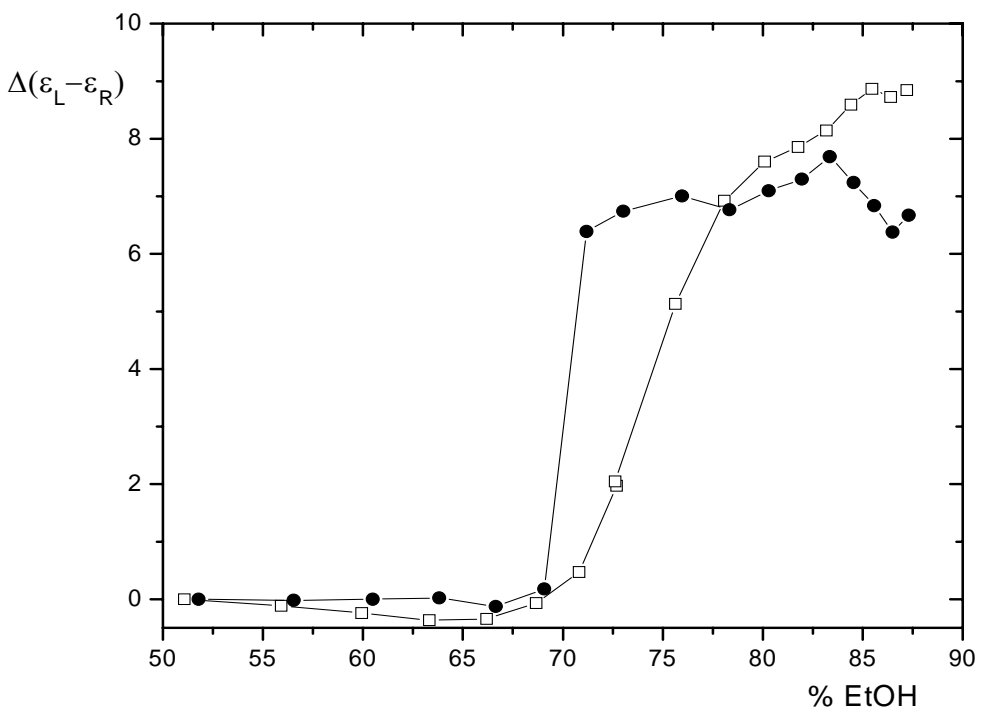

Figure 4.4 Transition curves from the $\mathrm{CD}$ experiments of poly $[\mathrm{d}(\mathrm{A}-\mathrm{T})](\bullet)\left(0^{\circ} \mathrm{C}, 260 \mathrm{~nm}, 70\right.$ $\mu \mathrm{M}$ poly [d(A-T)],125 $\mu \mathrm{M} \mathrm{NaCl}, 125 \mu \mathrm{M}$ Cacodylate $\mathrm{pH}$ 7, $25 \mu \mathrm{M}$ EDTA) and Salmon sperm DNA $(\square)\left(20^{\circ} \mathrm{C}, 267 \mathrm{~nm}, 110 \mu \mathrm{M}\right.$ Salmon sperm DNA, $125 \mu \mathrm{M} \mathrm{NaCl}, 125 \mu \mathrm{M}$ Cacodylate $\mathrm{pH}$ 7, $25 \mu \mathrm{M}$ EDTA) at various percentages $(v / v)$ of ethanol. Concentrations at the start of the experiment were given. 


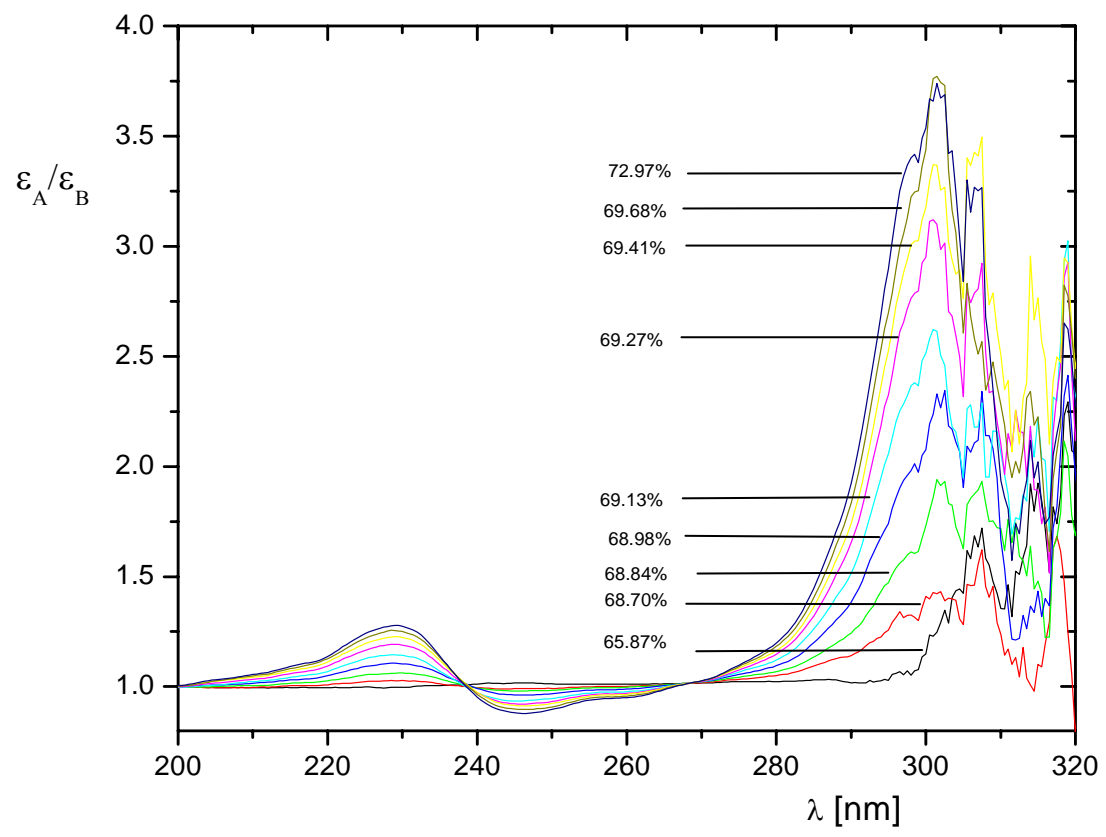

Figure 4.5 B-A-transition of poly [d(A-T)] indicated by absorption spectra at various ethanol percentages. The absorption spectra measured at the given ethanol percentages are divided by the absorption spectrum measured at $51.68 \%$ ( $\varepsilon$ in $\mathrm{M}^{-1}$ $\mathrm{cm}^{-1}$; \% in v/v-units; $0^{\circ} \mathrm{C}$, starting concentrations: $40 \mu \mathrm{M}$ poly [d(A-T)], $125 \mu \mathrm{M}$ $\mathrm{NaCl}, 125 \mu \mathrm{M}$ Cacodylate $\mathrm{pH}$ 7, $25 \mu \mathrm{M}$ EDTA).

Analysis of the absorbance spectra of poly [d(A-T)] showed that at wavelengths around $300 \mathrm{~nm}$ the relative absorbance of A-form DNA to that of B-form DNA is approximately four times higher than that at $280 \mathrm{~nm}$ (fig 4.5). This observation revealed the possibility of studying the B-A transition at long wavelengths where the large change in relative absorbance during the transition increases the sensitivity of measurements and thereby increases the accuracy of the determined reaction time constants.

At high salt concentrations, ethanol induces precipitation of DNA. Therefore, all experiments reported on B-A transition were conducted at low salt concentrations. Ivanov et al. (1974) showed that an increase in the $\mathrm{Na}^{+}$concentration gives rise to a small, but reproducible, shift of the transition towards the lower concentration of ethanol. The standard $\mathrm{Na}^{+}$concentration used in the present studies is $125 \mu \mathrm{M}$. Figure 4.8 shows the CD transition curve of poly $[\mathrm{d}(\mathrm{A}-\mathrm{T})]$ at $260 \mathrm{~nm}$, in a salt concentration, $500 \mu \mathrm{M}$, which is four times higher than that of the standard one. At this salt concentration also, the major spectral signatures corresponding to B-A 
transition remained the same.

\subsubsection{Transition effected by multivalent cations}

Ivanov et al (1974) demonstrated that spermine and spermidine stabilize the A-form DNA. Figure 4.6 shows the absorbance difference spectra of poly [d(A$\mathrm{T})$ ] at $62 \%$ ethanol $(\mathrm{v} / \mathrm{v})$ with various concentrations of spermine. Absorption difference spectra revealed that an increase in spermine concentration induces an increase in the intensity of the $286 \mathrm{~nm}$ band and a decrease in intensity of the $248 \mathrm{~nm}$ band. The spectral signatures observed were in accordance with the B-A transition. Charge density in A-form is larger than that in B-form. According to the polyelectrolyte theory, proposed by Manning (1977 a, 1979, 2002), an increase in the concentration of cations will stabilize the more densely charged A-conformation. Therefore, the transition observed in the presence of spermine is in agreement with the theory. The characteristics of the transition were confirmed further by CD titration where all the spectral signatures expected for B-A transition were observed.

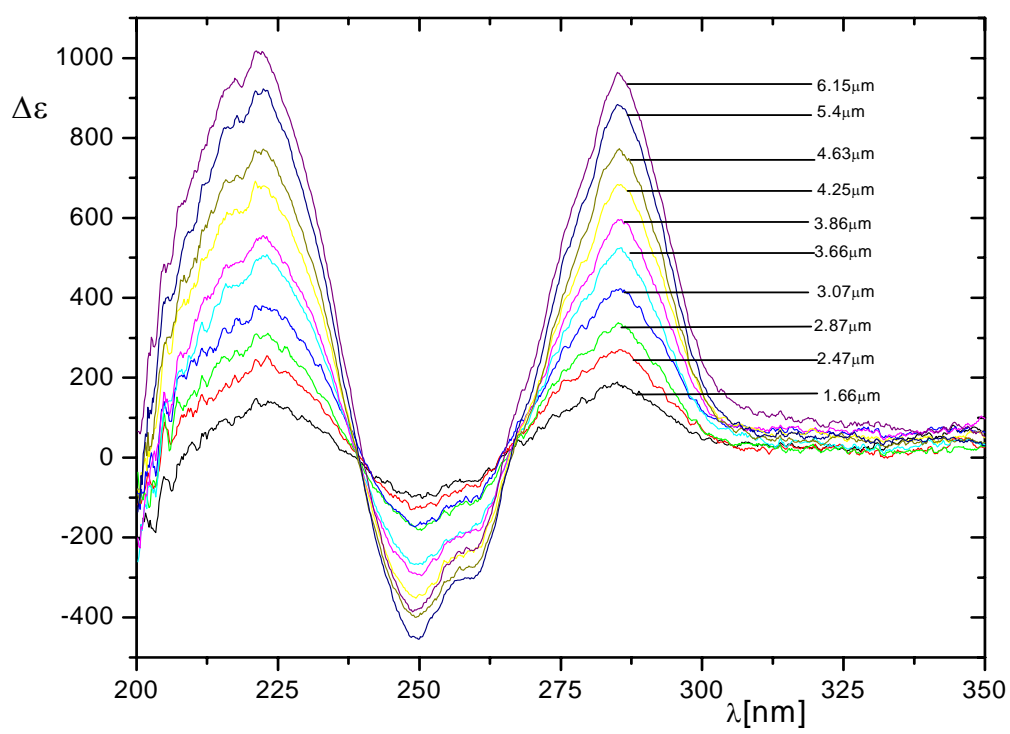

Figure 4.6 B-A-transition of poly [d(A-T)] indicated by absorption spectra at various spermine concentrations. The absorption spectrum measured at $62 \%$ ethanol was subtracted from the absorption spectra measured at the given spermine concentrations $\left(\Delta \varepsilon\right.$ in $\mathrm{M}^{-1} \mathrm{~cm}^{-1}$; $0^{\circ} \mathrm{C}$, starting concentrations: $40 \mu \mathrm{M}$ DNA, $125 \mu \mathrm{M} \mathrm{NaCl}, 125 \mu \mathrm{M}$ Cacodylate $\mathrm{pH}$ 7, $25 \mu \mathrm{M}$ EDTA). 


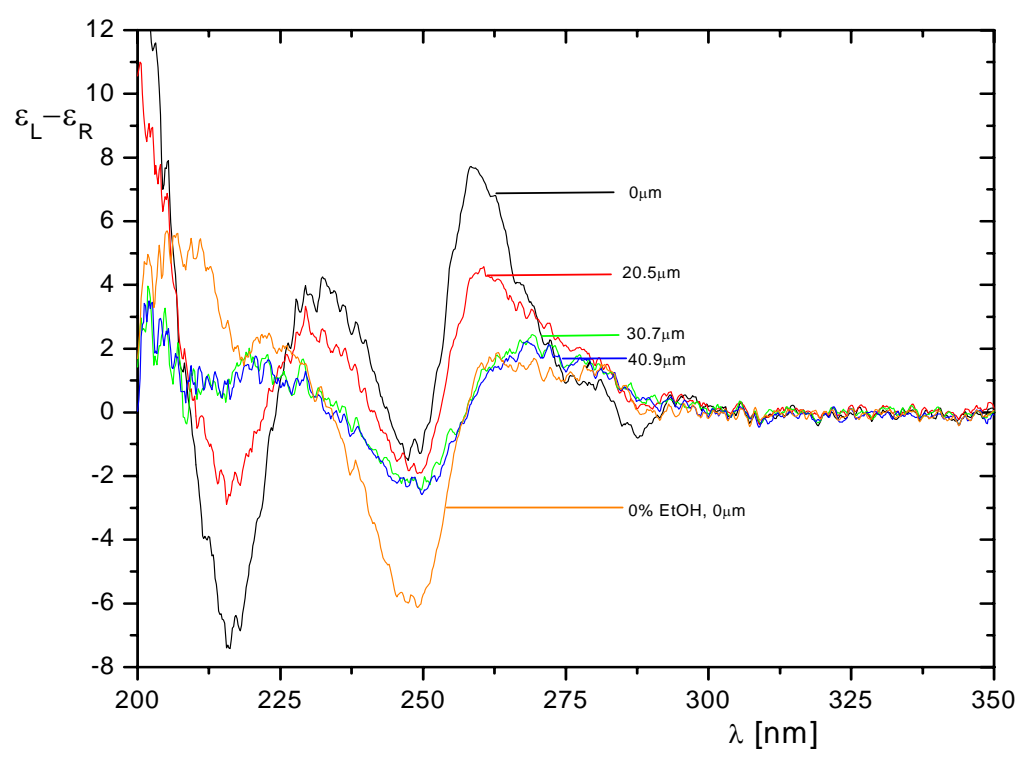

Figure 4.7 B-A-transition of 77.4\% EtOH-poly [d(A-T)] indicated by CD spectra at various $\mathrm{Mg}^{2+}$ concentrations. $\left(0^{\circ} \mathrm{C}\right.$, starting concentrations: $70 \mu \mathrm{M}$ poly $[\mathrm{d}(\mathrm{A}-\mathrm{T})]$, $125 \mu \mathrm{M} \mathrm{NaCl}, 125 \mu \mathrm{M}$ Cacodylate $\mathrm{pH}$ 7, $25 \mu \mathrm{M}$ EDTA). For comparison CD spectra of poly [d(A-T)] in buffer alone is also given.

Ivanov et al (1974) suggested that $\mathrm{Mg}^{2+}$ stabilizes the B-form of DNA. Figure 4.7 shows the CD spectra of poly [d(A-T)] at 77.4\% ethanol (v/v) with various concentrations of $\mathrm{Mg}^{2+}$. For comparison, the spectrum of poly [d(A-T)] in buffer alone, which is in B-form, is given. The decrease in the $260 \mathrm{~nm}$ band with increase in $\mathrm{Mg}^{2+}$ concentration is in agreement with the B-A transition. But at $248 \mathrm{~nm}$, the expected decrease in intensity is not observed. This implies that the observed conformation might be some other form of the B-family. Absorption difference spectra showed that an increase in $\mathrm{Mg}^{2+}$ concentration induces a decrease in the intensity of the $286 \mathrm{~nm}$ band and the spectral signatures observed were in accordance with the B-A transition. The transition observed with $\mathrm{Mg}^{2+}$ was not in agreement with the polyelectrolyte theory. The observed deviation from the theory might be due to some specific site binding nature of $\mathrm{Mg}^{2+}$. 


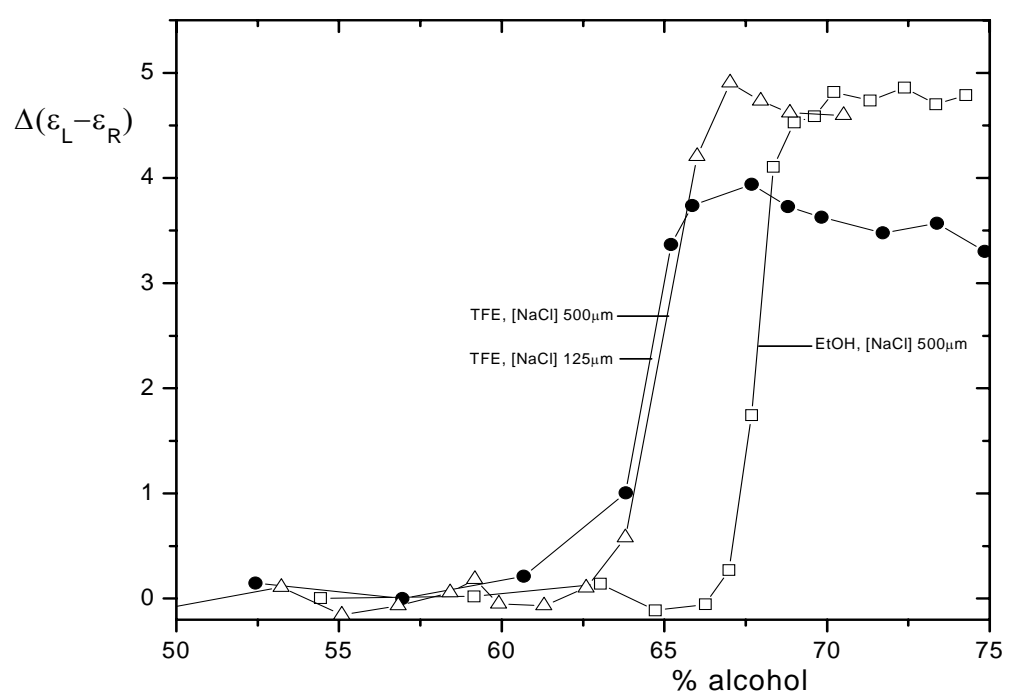

Figure 4.8 Transition curves from the $\mathrm{CD}$ experiments of poly [d(A-T)] at different conditions. ( $\square$ ) (\% in $\mathrm{v} / \mathrm{v}$ units of ethanol; $0^{\circ} \mathrm{C}$, starting concentrations:70 $\mu \mathrm{M}$ poly [d(AT)],500 $\mu \mathrm{M} \mathrm{NaCl}, 500 \mu \mathrm{M}$ Cacodylate $\mathrm{pH}$ 7, $100 \mu \mathrm{M}$ EDTA) (•) (\% in v/v units of TFE; $0^{\circ} \mathrm{C}$, starting concentrations: $70 \mu \mathrm{M}$ poly [d(A-T)], $125 \mu \mathrm{M} \mathrm{NaCl}, 125 \mu \mathrm{M}$ Cacodylate $\mathrm{pH}$, $25 \mu \mathrm{M}$ EDTA) $(\Delta)\left(\%\right.$ in $\mathrm{v} / \mathrm{v}$ units of TFE; $0^{\circ} \mathrm{C}$, starting concentrations:70 $\mu \mathrm{M}$ poly [d(AT)],500 $\mu \mathrm{M} \mathrm{NaCl}, 500 \mu \mathrm{M}$ Cacodylate $\mathrm{pH}$ 7, $100 \mu \mathrm{M}$ EDTA).

\subsubsection{Transitions effected by TFE}

Minchenkova et al. (1986) showed that apart from ethanol, TFE also can induce the B-A transition. They suggested that the use of TFE would decrease the aggregation of DNA at high alcohol percentage. The CD and absorbance difference spectra of poly $[d(A-T)]$ at various concentrations of TFE showed the same spectral signatures as that with ethanol. The spectra showed that TFE could induce the B-A transition at about 5\% lower alcohol content than ethanol. The CD transition curves at $260 \mathrm{~nm}$ are given in figure 4.8 . 


\begin{tabular}{|l|l|l|l|l|l|l|l|}
\hline sample & buffer & solvent & $\begin{array}{l}\text { Source } \\
\text { spectra }\end{array}$ & $\begin{array}{l}\% \\
\text { alcohol } \\
\text { for } \\
20 \% \text { A- } \\
\text { form }\end{array}$ & $\begin{array}{l}\text { alcohol } \\
\text { for } \\
80 \% \text { A- } \\
\text { form }\end{array}$ & $\begin{array}{l}\text { Width of } \\
\text { transition } \\
\text { in } \% \\
\text { alcohol }\end{array}$ & $\begin{array}{l}\text { \%alcohol } \\
\text { for 50\% } \\
\text { A- form }\end{array}$ \\
\hline $\begin{array}{l}\text { 95 bp } \\
\text { restriction } \\
\text { fragment } \\
\text { (Hillen } e t \\
\text { al., } 1980)\end{array}$ & $\begin{array}{l}0.4 \mathrm{mMNO}_{4} \\
\text { EDTA }\end{array}$ & EtOH & CD spectra & 71.41 & 73.86 & 2.45 & 72.64 \\
\hline $\begin{array}{l}\text { Salmon } \\
\text { sperm } \\
\text { DNA }\end{array}$ & $1 / 4$ NCE 7 & EtOH & CD spectra & 71.34 & 76.41 & 5.07 & 73.72 \\
\hline $\begin{array}{l}\text { Lambda } \\
\text { DNA }\end{array}$ & $1 / 4$ NCE 7 & EtOH & CD spectra & 71.03 & 76.21 & 5.18 & 73.68 \\
\hline $\begin{array}{l}\text { Plasmid } \\
\text { DNA }\end{array}$ & $1 / 4$ NCE 7 & EtOH & $\begin{array}{l}\text { Absorbance } \\
\text { spectra }\end{array}$ & 71.41 & 74.92 & 3.51 & 73.24 \\
\hline $\begin{array}{l}100 \text { bp } \\
\text { poly } \\
\text { d(A-T) }\end{array}$ & $1 / 4$ NCE 7 & EtOH & CD spectra & 69.24 & 71.02 & 1.78 & 69.99 \\
\hline $\begin{array}{l}\text { poly } \\
\text { d(A-T) }\end{array}$ & $1 / 4$ NCE 7 & EtOH & $\begin{array}{l}\text { Absorbance } \\
\text { spectra }\end{array}$ & 68.83 & 69.49 & 0.66 & 69.05 \\
\hline $\begin{array}{l}\text { poly } \\
\text { d(A-T) }\end{array}$ & NCE 7 & EtOH & CD spectra & 66.87 & 67.82 & 0.95 & 67.43 \\
\hline $\begin{array}{l}\text { poly } \\
\text { d(A-T) }\end{array}$ & $1 / 4$ NCE 7 & TFE & CD spectra & 63.03 & 65 & 1.97 & 64.51 \\
\hline $\begin{array}{l}\text { poly } \\
\text { d(A-T) }\end{array}$ & TFE & $\begin{array}{l}\text { Absorbance } \\
\text { spectra }\end{array}$ & 63.55 & 65.48 & 1.94 & 64.81 \\
\hline
\end{tabular}

Table 4.1 The B-A transition parameters obtained from CD and absorbance difference spectra

\subsubsection{Selection of optimal probe and conditions}

The B-A-transition of DNA was studied by CD and absorption difference spectra and the spectral changes were characterized for different types of samples at different conditions (Table 4.1). With ethanol, an increase in salt concentration by four times induced the B-A transition at about $2 \%$ lower ethanol content than at standard salt concentration. TFE induces the B-A transition at 5\% lower alcohol content than ethanol. 
Comparison of poly $[\mathrm{d}(\mathrm{A}-\mathrm{T})]$ and natural DNA transition curves revealed that the width of transition in natural DNA is almost 5 times broader than that of poly [d(A-T)] (Table 4.1). Because of its narrow transition width, poly [d(A-T)] is taken as the suitable probe for the initial studies on the B-A transition.

In order to have an explicit understanding about a process, it is necessary to have some awareness about the potential side reactions, which might interfere with the process under investigation. Either the stopped flow technique or the electric field jump technique seems to be the optimal method to follow the kinetics of the B-A transition. Two potential side reactions, which might couple with B-A transition, are helix-coil transition and aggregation. The absorbance difference spectra of poly [d(AT)] for B-A transition showed two clear isobestic points indicating that only two conformations are involved in the process. This shows the absence of aggregation of DNA under the present experimental condition. The superposition of spectral changes of denaturation with that of B-A transition can be avoided by measuring the transition at wavelengths where the spectral changes of denaturation is minimal compared to that of B-A transition. Therefore, to determine the optimal wavelength to follow the B-A transition, the denaturation spectra of poly $[\mathrm{d}(\mathrm{A}-\mathrm{T})]$ and natural DNA should be studied.

\subsubsection{Denaturation spectra}

In order to find an optimal wavelength to study the B-A transition, the denaturation spectra of poly [d(A-T)] (fig 4.9) and natural DNA were recorded. From the spectrum it is clear that denaturation of poly [d(A-T)] does not have any considerable amplitude at $280 \mathrm{~nm}$. The denaturation spectra of natural DNA showed that at the wavelengths of interest that is at $248 \mathrm{~nm}$ and $265 \mathrm{~nm}$, denaturation has some considerable amplitude. So for poly [d(A-T)] $280 \mathrm{~nm}$ is taken as the ideal wavelength for following the B-A transition whereas for natural DNA the reaction is followed at both wavelengths. 


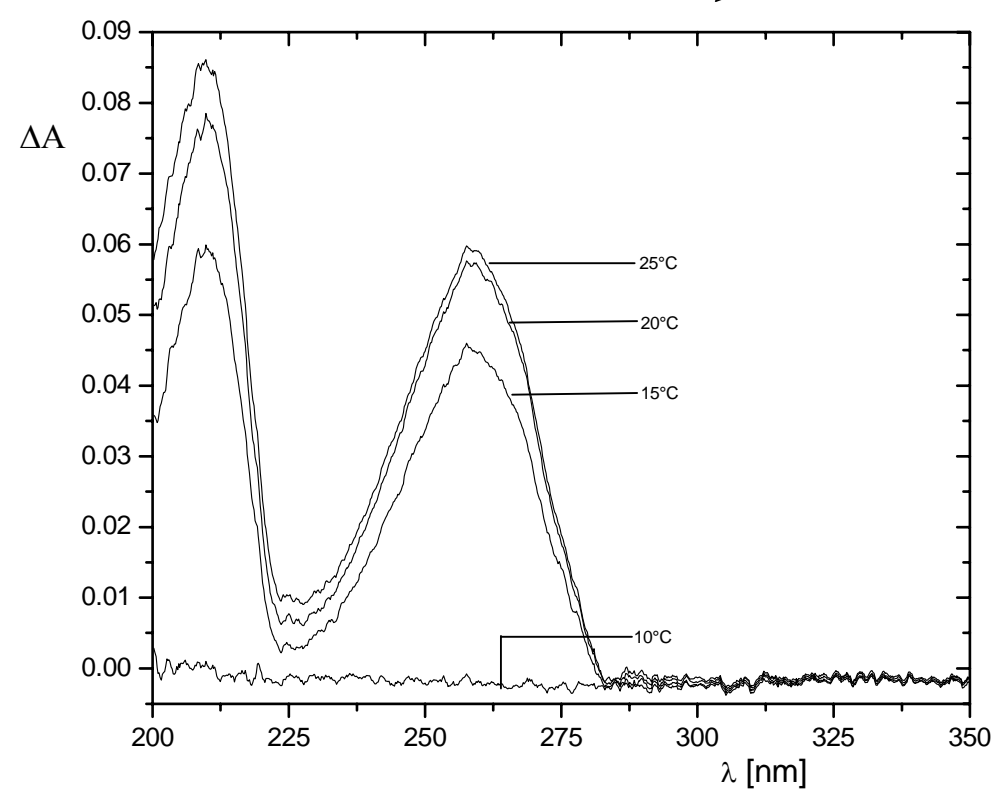

Figure 4.9 Absorption difference spectrum of $60 \% \mathrm{EtOH}(\mathrm{v} / \mathrm{v})-$ poly [d(A-T)] at various temperature. (20 $\mu \mathrm{M}$ poly[d(A-T)], $100 \mu \mathrm{M} \mathrm{NaCl}, 100 \mu \mathrm{M}$ Cacodylate, $\mathrm{pH}$ 7, $20 \mu \mathrm{M}$ EDTA). Absorption spectrum at $0^{\circ} \mathrm{C}$ was subtracted from spectrum at each temperature and plotted.

\subsubsection{Melting temperature measurements}

Melting temperatures of poly $[\mathrm{d}(\mathrm{A}-\mathrm{T})]$ at various percentages of ethanol were determined in order to find out the optimal working temperature in the B-A transition range. From figure 4.10 it is clear that above 55\% ethanol (v/v), the melting temperature of poly $[\mathrm{d}(\mathrm{A}-\mathrm{T})]$ shows an increase with increasing ethanol percentage. This indicates that the double helix is stabilized in the presence of ethanol. B-A transition occurs at $\sim 70 \%$ of ethanol. In this range the melting temperature of poly [d(A-T)] is around $18^{\circ} \mathrm{C}$. Therefore $8^{\circ} \mathrm{C}$ was taken as the optimal working temperature for poly $[\mathrm{d}(\mathrm{A}-\mathrm{T})]$. 


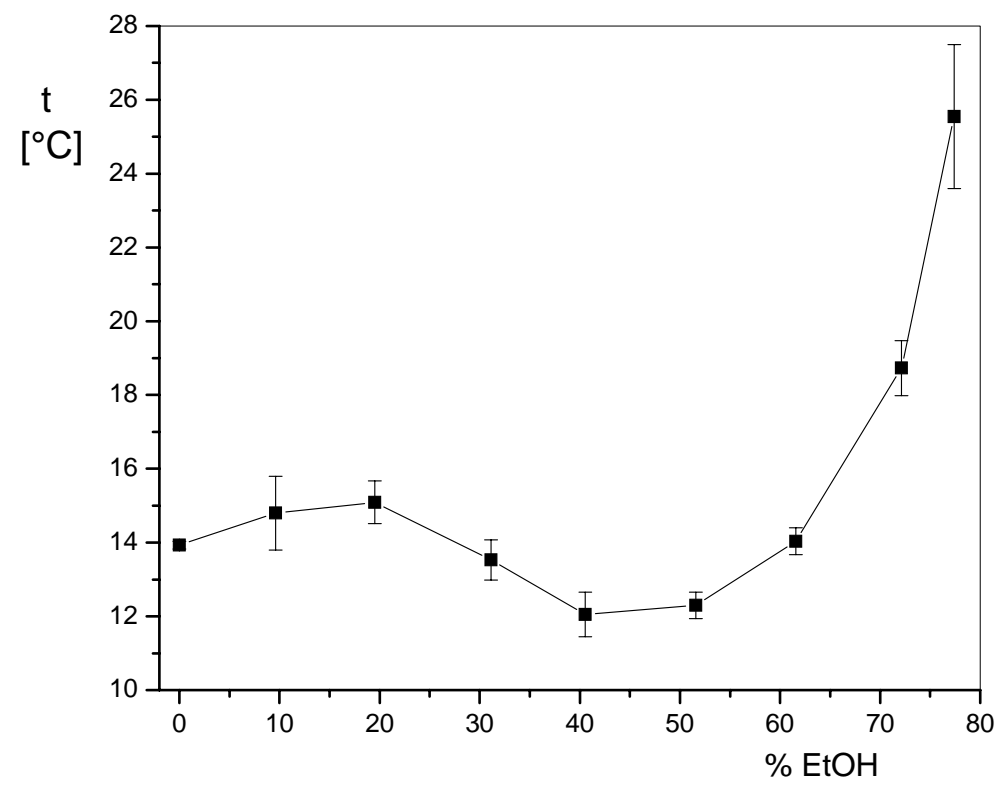

Figure 4.10 Melting temperature of poly [d(A-T)] as a function of ethanol (\% in v/v units, 15 $\mu \mathrm{M}$ poly[d(A-T)]). Starting ion concentration: $(125 \mu \mathrm{M} \mathrm{NaCl}, 125 \mu \mathrm{M}$ Cacodylate $\mathrm{pH}$ 7, 25 $\mu \mathrm{M}$ EDTA).

\subsection{Stopped flow measurement}

The B-A transition of DNA can be induced by addition of ethanol to a DNA solution and the transition can be easily studied by following the absorbance changes at $248 \mathrm{~nm}$ or at $286 \mathrm{~nm}$. Therefore, stopped flow technique was selected as the first method to study the kinetics of this transition. Solutions were taken in such a way that a DNA concentration, which corresponds to an absorbance of 1 , is obtained in the mixing chamber. Experiments were conducted such that the proportion of ethanol was changed from $60 \%$, where the DNA is in equilibrium B-form, to $80 \%$, where it is in equilibrium A-form. Figure 4.11 shows the transient up to 0.1 seconds, which clearly shows the absence of any process occurring under this condition. Experiments were repeated under the same conditions and the transients recorded up to 20 seconds did not reveal any change in the light intensity. Further stopped flow experiments were performed at ethanol percentages outside the B-A transition range in which the ethanol proportion was changed from $0 \%$ to $50 \%$ and from $20 \%$ to $60 \%$ 
ethanol. The transients did not reveal any indication for the occurrence of any physical or chemical processes.

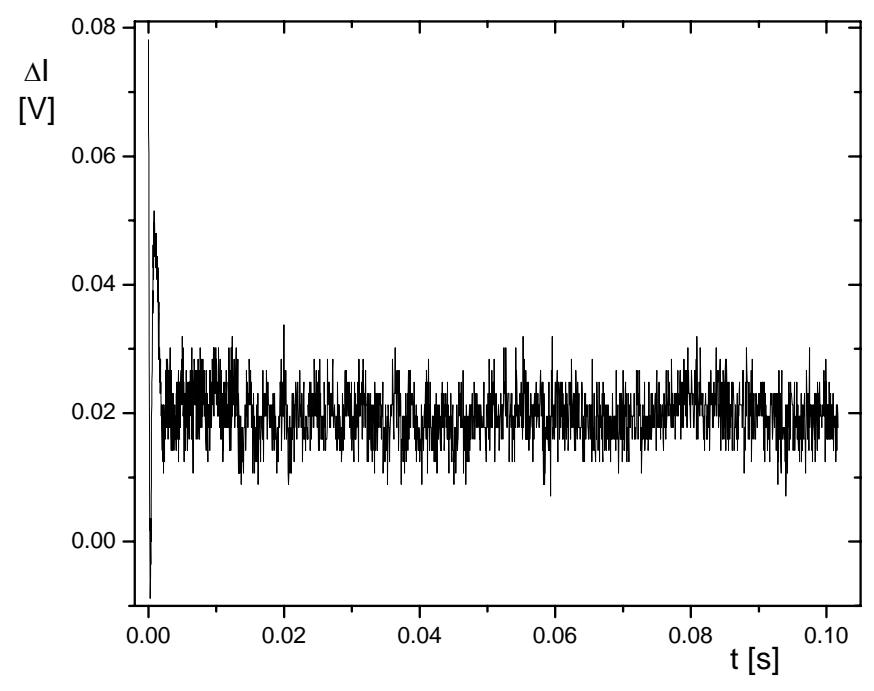

Figure 4.11 Transients observed at $248 \mathrm{~nm}$ after mixing of solutions in the stopped flow experiment at $19^{\circ} \mathrm{C}$. Contents in Syringe A. (60\% EtOH (v/v)-1.818 mM sonicated Salmon sperm DNA, $150 \mu \mathrm{M} \mathrm{NaCl}, 150 \mu \mathrm{M}$ Cacodylate $\mathrm{pH}$ 7, $30 \mu \mathrm{M}$ EDTA) Contents in Syringe B. EtOH.

Absorbance changes at $248 \mathrm{~nm}$ were recorded for DNA samples as a function of time, where ethanol percentages was changed from $0 \%$ to $50 \%, 60 \%, 70 \%$ and $80 \%$ in a Cary spectrophotometer with quick mixing of the sample. The recording of absorbance was started within 20 seconds after mixing. DNA samples with $50 \%$ and $60 \%$ of ethanol which are outside the B-A transition range, showed an increase of absorbance of approximately 0.004 in 6 minutes whereas samples at $70 \%$ and $80 \%$ ethanol showed a decrease in absorbance of approximately 0.002 in 6 minutes. These small changes in absorbance might be due to settling of air bubbles or dust particles. These experiments revealed the absence of any physical or chemical process occurring in this time range.

It is known that high ethanol percentages induce aggregation of DNA and this is reflected by an increase in absorbance. Stopped flow experiments were conducted in such a way that ethanol percentages were increased from $70 \%$ to $85 \%$ and also from $80 \%$ to $90 \%$. Under these conditions, aggregation of DNA is expected 
to occur (Potaman et al., 1980). At both these percentages of ethanol, a decrease in the light intensity was observed in stopped flow experiments. Figure 4.12 shows the transient observed after mixing 80\% EtOH-DNA solution with pure EtOH, which results in a final ethanol content of $90 \%$ in solution. At $248 \mathrm{~nm}$, the B-A transition is reflected by a decrease in absorbance, whereas aggregation by an increase in absorbance. The nature of the transients and the ethanol percentages at which this change is observed confirms the assignment of the observed decrease in light intensity to aggregation.

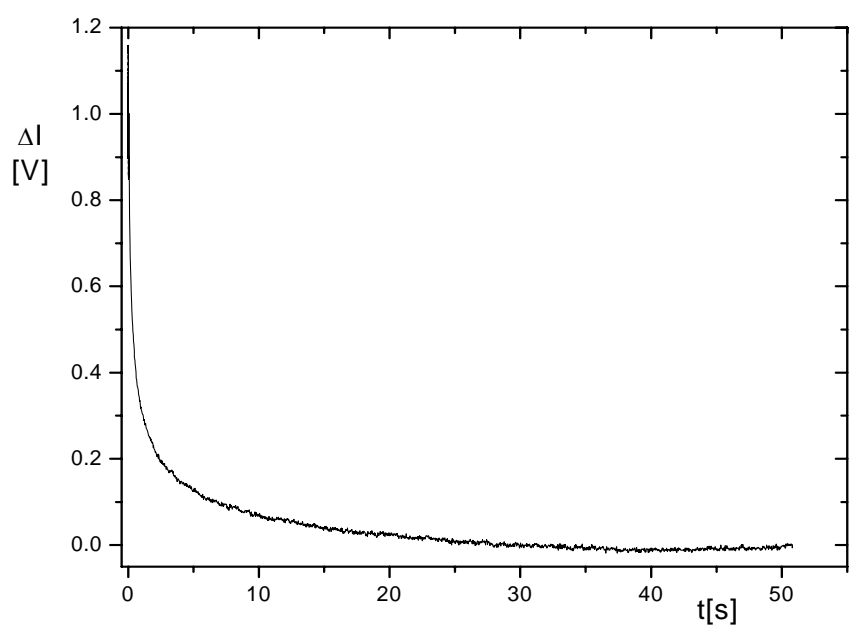

Figure 4.12 Transients observed at $248 \mathrm{~nm}$ after mixing of solutions in the stopped flow experiment at $19^{\circ} \mathrm{C}$. Contents in Syringe A. (80\% EtOH (v/v)-1.818 mM sonicated Salmon sperm DNA, $150 \mu \mathrm{M} \mathrm{NaCl}, 150 \mu \mathrm{M}$ Cacodylate $\mathrm{pH}$ 7, $30 \mu \mathrm{M}$ EDTA) Contents in Syringe B. EtOH.

The stopped flow experiments did not reveal any spectral change, which can be attributed to the B-A transition. This confirms that the B-A transition occurs faster than millisecond time scale.

\subsubsection{Technical problems occurred in stopped flow experiments}

The density of an ethanol-water solution varies with changes in the proportion of the components. As a result, while setting up the instrument, some artefacts were observed. Initial stopped flow experiments in the B-A transition range, where ethanol percentage was increased from $70 \%$ ethanol to $85 \%$, did not show any change in the intensity of light up to $\sim 25$ seconds. But after 25 seconds an increase in 
light intensity was observed. Experiments conducted in the Cary spectrophotometer did not reveal any change in light intensity similar to that observed in stopped flow experiment at this time scale. This confirmed that the observed changes are associated with some physical process occurring during the stopped flow experiment.

Further studies showed that the magnitude of the change in amplitude observed in the slow time scale has a strong dependence on the ethanol concentration. Because of the difference in ethanol percentage in the syringes, convection may occur between the mixing chamber and syringes. Under the present experimental conditions an increase in the intensity of the transmitted light is observed which suggests the dilution of the sample in the mixing chamber with time. To confirm the above argument, control experiments were done with same solution in both syringes. In this case there was not any increase in the intensity of light. For further confirmation of the characteristics of this effect and to make sure that this effect is not due to any conformational change in DNA but due to some absorbance change by convection, stopped flow experiments were conducted with samples like AMP, uridine and acetone which shows absorbance properties in UV-Visible range. The ethanol percentage was changed from $50 \%$ to $75 \%$ and changes similar to that with DNA were observed. These observations supported the assignment of the observed effect to convection.

In order to minimize problems due to convection, the shutter, which separates the observation cell and mixing chamber from syringes, was closed immediately after the termination of the flow. Under this condition, the observed increase in the light intensity in the slow time scale disappeared. This observation further verified that the observed increase in light intensity in the slow time scale was due to convection. 


\subsection{Field jump experiments}

\subsubsection{Experiment with poly [d(A-T)] and ethanol}

Electric field jump experiments were performed on poly [d(A-T)] fragments with an average chain length of 1500 bp in a buffer containing only monovalent salt at various ethanol percentages. In this case reaction amplitudes appeared under magic angle conditions as shown in figure 4.13. The amplitude measured at $280 \mathrm{~nm}$ appears only in the limited range of ethanol contents (fig. 4.14) with a clear maximum close to the center of the B-A-transition, which has been determined independently by measurements of CD and absorbance difference spectra under the same experimental conditions (fig 4.1). The field induced reaction amplitude is not found outside the B-A-transition range. These data clearly reflect that these amplitudes belong to the B-A-transition. An increase in light intensity is observed at $280 \mathrm{~nm}$ during the application of electric field. At $280 \mathrm{~nm}$ the absorbance of A-form DNA is higher than that of B-form DNA. This suggests under electric field pulses A-form gets converted to B-form. That is, electric field stabilizes the B-form compared to the A-form.

The absence of any considerable reaction amplitude at $270 \mathrm{~nm}$ and the reversal of field induced reaction amplitude at $248 \mathrm{~nm}$ confirmed the assignment of the observed amplitude to B-A transition. These observations are in agreement with the absorbance difference spectra of B-A-transition (fig 4.1). At $270 \mathrm{~nm}$ a small decrease in light intensity, which is of the magnitude of $\sim 3 \mathrm{mV}$, is observed during the application of field pulses. This is attributed to denaturation of the sample under field pulses and plotted as a function of ethanol in figure 4.15. The figure clearly shows the absence of any dependence of the amplitude on ethanol percentage at this wavelength. If the amplitude observed at $280 \mathrm{~nm}$ corresponds to helix-coil transition or aggregation, it should be observed at $270 \mathrm{~nm}$ as well. The absence of any such observation supports the assignment of the reaction amplitude at $280 \mathrm{~nm}$ to the B-A transition. 


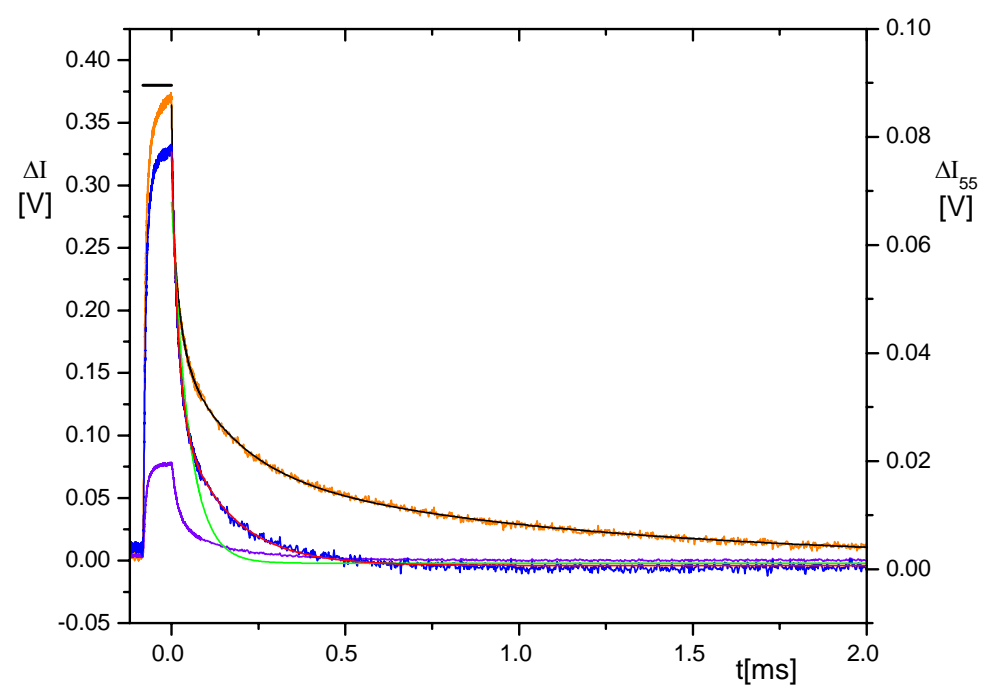

Figure 4.13 Field induced change of the transmission $\Delta \mathrm{I}$ at $280 \mathrm{~nm}$ for poly [d(A-T)] at polarizer orientations $\varphi=0^{\circ}$ and $55^{\circ}$ with respect to the field vector. Corrected dichroism transients ( $\Delta \mathrm{I}_{0}-\Delta \mathrm{I}_{55}$, orange) with a fit of the decay by 4 exponentials (black, $2.25 \mu \mathrm{s}, 22.2 \mu \mathrm{s}$, $165 \mu$ s and 1 ms with relative amplitudes 22, 30, 27 and 21\% respectively); the magic angle transients ( $\Delta \mathrm{I}_{55}$, average of 5 shots) is shown both at the same scale as the dichroism (magenta, left scale) and magnified (blue, right scale) with a fit of the decay by 2 exponentials (red, $\tau_{1}=$ $17.5 \mu \mathrm{s}, \tau_{2}=145 \mu \mathrm{s}, \mathrm{A}_{1}=61 \% \mathrm{~A}_{2}=39 \%$ ) and by 1 exponential (green) with $49 \mu \mathrm{s}$. The bar indicates the duration of the field pulse. $70.2 \%$ ethanol $(\mathrm{v} / \mathrm{v}), 8^{\circ} \mathrm{C}, 8.5 \mu \mathrm{M}$ poly $[\mathrm{d}(\mathrm{A}-\mathrm{T})], 75$ $\mu \mathrm{M} \mathrm{NaCl}, 75 \mu \mathrm{M}$ cacodylate $\mathrm{pH}$ 7, $15 \mu \mathrm{M}$ EDTA; field pulse $3.45 \times 10^{6} \mathrm{~V} / \mathrm{m}$ ).

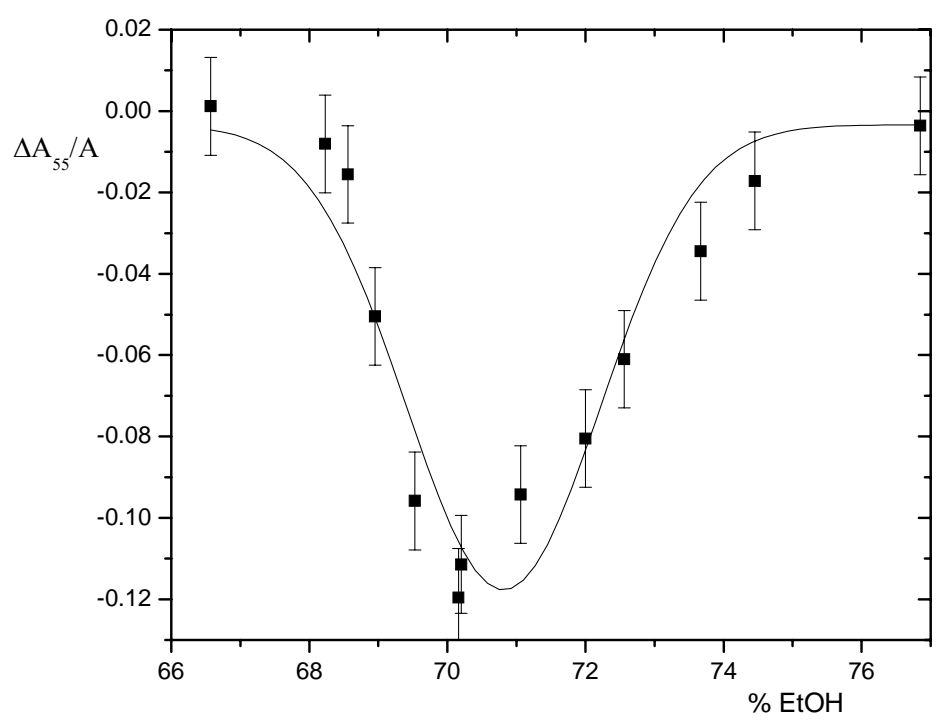


Figure 4.14 Relative magic angle amplitudes $\Delta \mathrm{A}_{55} / \mathrm{A}$ of poly [d(A-T)] at $280 \mathrm{~nm}$ as a function of the ethanol content in $\%$ units $(\mathrm{v} / \mathrm{v})$. The line represents a Gaussian fit (center 70.81 , width 2.81 , offset -0.0034 , height 0.11$).\left(8^{\circ} \mathrm{C}, 8.5 \mu \mathrm{M}\right.$ poly [d(A-T)],75 $\mu \mathrm{M} \mathrm{NaCl}$, $75 \mu \mathrm{M}$ cacodylate $\mathrm{pH} 7,15 \mu \mathrm{M}$ EDTA; field pulse $\left.3.45 \times 10^{6} \mathrm{~V} / \mathrm{m}\right)$.

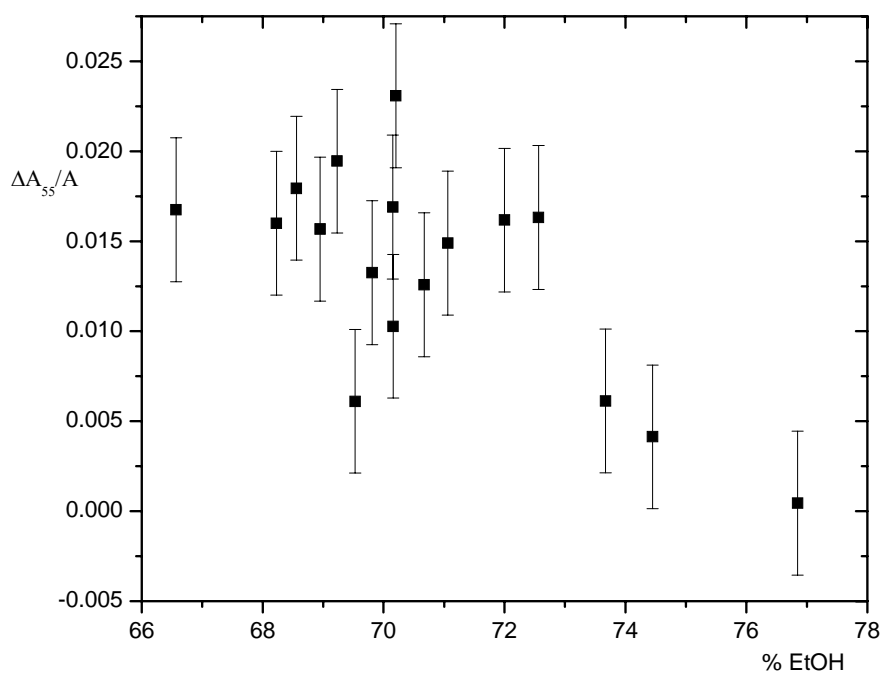

Figure 4.15 Relative magic angle amplitudes $\Delta \mathrm{A}_{55} / \mathrm{A}$ of poly [d(A-T)] at $270 \mathrm{~nm}$ as a function of the ethanol content in $\%$ units $(\mathrm{v} / \mathrm{v}),\left(8^{\circ} \mathrm{C}, 8.5 \mu \mathrm{M}\right.$ poly [d(A-T)],75 $\mu \mathrm{M} \mathrm{NaCl}, 75$ $\mu \mathrm{M}$ cacodylate $\mathrm{pH}$ 7, $15 \mu \mathrm{M}$ EDTA; field pulse $3.45 \times 10^{6} \mathrm{~V} / \mathrm{m}$ ).

Figure 4.16 shows the transients at polarizer orientation $\varphi=90^{\circ}$ with respect to the field vector at various ethanol percentages. After pulse termination, in the fast time scale, a distinct increase in light intensity is observed at ethanol percentages in the B-A transition interval. This effect is completely absent outside the B-A transition range. It is known that the field induced reaction effects will be reflected in the transients measured at all orientations of the polarized light. To check whether the effect belongs to the B-A transition, the transients are transformed to the same level of light intensity and the transients measured at $\varphi=55^{\circ}$ is subtracted from the corresponding transients at $\varphi=90^{\circ}$. After subtraction the transients at $\varphi=90^{\circ}$ appeared similar at all percentages of ethanol. This is an obvious verification, which shows that an additional process other than orientation is occurring in the B-A-transition interval. This further confirmed the proper separation of field induced orientation and reaction effects using the magic angle technique. 


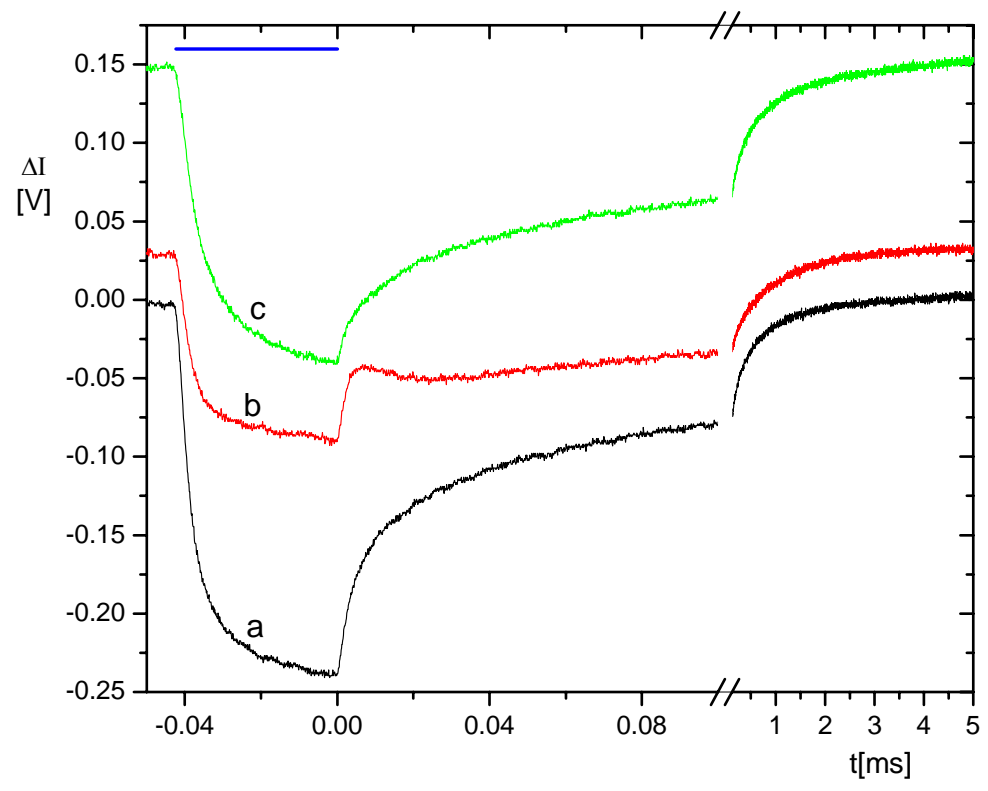

Figure 4.16 Field induced change of the transmission $\Delta \mathrm{I}$ at $280 \mathrm{~nm}$ for poly [d(A-T)] at polarizer orientation $\varphi=90^{\circ}$ with respect to the field vector at different ethanol percentages; a) $66.57 \%$, b) $70.20 \%$, c) $74.45 \%$ of ethanol. The bar indicates the duration of the field pulse. In order to have a clear separation between the transients 0.03 was added to $b$ and 0.15 was added to $c .\left(\mathrm{v} / \mathrm{v}, 8^{\circ} \mathrm{C}, 8.5 \mu \mathrm{M}\right.$ poly[d(A-T)], $75 \mu \mathrm{M} \mathrm{NaCl}, 75 \mu \mathrm{M}$ cacodylate $\mathrm{pH}$ 7, $15 \mu \mathrm{M}$ EDTA; field pulse $3.45 \times 10^{6} \mathrm{~V} / \mathrm{m}$ ).

The relatively high amplitudes observed at the magic angle indicate that the field pulses can drive the reaction close to completion. Figure 4.17 shows the dependence of time constants representing the main amplitude of the B-A reaction on the ethanol concentration. The time constants for the B-A reaction under the field free state decreases with increasing ethanol content. This is because the rate of the B to A reaction increases with increase in ethanol percentage. The opposite direction is observed for the A-B reaction, which occurs in the presence of electric field. The time constants for the opposite processes are equivalent at $\sim 71 \%$ ethanol, shifted from the midpoint of the B-A-equilibrium towards the domain of the A-DNA. This is due to the fact that the field pulses accelerate the $\mathrm{A} \rightarrow \mathrm{B}$ reaction. Under the present experimental conditions, the field strength applied causes a large perturbation from the equilibrium state and therefore the forward and backward time constants differ in 
their magnitude. A reduction in the field strength to reduce the perturbation will result in a decrease in the change in amplitude making an accurate determination of time constants difficult. If the process would be followed without large perturbations, the time constants would be equivalent at any given point of the transition.

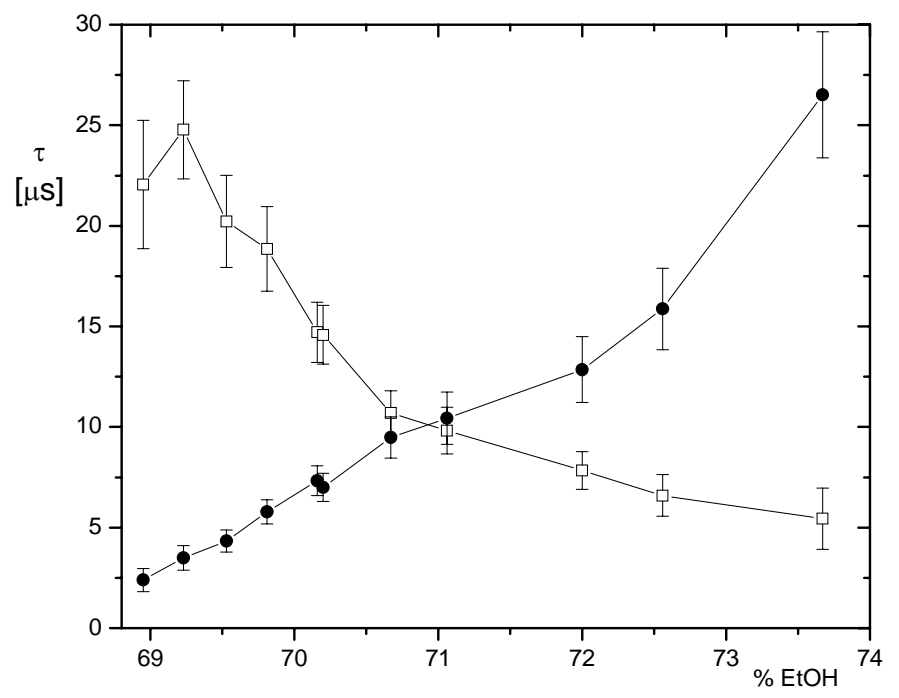

Figure 4.17 Magic angle time constants of the B-A-transition of poly [d(A-T)] at $280 \mathrm{~nm}$ in the field free state $\left(\square, \tau_{1}^{\mathrm{d}}\right)$ and of the $A-B$ transition under electric field pulses $\left(\bullet, \tau_{2}^{\mathrm{r}}\right)$ as $a$ function of the ethanol content in $\%$ units $(\mathrm{v} / \mathrm{v}),\left(8^{\circ} \mathrm{C}, 8.5 \mu \mathrm{M}\right.$ poly [d(A-T)], $75 \mu \mathrm{M} \mathrm{NaCl}, 75$ $\mu \mathrm{M}$ cacodylate $\mathrm{pH} 7,15 \mu \mathrm{M}$ EDTA, field pulse $\left.3.45 \times 10^{6} \mathrm{~V} / \mathrm{m}\right)$.

In figure 4.5 it is shown that at wavelengths around $300 \mathrm{~nm}$ the relative absorbance of A-form DNA to that of B-form DNA is approximately four times higher than that at $280 \mathrm{~nm}$. At longer wavelengths, the isotropic absorbance and the dichroism amplitude of DNA samples are smaller than that at shorter wavelengths. Therefore, field jump experiments with standard field strengths conducted at wavelengths around $300 \mathrm{~nm}$ showed that even at a very high concentration of DNA the observed amplitude at the parallel orientation of polarized light is within the $10 \%$ limit of the incident light intensity. As the concentration of DNA increases the amplitude of B-A transition also increases. This increase in amplitude coupled with the increase in relative absorbance of A-form at wavelengths in the range $295 \mathrm{~nm}$ to $302 \mathrm{~nm}$ makes the reaction amplitude large enough for an explicit determination of the time constants for the B-A transition.

Field jump experiments are conducted at $302 \mathrm{~nm}$ and the reaction amplitudes appeared under different angular positions is shown in figure 4.18. The 
concentration of the sample was adjusted so that the observed amplitude at the parallel orientation of polarized light is within $10 \%$ of the incident light intensity. An important observation from these experiment is that almost $80 \%$ of the observed amplitude at the parallel orientation of polarized light comes from the reaction effect. The large amplitude observed at the magic angle condition is optimal for an accurate determination of the reaction time constants at various percentages of ethanol. The dependence of magic angle amplitude measured at $302 \mathrm{~nm}$ on ethanol percentage confirms that the observed process is B-A transition (figure 4.19). The ethanol percentage at which the maximum amplitude observed is identical at $302 \mathrm{~nm}$ and 280 $\mathrm{nm}$. However, at ethanol percentages below the B-A transition range some reaction amplitude, which is about $2 \%$ of the maximum B-A transition amplitude, was observed. It is known that field pulses induce some stretching of DNA double helix and the small amplitude observed outside the B-A transition range is assigned to some internal conformational change due to this stretching.

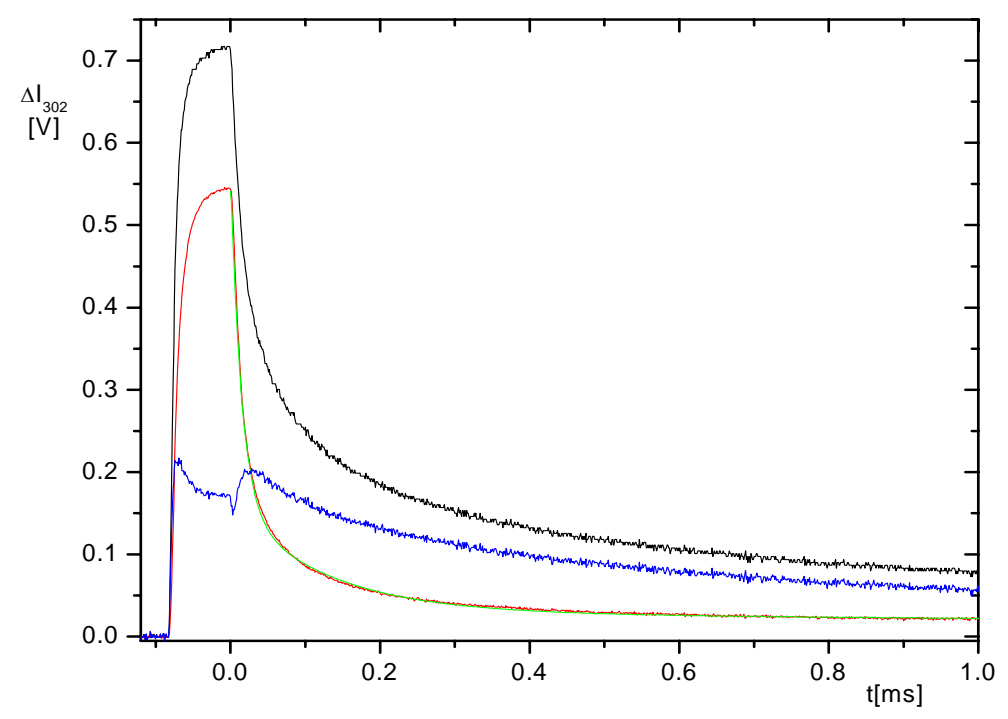

Figure 4.18 Field induced change of the transmission $\Delta \mathrm{I}$ at $302 \mathrm{~nm}$ for poly [d(A-T)] at polarizer orientations $\varphi=0^{\circ}$ and $55^{\circ}$ with respect to the field vector. uncorrected dichroism transients $\left(\Delta \mathrm{I}_{0}\right.$, black $)$; the magic angle transients $\left(\Delta \mathrm{I}_{55}\right.$, average of 5 shots, red) with a fit of the decay by 3 exponentials (green, $\tau_{1}=14.4 \mu \mathrm{s}, \tau_{2}=123 \mu \mathrm{s}, \tau_{3}=1.8$ ms, $\mathrm{A}_{1}=72 \% \mathrm{~A}_{2}=25 \%$ and $\left.\mathrm{A} 3=3 \%\right)$; corrected dichroism transients $\left(\Delta \mathrm{I}_{0}-\Delta \mathrm{I}_{55}\right.$, blue). $70.5 \%$ ethanol (v/v), $8^{\circ} \mathrm{C}, 160 \mu \mathrm{M}$ poly [d(A-T)], $75 \mu \mathrm{M} \mathrm{NaCl}, 75 \mu \mathrm{M}$ cacodylate $\mathrm{pH}$, $15 \mu \mathrm{M}$ EDTA; field pulse $\left.3.45 \times 10^{6} \mathrm{~V} / \mathrm{m}\right)$. 


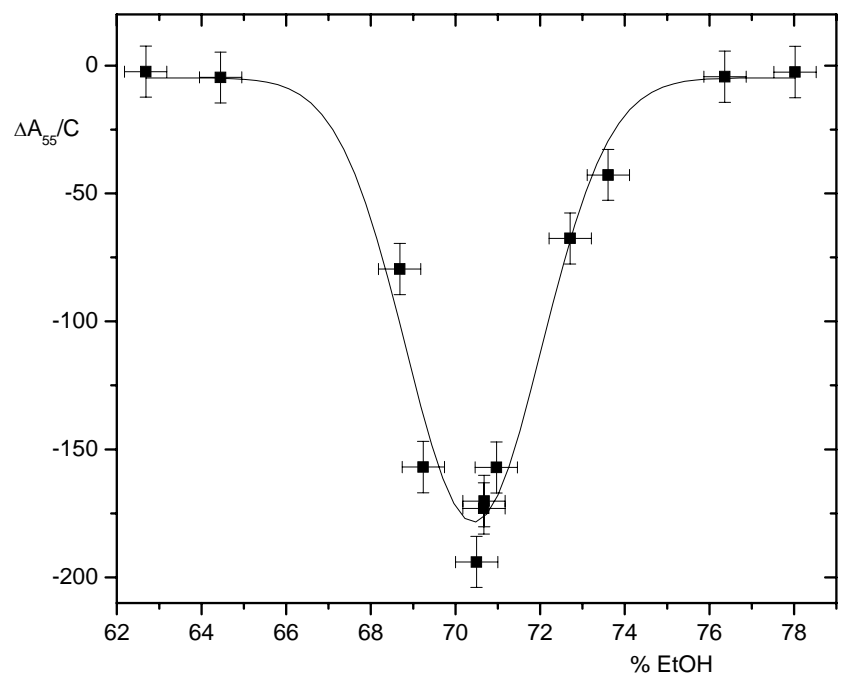

Figure 4.19 Relative magic angle amplitudes $\Delta \mathrm{A}_{55} / \mathrm{C}$ of poly [d(A-T)] at $302 \mathrm{~nm}$ as a function of the ethanol content in $\%$ units $(\mathrm{v} / \mathrm{v})$, The line represents a Gaussian fit. (center 70.43 , width 3.21, offset -4.82 , height 174$)$, $\left(8^{\circ} \mathrm{C}, 160 \mu \mathrm{M}\right.$ poly $[\mathrm{d}(\mathrm{A}-\mathrm{T})], 75$ $\mu \mathrm{M} \mathrm{NaCl}, 75 \mu \mathrm{M}$ cacodylate $\mathrm{pH}$ 7, $15 \mu \mathrm{M}$ EDTA; field pulse $3.45 \times 10^{6} \mathrm{~V} / \mathrm{m}$ ).

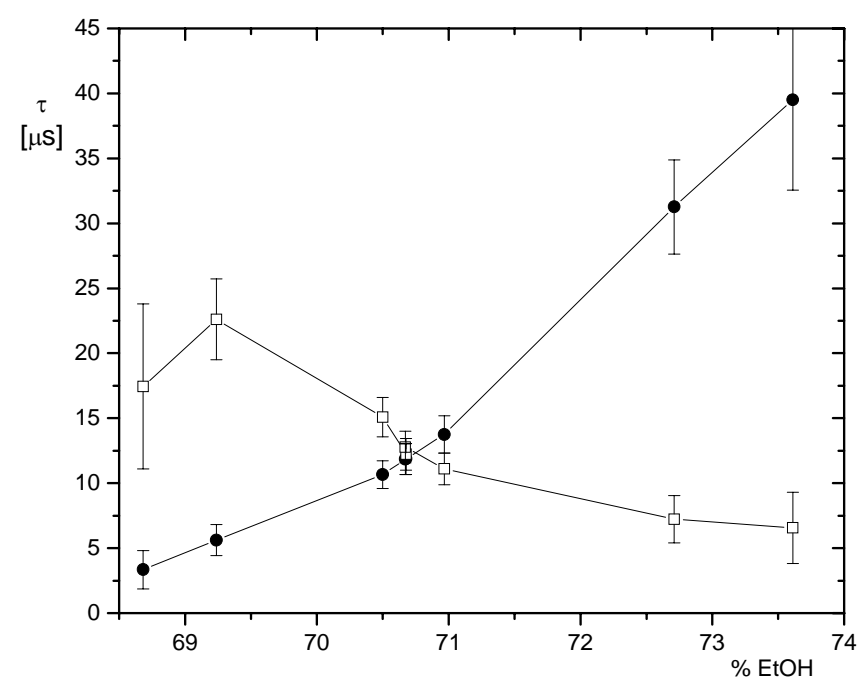

Figure 4.20 Magic angle time constants of the B-A-transition of poly [d(A-T)] at 302 $n m$ in the field free state $\left(\square, \tau^{\mathrm{d}}{ }_{1}\right)$ and of the A-B transition under electric field pulses $\left(\bullet, \tau_{2}^{\mathrm{r}}\right)$ as a function of the ethanol content in $\%$ units $(\mathrm{v} / \mathrm{v}),\left(8^{\circ} \mathrm{C}, 160 \mu \mathrm{M}\right.$ poly $[\mathrm{d}(\mathrm{A}-$ T)], $75 \mu \mathrm{M} \mathrm{NaCl}, 75 \mu \mathrm{M}$ cacodylate $\mathrm{pH}$ 7, $15 \mu \mathrm{M}$ EDTA, field pulse $3.45 \times 10^{6} \mathrm{~V} / \mathrm{m}$ ). 
Figure 4.20 shows the dependence of time constants representing the main amplitude of the B-A reaction at $302 \mathrm{~nm}$ on ethanol concentration. The B-A transition observed after the pulse termination required three exponentials for an accurate fit (fig 4.18). The dependence of reaction amplitudes on ethanol concentrations and the magnitude of reaction time constants which represents the main amplitude of B-A reaction at this wavelength are exactly similar to that observed at $280 \mathrm{~nm}$ with low concentration of poly $[\mathrm{d}(\mathrm{A}-\mathrm{T})]$. The occurrence of the third time constant, which corresponds to approximately $5 \%$ of the total amplitude, might be due to some aggregation process occurring under this condition.

\subsubsection{Chain length dependence in B-A transition}

Ivanov and Krylov (1992) showed that the B-A transition in DNA is a cooperative process with an estimated cooperative length in the range from 10 to $30 \mathrm{bp}$. Therefore, optimal amplitudes are expected in the range of chain lengths above the cooperative length. For an experimental verification of any chain length dependence in B-A transition, field jump experiments were done with two poly [d(A-T)] fragments with different chain lengths. The rotational diffusion time constants are very strongly dependent on the chain length, whereas the time constants for the B-A transition are expected to show much less chain length dependence, for chain lengths above the cooperative length. Poly [d(A-T)] samples with an average chain length of 70 bp and 120 bp were used. For short oligomers, B-A- transition is expected to be broadened, whereas an approximately constant width is expected for chain lengths above the cooperative length.

\subsubsection{Experiments with 70 bp poly [d(A-T)] fragment}

In order to study the chain length dependence of B-A transition field jump experiments were performed on a poly $[\mathrm{d}(\mathrm{A}-\mathrm{T})]$ fragment with an average chain length of $70 \mathrm{bp}$. Gel electrophoresis showed a distribution of chain lengths between $60 \mathrm{bp}$ and $80 \mathrm{bp}$. Field jump experiments were performed on this fragment at $280 \mathrm{~nm}$ and the amplitudes observed in $70.4 \%$ ethanol are shown in figure 4.21 . The reaction 
amplitudes observed at the magic angle are smaller than that observed for the polymer with 1500 bp, but can still be characterized with a sufficiently high accuracy. The B-A transients observed after pulse termination required two exponentials for a satisfactory fit ( $\tau_{1}=8.25 \mu \mathrm{s}, \tau_{2}=67.8 \mu \mathrm{s}, \mathrm{A}_{1}=87 \% \mathrm{~A}_{2}=13 \%$, at $70.4 \%$ ethanol). These time constants are close to that observed for the long polymer. The main difference is in the relative amplitude of the slow process, which is clearly smaller than that observed for the long polymer.

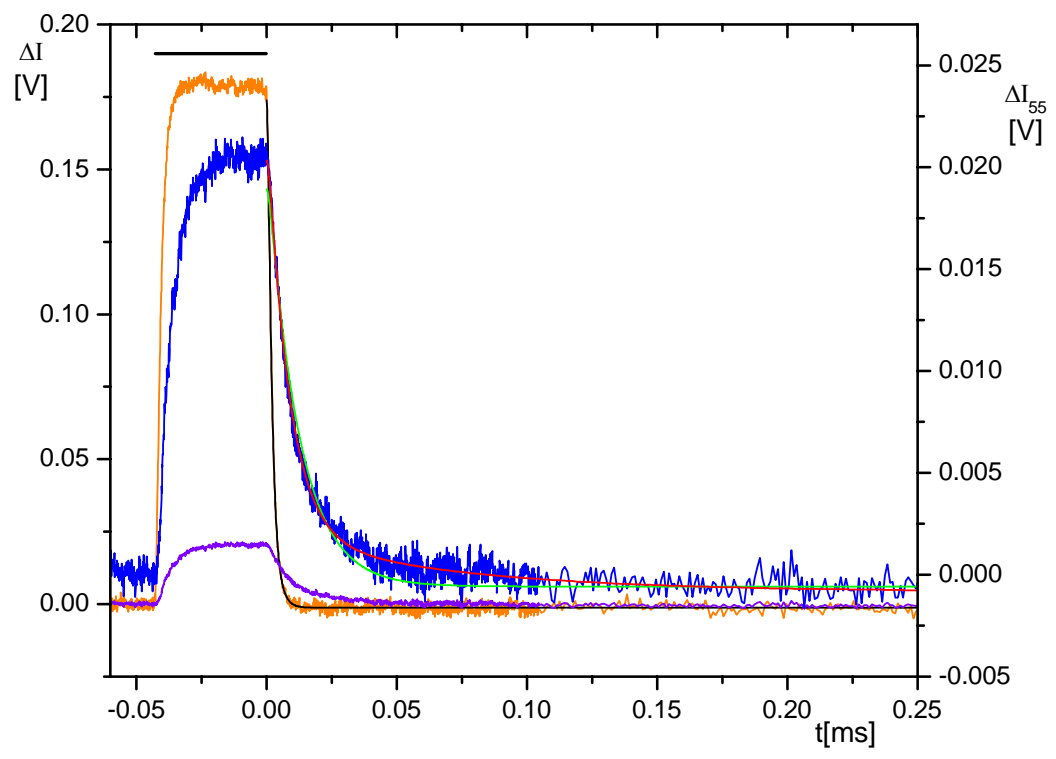

Figure 4.21 Field induced change of the transmission $\Delta \mathrm{I}$ at $280 \mathrm{~nm}$ for 70 bp poly [d(A-T)] at polarizer orientations $\varphi=0$ and $55^{\circ}$ with respect to the field vector. Corrected dichroism transients $\left(\Delta \mathrm{I}_{0}-\Delta \mathrm{I}_{55}\right.$, orange) with a fit of the decay by 2 exponentials (black, $\tau_{1}=0.83 \mu \mathrm{s}, \tau_{2}=$ $\left.2.19 \mu \mathrm{s}, \mathrm{A}_{1}=61 \% \mathrm{~A}_{2}=39 \%\right)$; the magic angle transients $\left(\Delta \mathrm{I}_{55}\right.$, average of 5 shots $)$ is shown both at the same scale as the dichroism (magenta, left scale) and magnified (blue, right scale) with $a$ fit of the decay by 2 exponentials (red, $\tau_{1}=8.25 \mu \mathrm{s}, \tau_{2}=67.8 \mu \mathrm{s}, \mathrm{A}_{1}=87 \% \mathrm{~A}_{2}=13 \%$ ) and by 1 exponential (green) The bar indicates the duration of the field pulse. (70.4\% ethanol (v/v), $8^{\circ} \mathrm{C}, 8.5 \mu \mathrm{M}$ poly [d(A-T)], $75 \mu \mathrm{M} \mathrm{NaCl}, 75 \mu \mathrm{M}$ cacodylate $\mathrm{pH}$ 7, $15 \mu \mathrm{M}$ EDTA; field pulse $\left.3.45 \times 10^{6} \mathrm{~V} / \mathrm{m}\right)$.

The dichroism decay transient of 70 bp poly $[\mathrm{d}(\mathrm{A}-\mathrm{T})]$ fragment and its fit by two exponentials $\left(\tau_{1}=0.83 \mu \mathrm{s}, \tau_{2}=2.19 \mu \mathrm{s}\right)$ are shown in figure 4.21. The dichroism decay time constants are a measure of the hydrodynamic dimensions. It is known that B and A forms differ in their hydrodynamic dimensions and this should be 
reflected in the dichroism decay time constants. Dichroism decay time constants are very much dependent on the viscosity and different ethanol content have different viscosities. For quantitative comparison, the time constants were corrected to the state of water at $20^{\circ} \mathrm{C}$ and plotted as a function of ethanol as shown in figure 4.22. The corrected dichroism decay time constants clearly show the expected decrease of the hydrodynamic length upon the B-A transition. Gel electrophoresis of the sample showed a broad distribution of chain lengths. To follow the change in hydrodynamic dimensions during the transition the chain length of the sample should be calibrated to a finite value. This calibration of chain length was done using the corrected integral dichroism decay time constant of the B-form, based on a rise per base pair of $3.4 \AA$, and an effective chain length of 76 bp is obtained. Using this chain length and the decay time constant measured for the A-form, an effective rise per base pair of $3.0 \AA$ is obtained for the A-form. These calculations are based on the wormlike chain model with a persistence length of $1000 \AA$ found for DNA at low salt concentrations.

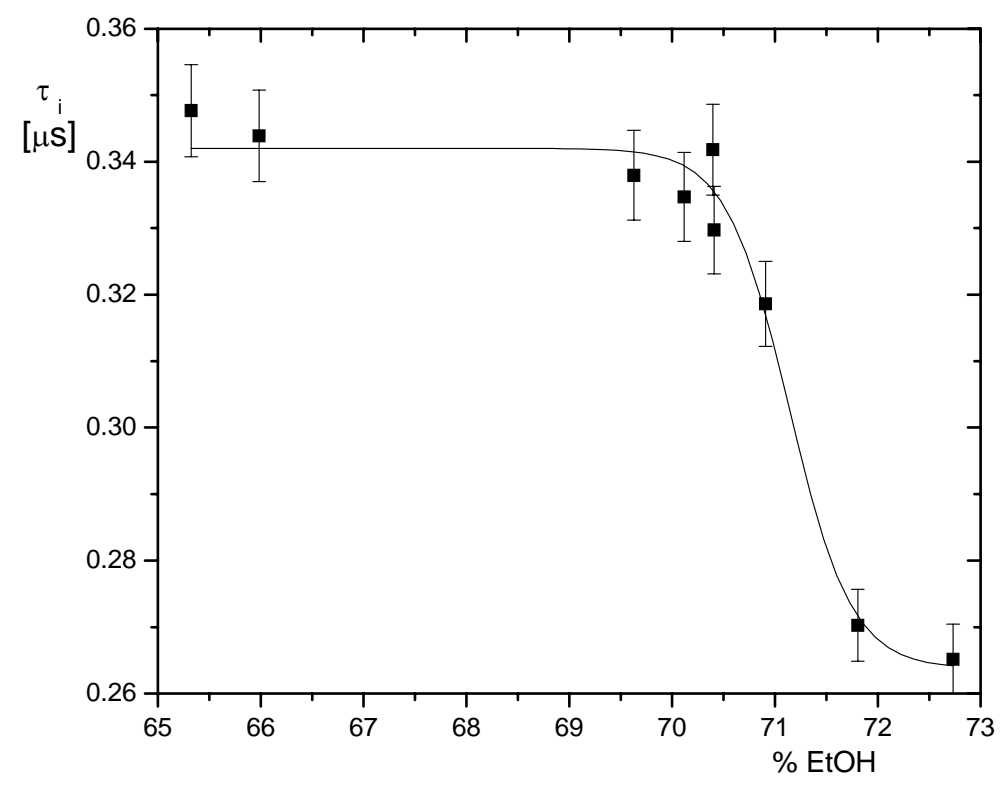

Figure 4.22. Integral dichroism decay time constants $\tau_{\mathrm{i}}$ for $70 \mathrm{bp}$ poly [d(A-T)] at $280 \mathrm{~nm}$ as a function of the ethanol content $(v / v)$ corrected to the state of water at $20^{\circ} \mathrm{C} .(75 \mu \mathrm{M} \mathrm{NaCl}, 75$ $\mu \mathrm{M}$ cacodylate $\mathrm{pH} 7,15 \mu \mathrm{M}$ EDTA; field pulse $\left.3.45 \times 10^{6} \mathrm{~V} / \mathrm{m}\right) \tau_{\mathrm{i}}$ was calculated from the parameters of the two exponential fit according to $\tau_{i}=\tau_{1} \cdot A_{1} /\left(A_{1}+A_{2}\right)+\tau_{2} \cdot A_{2} /\left(A_{1}+A_{2}\right)$, where $\tau_{1}, \tau_{2}$ are the time constants and $A_{1}, A_{2}$ are the amplitudes of the fit to the dichroism decay. The line represents a fit by a sigmoidal function. 


\subsubsection{Experiments with 120 bp poly [d(A-T)] fragment}

For further clarification, experiments were conducted on a poly [d(A-T)] sample with an average chain length of 120 bp. Gel electrophoresis showed a distribution of chain lengths between $90 \mathrm{bp}$ and $160 \mathrm{bp}$. The amplitudes measured at $280 \mathrm{~nm}$ appear only in the B-A-transition range and shows a maximum at $70.4 \%$ ethanol (fig. 4.23). The dependence of the magic angle amplitude on ethanol percentage confirmed that the observed process is B-A transition.

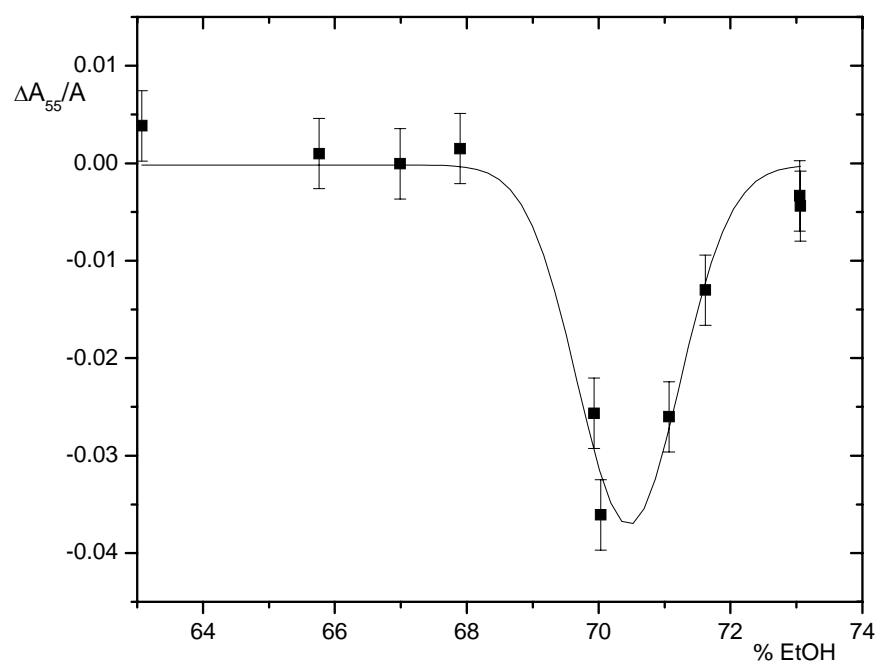

Figure 4.23 Relative magic angle amplitudes $\Delta \mathrm{A}_{55} / \mathrm{A}$ of $120 \mathrm{bp}$ poly[d(A-T)] at $280 \mathrm{~nm}$ as a function of the ethanol content in \% units (v/v). The line represents a Gaussian fit. (center 70.46, width 1.55 , offset -0.00019 , height 0.037$)$, $\left(8^{\circ} \mathrm{C}, 8.5 \mu \mathrm{M}\right.$ poly [d(A-T)], $75 \mu \mathrm{M}$ $\mathrm{NaCl}, 75 \mu \mathrm{M}$ cacodylate $\mathrm{pH}$ 7, $15 \mu \mathrm{M}$ EDTA; field pulse $3.45 \times 10^{6} \mathrm{~V} / \mathrm{m}$ ).

The B-A transients observed after pulse termination required two exponentials for a satisfactory fit $\left(\tau_{1}=10.66 \mu \mathrm{s}, \tau_{2}=212 \mu \mathrm{s}, \mathrm{A}_{1}=86 \% \mathrm{~A}_{2}=14 \%\right.$, at $70.03 \%$ ethanol). These time constants are close to that observed for the long polymer and 70 bp fragment.

The dichroism decay transients required two exponentials for satisfactory fit. These time constants were then corrected to the state of water at $20^{\circ} \mathrm{C}$ and analysed (fig. 4.24). Observed dichroism decay time constants are greater than that for the $70 \mathrm{bp}$ fragments, which is in accordance with the chain length of the two samples. The corrected dichroism decay time constants showed the expected decrease with increase in ethanol percentage. Gel electrophoresis of the sample gave a broad 
distribution of chain lengths. In order to follow the decrease in hydrodynamic dimensions during the $\mathrm{B} \rightarrow \mathrm{A}$ transition the chain length of the fragment should be calibrated to a finite value. Calibration of the chain length is done using the corrected integral dichroism decay time constant of the B- form, based on a rise per base pair of $3.4 \AA$, and the obtained effective chain length for the sample is $98 \mathrm{bp}$. Using this chain length and the decay time constant measured for A-form the effective rise per base pair is found to be $3.0 \AA$ for the A-form based on the worm like chain model with a persistence length of $1000 \AA$ found for DNA at low salt concentrations.

These studies reveal that the time constants of B-A transition of DNA is independent of chain length of the fragments whereas the dichroism decay time constants are clearly dependent on the chain length. The extent of perturbation from the equilibrium state under field pulses decreases with decrease in chain length and therefore the reaction amplitude observed in short chain fragments are smaller than that in long chain polymers.

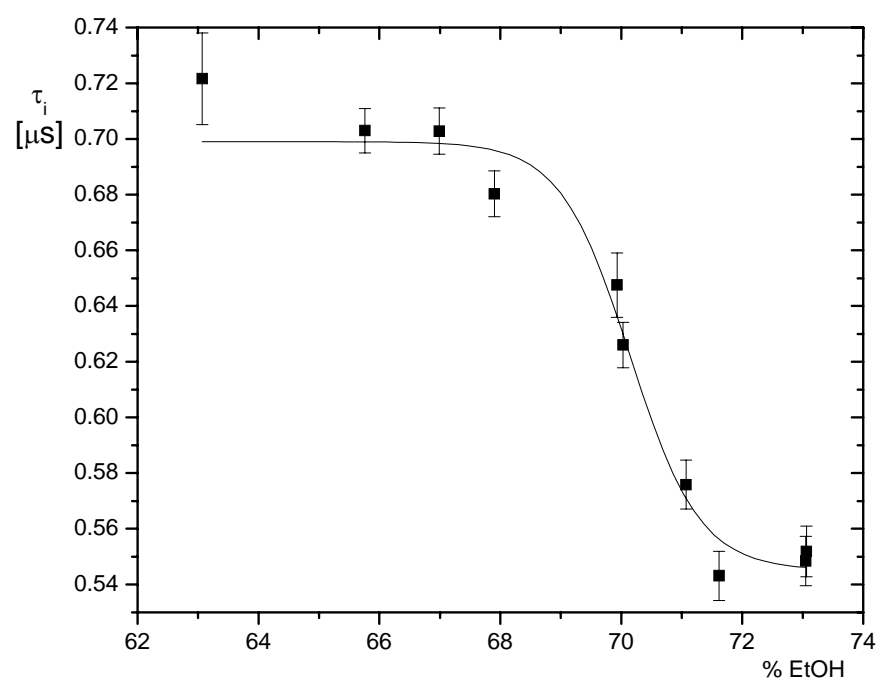

Figure 4.24 Integral dichroism decay time constants $\tau_{\mathrm{i}}$ for $120 \mathrm{bp}$ poly [d(A-T)] at $280 \mathrm{~nm}$ as a function of the ethanol content $(\mathrm{v} / \mathrm{v})$ corrected to the state of water at $20^{\circ} \mathrm{C} .(75 \mu \mathrm{M} \mathrm{NaCl}, 75$ $\mu \mathrm{M}$ cacodylate $\mathrm{pH} 7,15 \mu \mathrm{M}$ EDTA; field pulse $\left.3.45 \times 10^{6} \mathrm{~V} / \mathrm{m}\right) \tau_{\mathrm{i}}$ was calculated from the parameters of the two exponential fit according to $\tau_{\mathrm{i}}=\tau_{1} \cdot \mathrm{A}_{1} /\left(\mathrm{A}_{1}+\mathrm{A}_{2}\right)+\tau_{2} \cdot \mathrm{A}_{2} /\left(\mathrm{A}_{1}+\mathrm{A}_{2}\right)$, where $\tau_{1}, \tau_{2}$ are the time constants and $A_{1}, A_{2}$ are the amplitudes of the fit to the dichroism decay. The line represents a fit by a sigmoidal function. 


\subsubsection{Ionic strength dependence in B-A transition}

Reaction rates of polyelectrolytes are usually strongly dependent on the ionic strength. Thus, the B-A reaction should be analyzed at different salt concentrations. However, limitations imposed both by the experimental system and by the method preclude an analysis over a wide range of ionic strengths. The standard $\mathrm{Na}^{+}$concentration used in field jump experiments is $75 \mu \mathrm{M}$. Experiments were done on a sample with $\mathrm{Na}^{+}$concentration of $300 \mu \mathrm{M}$, which is four times higher than that of the standard value. Under these conditions, it was shown in CD and absorbance difference spectra that the midpoint of the transition is shifted towards the lower ethanol percentage by about $2 \%$ (fig 4.8). Figure 4.25 shows the dependence of the amplitude measured at $280 \mathrm{~nm}$ on ethanol percentage. B-A-transition amplitudes and transients showed all the characteristic features which were observed at the standard ion concentration.

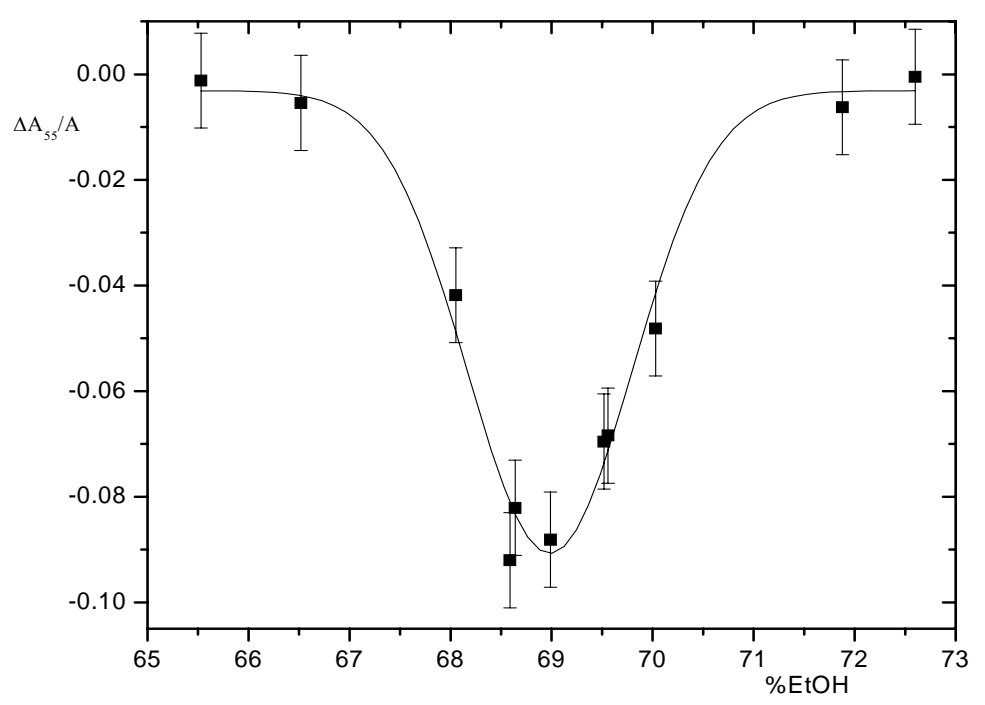

Figure 4.25 Relative magic angle amplitudes $\Delta \mathrm{A}_{55} / \mathrm{A}$ of poly [d(A-T)] as a function of the ethanol content in \% units (v/v). The line represents a Gaussian fit. (center 68.98, width 1.63 , offset -0.0031 , height 0.088$),\left(8^{\circ} \mathrm{C}, 8.5 \mu \mathrm{M}\right.$ poly [d(A-T)], $300 \mu \mathrm{M} \mathrm{NaCl}, 300 \mu \mathrm{M}$ cacodylate $\mathrm{pH}$ 7, $60 \mu \mathrm{M}$ EDTA; field pulse $\left.3.45 \times 10^{6} \mathrm{~V} / \mathrm{m}\right)$.

The time constants of the B-A transients (fig 4.26) at the midpoint of the transition are close to those observed in the standard buffer. Thus, the dependence of the time constants on the ionic strength is relatively small, if the same state of transition is considered. In order to have an explicit idea about the dependence of B-A 
reaction time constants on ionic strength, the analysis should be extended to a wider range of ionic strengths.

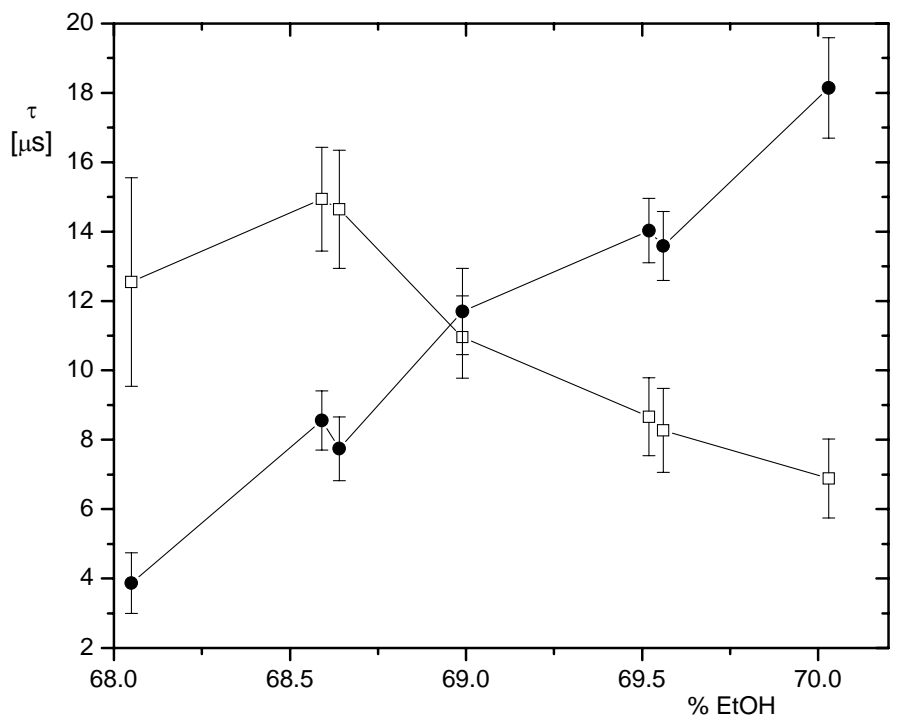

Figure 4.26 Magic angle time constants of the B-A-transition of poly [d(A-T)] at $280 \mathrm{~nm}$ in the field free state $\left(\square, \tau_{1}^{\mathrm{d}}\right)$ and of the A-B transition under electric field pulses $\left(\bullet, \tau_{2}^{\mathrm{r}}\right)$ as a function of the ethanol content in $\%$ units $(\mathrm{v} / \mathrm{v}),\left(8^{\circ} \mathrm{C}, 8.5 \mu \mathrm{M}\right.$ poly $[\mathrm{d}(\mathrm{A}-\mathrm{T})], 300 \mu \mathrm{M} \mathrm{NaCl}$, $300 \mu \mathrm{M}$ cacodylate $\mathrm{pH}$ 7, $60 \mu \mathrm{M}$ EDTA, field pulse $3.45 \times 10^{6} \mathrm{~V} / \mathrm{m}$ ).

\subsubsection{Experiments with poly $[\mathrm{d}(\mathrm{A}-\mathrm{T})]$ and TFE}

It is known that TFE also can induce the B-A transition in DNA (Minchenkova et.al, 1986). The CD and absorbance spectra showed that TFE could induce B-A transition at a lower alcohol percentage than ethanol (fig 4.8).

Field jump experiments were done on poly [d(A-T)]-TFE solutions at standard salt concentration and at a salt concentration four times higher than that of the standard value. The amplitudes measured at $280 \mathrm{~nm}$, in a salt concentration four times higher than the standard solution, as a function of TFE is shown in fig 4.27. The maximum amplitude observed is close to the midpoint of transition, which has been determined independently by measurements of CD and absorbance difference spectra under the same experimental conditions (fig 4.8). As in cases with ethanol, a reversal of amplitude was observed at $248 \mathrm{~nm}$ and a small denaturation amplitude, which is $3 \mathrm{mV}$, was observed at $270 \mathrm{~nm}$. These observations reconfirm that the observed process under magic angle condition is B-A transition. 


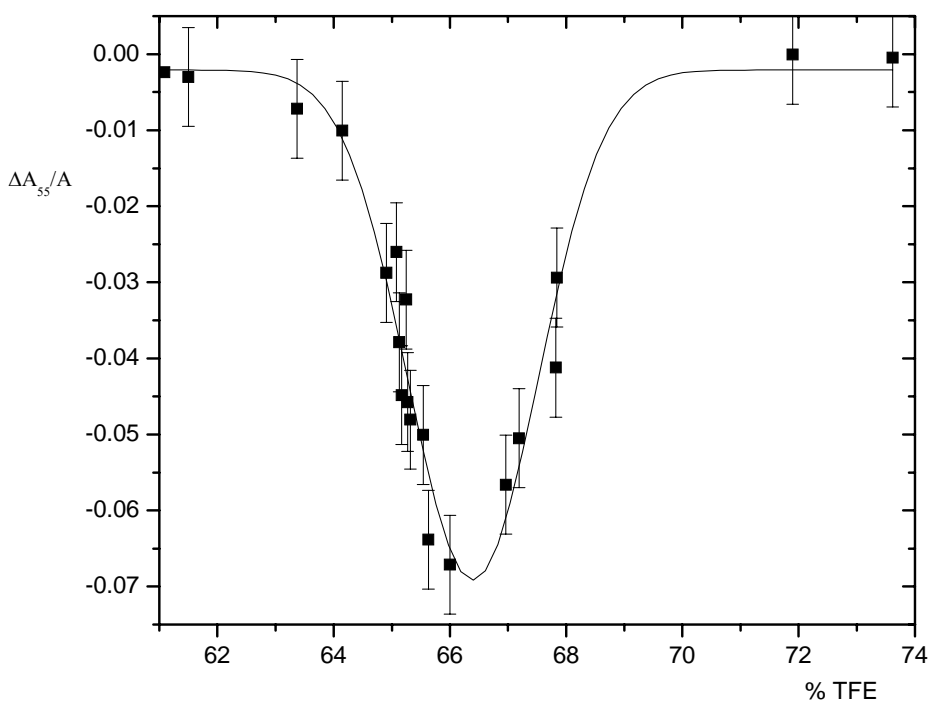

Figure 4.27 Relative magic angle amplitudes $\Delta \mathrm{A}_{55} / \mathrm{A}$ of poly [d(A-T)] at $280 \mathrm{~nm}$ as a function of the TFE content in \% units (v/v). The line represents a Gaussian fit. (center 66.39 , width 2.09 , offset -0.0018 , height 0.067$)$, $\left(8^{\circ} \mathrm{C}, 8.5 \mu \mathrm{M}\right.$ poly [d(A-T)], $300 \mu \mathrm{M}$ $\mathrm{NaCl}, 300 \mu \mathrm{M}$ cacodylate $\mathrm{pH}$ 7, $60 \mu \mathrm{M}$ EDTA; field pulse $\left.3.45 \times 10^{6} \mathrm{~V} / \mathrm{m}\right)$.

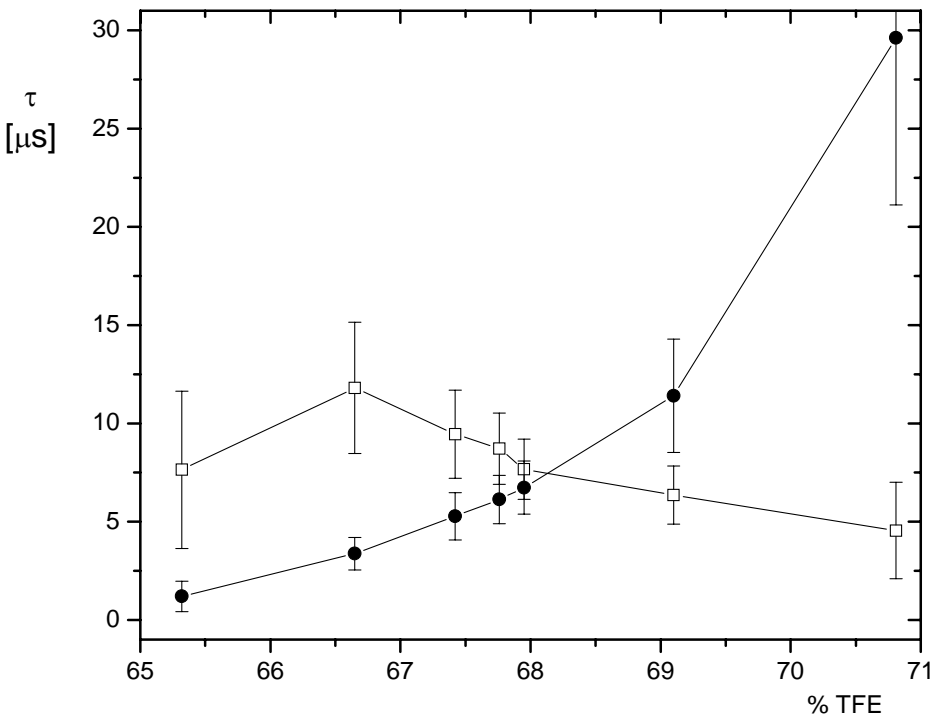

Figure 4.28 Magic angle time constants of the B-A-transition of poly [d(A-T)] at $280 \mathrm{~nm}$ in the field free state $\left(\square, \tau_{1}^{\mathrm{d}}\right)$ and of the $A-B$ transition under electric field pulses $\left(\bullet, \tau_{2}^{\mathrm{r}}\right)$ as a function of the TFE content in $\%$ units $(\mathrm{v} / \mathrm{v}),\left(8^{\circ} \mathrm{C}, 8.5 \mu \mathrm{M}\right.$ poly [d(A-T)], $75 \mu \mathrm{M} \mathrm{NaCl}, 75$ $\mu \mathrm{M}$ cacodylate $\mathrm{pH}$ 7, $15 \mu \mathrm{M}$ EDTA, field pulse $\left.3.45 \times 10^{6} \mathrm{~V} / \mathrm{m}\right)$. 
The B-A-transition time constants observed are in the same range as that in ethanol, in both salt concentrations. The dependence of the B-A transition time constants on TFE percentage at standard salt concentration is given in figure 4.28. The fact that the use of a different solvent to reduce the water activity did not change the reaction time constants confirmed that the process observed in both solvents are the same.

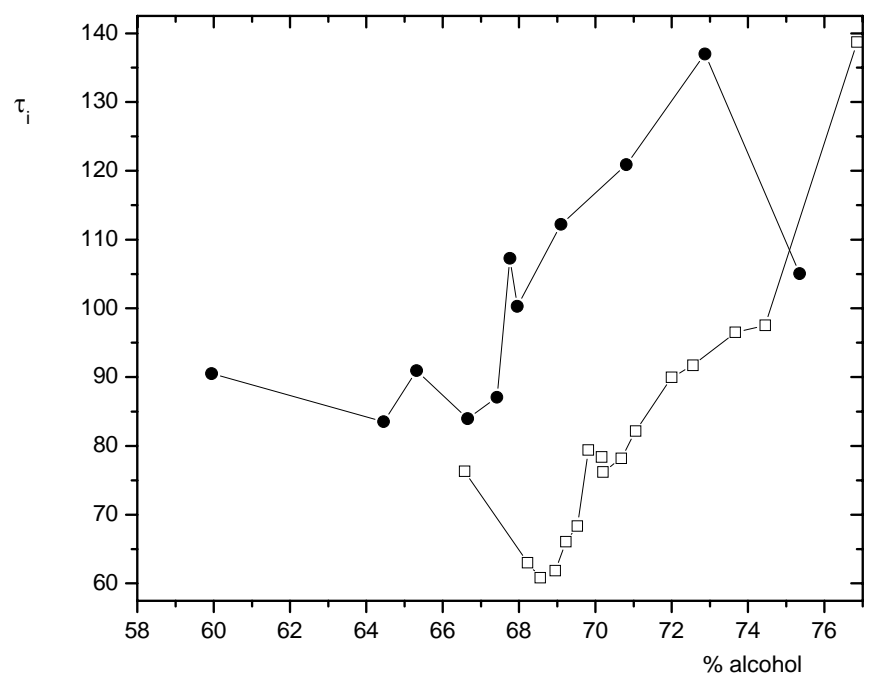

Figure 4.29. Integral dichroism decay time constants $\tau_{\mathrm{i}}$ for poly [d(A-T)] at $280 \mathrm{~nm}$ as a function of the $(\square)$ ethanol and $(\bullet)$ TFE content $(\mathrm{v} / \mathrm{v})$ corrected to the state of water at $20^{\circ} \mathrm{C}$. (8.5 $\mu \mathrm{M}$ poly [d(A-T)], $75 \mu \mathrm{M} \mathrm{NaCl}, 75 \mu \mathrm{M}$ cacodylate $\mathrm{pH}$ 7, $15 \mu \mathrm{M}$ EDTA; field pulse $\left.3.45 \times 10^{6} \mathrm{~V} / \mathrm{m}\right) \tau_{\mathrm{i}}$ was calculated from the parameters of the two exponential fit according to $\tau_{\mathrm{i}}=\tau_{1} \cdot \mathrm{A}_{1} /\left(\mathrm{A}_{1}+\mathrm{A}_{2}+\mathrm{A}_{3}\right)+\tau_{2} \cdot \mathrm{A}_{2} /\left(\mathrm{A}_{1}+\mathrm{A}_{2}+\mathrm{A}_{3}\right)+\tau_{3} \cdot \mathrm{A}_{3} /\left(\mathrm{A}_{1}+\mathrm{A}_{2}+\mathrm{A}_{3}\right)$, where $\tau_{1}, \tau_{2}, \tau_{3}$ are the time constants and $A_{1}, A_{2}, A_{3}$ are the amplitudes of the fit to the dichroism decay.

It is known that at high ethanol concentration aggregation of DNA occurs. Dichroism decay time constants reflect the hydrodynamic dimensions of the sample. The analyses of dichroism decay time constants in TFE, which are corrected to the state of water at $20^{\circ} \mathrm{C}$, gave almost similar values as that in ethanol (fig 4.29).

Ivanov and coworkers suggested that the use of TFE instead of ethanol as the alcohol component would reduce aggregation of DNA. (Minchenkova et.al., 1986). This statement should be examined by comparing the measured dichroism decay time 
constants of samples in ethanol and TFE. The suggestion about reduction of aggregation was based on the observation that TFE induce the B-A transition at about 5\% lower alcohol content than ethanol (Minchenkova et.al., 1986). If TFE decreases aggregation, it should be reflected in the dichroism decay time constant. But experiments showed almost identical time constants for samples in ethanol and TFE (fig. 4.29). So the basis of suggestion of using TFE instead of ethanol should be reconsidered.

\subsubsection{Experiments with natural DNA}

Field jump experiments with poly $[\mathrm{d}(\mathrm{A}-\mathrm{T})]$ showed that field pulses induce B-A transition in DNA and the reaction proceeds with time constants of $\sim 10$ $\mu \mathrm{s}$. When compared to the predictions of molecular dynamics this is unexpectedly slow. One major drawback of the experiments with poly $[\mathrm{d}(\mathrm{A}-\mathrm{T})]$ is that the observations are restricted to the case of A-T base pairs only. In order to check for any dependence of the kinetics of B-A transition on G-C content, field jump experiments were conducted on Salmon sperm DNA samples which are with average chain lengths of $200 \mathrm{bp}$ and $4600 \mathrm{bp}$. From the absorbance difference spectra, it was known that B-A transition of natural DNA could be followed either at $265 \mathrm{~nm}$ or at $248 \mathrm{~nm}$ (fig 4.2). Field jump experiments were done at various ethanol percentages in the B-A transition range and the reaction amplitudes appeared at $265 \mathrm{~nm}$ and $248 \mathrm{~nm}$ were not with sufficient magnitude for an accurate determination of time constants. Table 4.1 shows that the width of the B-A transition in natural DNA is almost 5 times broader than that in poly $[\mathrm{d}(\mathrm{A}-\mathrm{T})]$. Therefore the extent of perturbation from the equilibrium state upon the application of field pulses are smaller in natural DNA than in poly $[\mathrm{d}(\mathrm{A}-\mathrm{T})]$. At these wavelengths the denaturation spectra of natural DNA also exhibits significant amplitude. So increasing the field strength to achieve a considerable perturbation from the equilibrium state to increase the B-A transition amplitude will lead to coupling of B-A transition with denaturation of DNA double helix. Therefore, an accurate study of the kinetics of B-A transition in natural DNA turned out to be difficult at these wavelengths. 


\subsubsection{Experiments with 859 base pair DNA}

Hillen and Wells (1980) showed that the B-A transition width of DNA restriction fragments is narrower than that of natural DNA (table 4.1). Considering this fact field jump experiments were done on 859 base pair DNA restriction fragment. From the absorbance difference spectra, it was known that B-A transition of natural DNA could be followed either at $265 \mathrm{~nm}$ or at $248 \mathrm{~nm}$ (fig 4.2). Conditions for field jump experiment were standardized by finding out the threshold field strength for denaturation as described by Diekmann and Pörschke (1982). The threshold field strength for denaturation was determined by conducting experiments in the two different ethanol concentrations, that is, one at $60 \% \mathrm{EtOH}$ and other at $80 \%$ ethanol, which are outside the B-A transition range. Figure 4.30 shows the dependence of denaturation amplitude on field strength at $60 \%$ ethanol. In $60 \%$ ethanol the threshold value for the denaturation of DNA was approximately $40 \mathrm{kV} / \mathrm{cm}$. In figure 4.10 it was shown that an increase in ethanol percentage would increase the stability of the double helix. As the stability of double helix increase, the threshold field strength for denaturation also increases. This was further confirmed by checking the field induced denaturation at $80 \%$ ethanol which occurred at about $60 \mathrm{kV} / \mathrm{cm}$. Therefore 34.5 $\mathrm{kV} / \mathrm{cm}$ is taken as the standard field strength and experiments are done at $8^{\circ} \mathrm{C}$. The denaturation spectra did not reveal any suitable wavelength for the measurement of BA-transition where there is not considerable denaturation amplitude. Therefore the reaction was followed at both $265 \mathrm{~nm}$ and $248 \mathrm{~nm}$. 


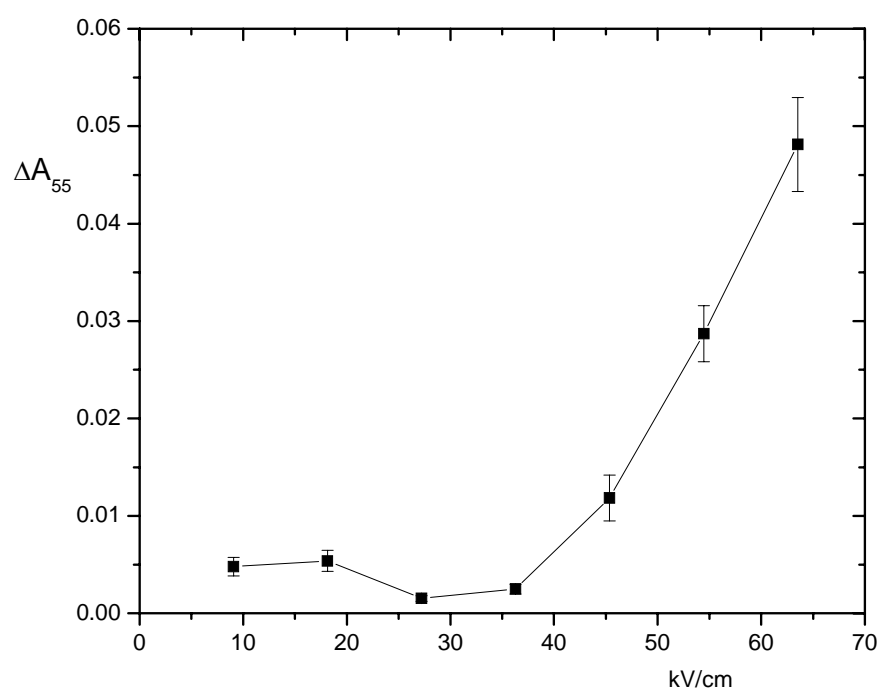

Figure 4.30. Magic angle amplitudes $\Delta \mathrm{A}_{55}$ of $859 \mathrm{bp} D N A$ at $265 \mathrm{~nm}$ as a function of field strength (60\% ethanol (v/v), $8^{\circ} \mathrm{C}, 5.25 \mu \mathrm{M} 859$ bp DNA, $75 \mu \mathrm{M} \mathrm{NaCl}, 75 \mu \mathrm{M}$ cacodylate $\mathrm{pH} 7$, $15 \mu \mathrm{M}$ EDTA).

Reaction amplitudes appeared under magic angle conditions, but the magnitude is smaller than that observed for poly [d(A-T)]. Figures 4.31 and 4.32 show the dependence of magic angle amplitude at $265 \mathrm{~nm}$ and $248 \mathrm{~nm}$ on the ethanol percentage. The change in amplitude is occurring only in the transition interval. The magic angle amplitude shows a clear maximum close to the center of B-A transition, which has been determined independently by measurements of CD and absorbance difference spectra for different natural DNA fragments (table 4.1). A decrease in light intensity is observed at $248 \mathrm{~nm}$ whereas an increase in light intensity occurred at 265 nm (fig 4.31 and fig 4.32). These observations are consistent with the absorbance difference spectra for B-A transition. An increase in field strength to perturb the system more from equilibrium and thereby to increase the amplitude will lead to the coupling of side reactions like helix-coil transition with the B-A transition. 


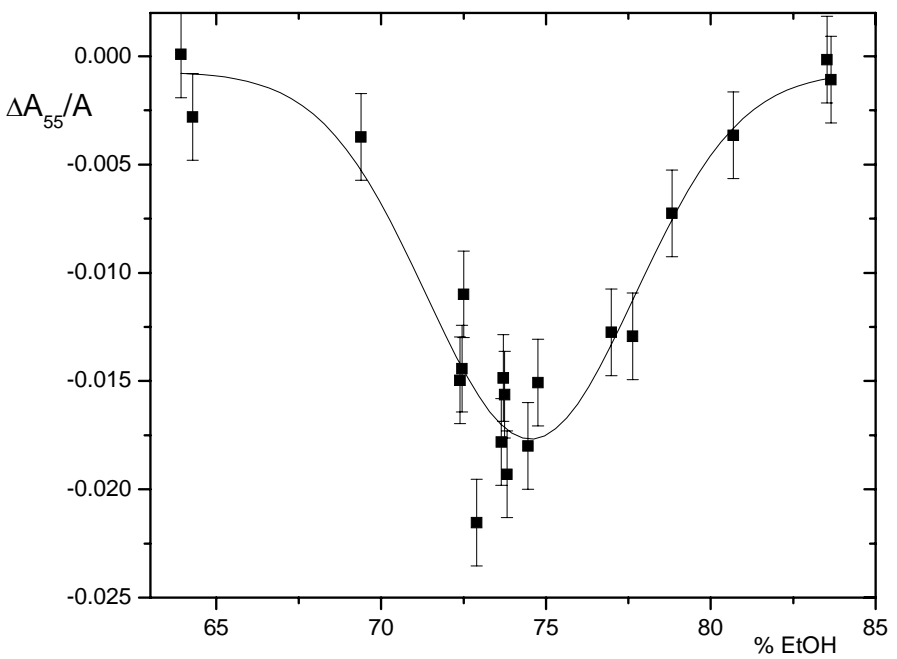

Figure 4.31. Relative magic angle amplitudes $\Delta \mathrm{A}_{55} / \mathrm{A}$ of $859 \mathrm{bp}$ DNA at $265 \mathrm{~nm}$ as a function of the ethanol content in \% units (v/v). The line represents a Gaussian fit (center 74.53, width 6.34, offset -0.0007, height 0.017), ( $8^{\circ} \mathrm{C}, 5.25 \mu \mathrm{M} 859$ bp DNA, $75 \mu \mathrm{M} \mathrm{NaCl}, 75 \mu \mathrm{M}$ cacodylate $\mathrm{pH}$ 7, $15 \mu \mathrm{M}$ EDTA; field pulse $3.45 \times 10^{6} \mathrm{~V} / \mathrm{m}$ ).

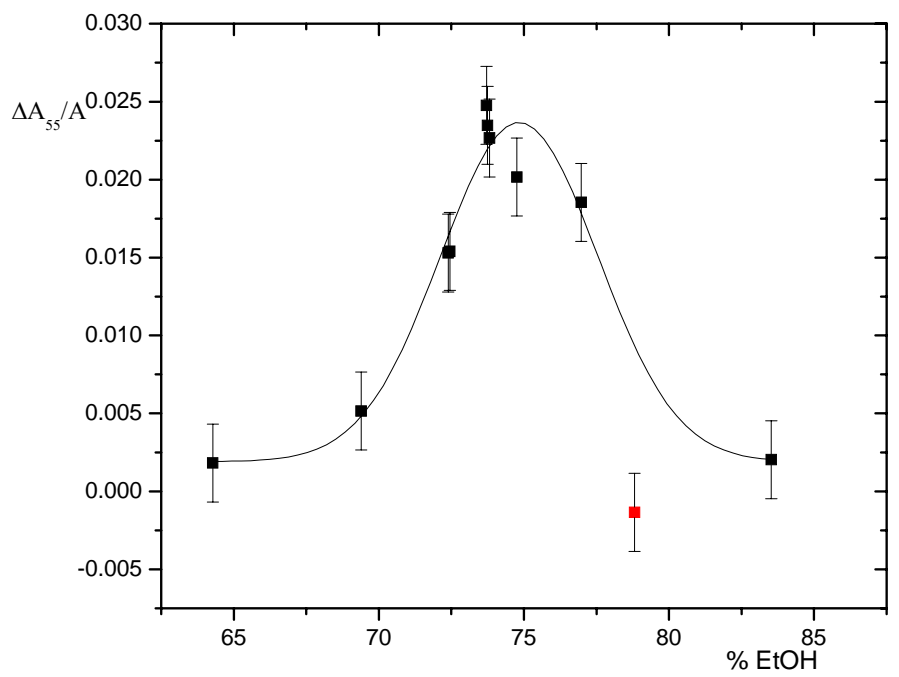

Figure 4.32. Relative magic angle amplitudes $\Delta \mathrm{A}_{55} / \mathrm{A}$ of $859 \mathrm{bp}$ DNA at $248 \mathrm{~nm}$ as a function of the ethanol content in \% units (v/v). The line represents a Gaussian fit. (center 74.84, width 5.42, offset -0.0019, height 0.022), ( $\left(8^{\circ} \mathrm{C}, 5.25 \mu \mathrm{M} 859\right.$ bp DNA, $75 \mu \mathrm{M} \mathrm{NaCl}, 75 \mu \mathrm{M}$ cacodylate $\mathrm{pH}$ 7, $15 \mu \mathrm{M}$ EDTA; field pulse $3.45 \times 10^{6} \mathrm{~V} / \mathrm{m}$ ). 
For an accurate fit, the dichroism decay transients required a three exponential fit at both $265 \mathrm{~nm}$ and $248 \mathrm{~nm}$ (fig 4.33 and 4.35). The magic angle amplitudes are small for an accurate determination of B-A transition time constants. But they give an idea about the range of expected time constant. The magic angle decay transients of the sample at $265 \mathrm{~nm}$ can be reasonably fitted with a single exponential which is with a time constant of $\sim 5 \mu$ s (fig 4.33). The transients at 248 nm showed a fast process ( $\tau \sim 5 \mu \mathrm{s}$ ) with most of the amplitude and a slow process ( $\tau$ $\sim 300 \mu \mathrm{s}$ ) with a small amplitude (fig 4.35). Figures 4.34 and 4.36 shows the dependence of time constants, which represents the main amplitude of the B-A transition on the ethanol percentage at $265 \mathrm{~nm}$ and $248 \mathrm{~nm}$.

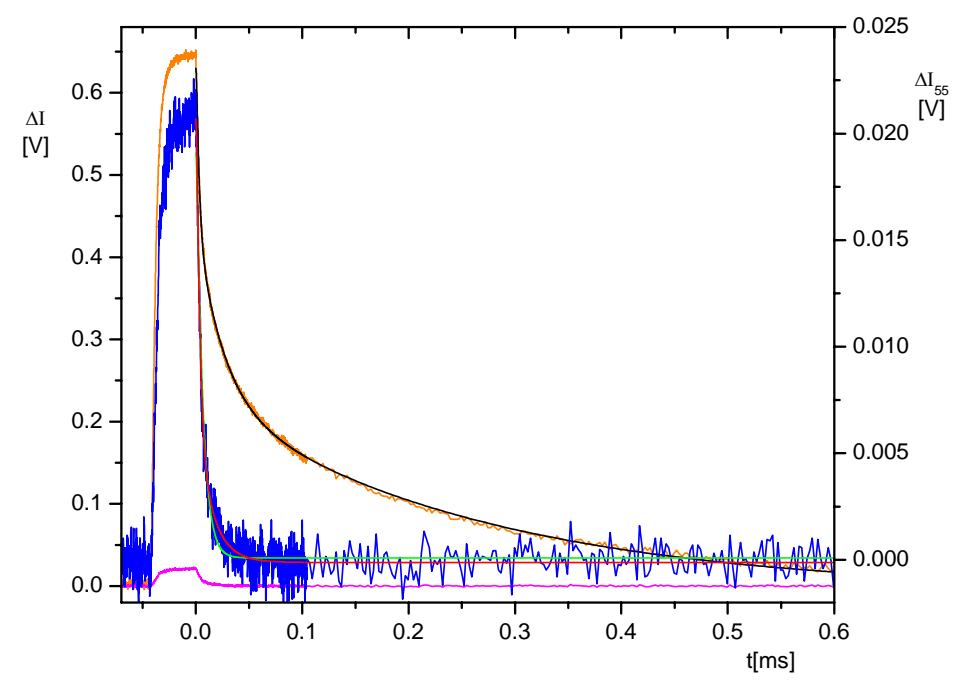

Figure 4. 33 Field induced change of the transmission $\Delta \mathrm{I}$ at $265 \mathrm{~nm}$ for $859 \mathrm{bp}$ DNA at polarizer orientations $\varphi=0^{\circ}$ and $55^{\circ}$ with respect to the field vector. Corrected dichroism transients $\left(\Delta \mathrm{I}_{0}-\Delta \mathrm{I}_{55}\right.$, orange) with a fit of the decay by 3 exponentials (black, $2.31 \mu \mathrm{s}, 24.2 \mu \mathrm{s}$, and $260 \mu$ s with relative amplitudes 29, 33, and 38\% respectively); the magic angle transients ( $\Delta \mathrm{I}_{55}$, average of 5 shots) is shown both at the same scale as the dichroism (magenta, left scale) and magnified (blue, right scale) with a fit of the decay by 2 exponentials (red, $\tau_{1}=3.06 \mu \mathrm{s}, \tau_{2}=$ $14.2 \mu \mathrm{s}, \mathrm{A}_{1}=68 \% \mathrm{~A}_{2}=32 \%$ ) and by 1 exponential (green) with $5.97 \mu \mathrm{s} .73 .8 \%$ ethanol (v/v), 
$8^{\circ} \mathrm{C}, 5.25 \mu \mathrm{M}$ DNA, $75 \mu \mathrm{M} \mathrm{NaCl}, 75 \mu \mathrm{M}$ cacodylate $\mathrm{pH}$ 7, $15 \mu \mathrm{M}$ EDTA; field pulse $3.45 \times 10^{6}$ $\mathrm{V} / \mathrm{m})$.

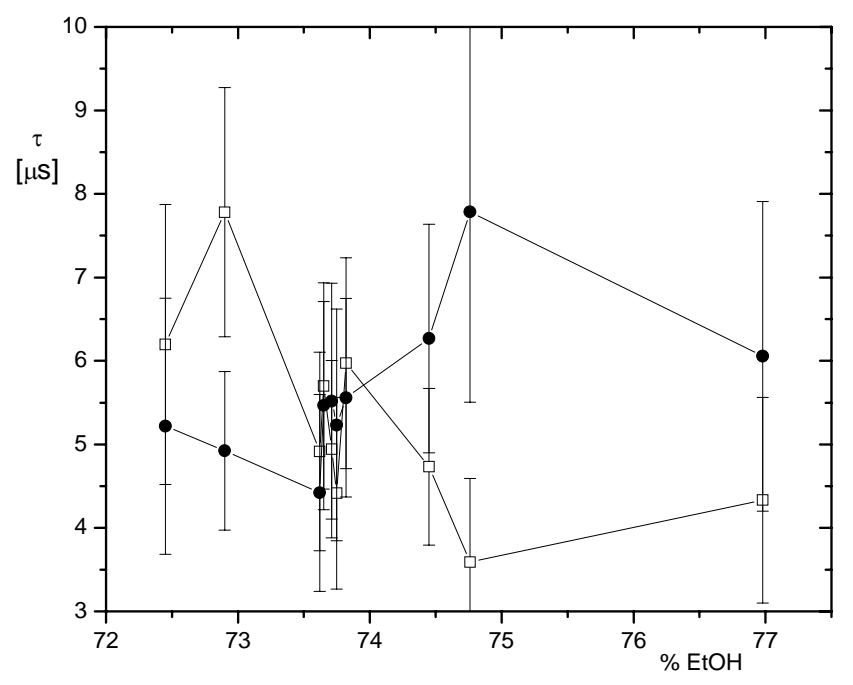

Figure 4.34 Magic angle time constants of the B-A-transition of 859 bp DNA at $265 \mathrm{~nm}$ in the field free state $\left(\square, \tau_{\mathrm{s}}^{\mathrm{d}}\right)$ and of the A-B transition under electric field pulses $\left(\bullet, \tau_{2}^{\mathrm{r}}\right)$ as a function of the ethanol content in $\%$ units $(\mathrm{v} / \mathrm{v}),\left(8^{\circ} \mathrm{C}, 5.25 \mu \mathrm{M}\right.$ DNA, $75 \mu \mathrm{M} \mathrm{NaCl}, 75 \mu \mathrm{M}$ cacodylate $\mathrm{pH}$ 7, $15 \mu \mathrm{M}$ EDTA, field pulse $\left.3.45 \times 10^{6} \mathrm{~V} / \mathrm{m}\right)$.

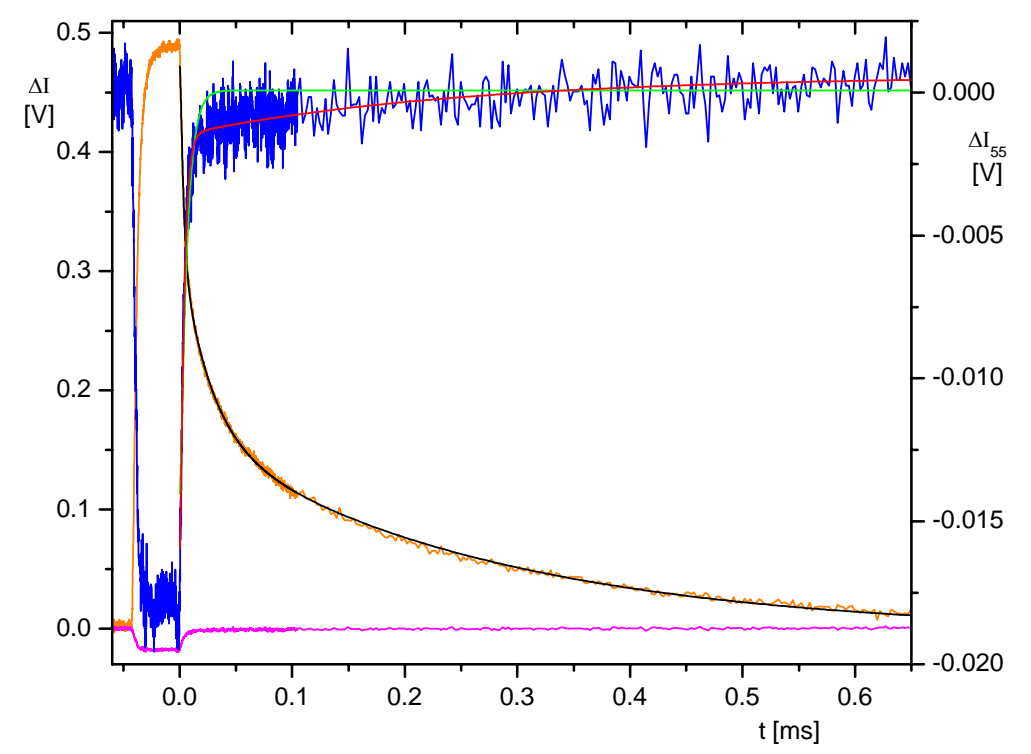

Figure 4.35 Field induced change of the transmission $\Delta \mathrm{I}$ at $248 \mathrm{~nm}$ for 859 bp DNA at polarizer orientations $\varphi=0^{\circ}$ and $55^{\circ}$ with respect to the field vector. Corrected dichroism transients ( $\Delta \mathrm{I}_{0}-\Delta \mathrm{I}_{55}$, orange) with a fit of the decay by 3 exponentials (black, $2.47 \mu \mathrm{s}, 25.3 \mu \mathrm{s}$, and $264 \mu$ s with relative amplitudes 32, 32, and 36\% respectively); the magic angle transients 
( $\Delta \mathrm{I}_{55}$, average of 5 shots) is shown both at the same scale as the dichroism (magenta, left scale) and magnified (blue, right scale) with a fit of the decay by 2 exponentials (red, $\tau_{1}=3.38 \mu$ s, $\tau_{2}=$ $\left.245 \mu \mathrm{s}, \mathrm{A}_{1}=87 \% \mathrm{~A}_{2}=13 \%\right)$ and by 1 exponential (green) with $5.94 \mu \mathrm{s}$. (73.8\% ethanol $(\mathrm{v} / \mathrm{v})$, $8^{\circ} \mathrm{C}, 5.25 \mu \mathrm{M}$ DNA, $75 \mu \mathrm{M} \mathrm{NaCl}, 75 \mu \mathrm{M}$ cacodylate $\mathrm{pH}$ 7, $15 \mu \mathrm{M}$ EDTA; field pulse $3.45 \times 10^{6}$ $\mathrm{V} / \mathrm{m})$.

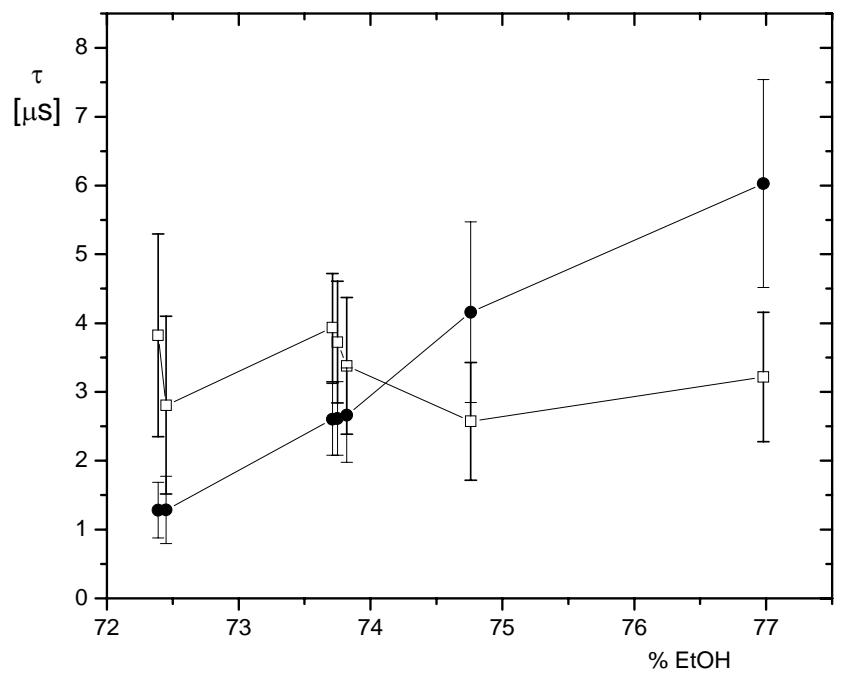

Figure 4.36 Magic angle time constants of the B-A-transition of $859 \mathrm{bp}$ DNA at $248 \mathrm{~nm}$ in the field free state $\left(\square, \tau_{1}^{\mathrm{d}}\right)$ and of the A-B transition under electric field pulses $\left(\bullet, \tau_{2}^{\mathrm{r}}\right)$ as a function of the ethanol content in $\%$ units (v/v), $\left(8^{\circ} \mathrm{C}, 5.25 \mu \mathrm{M}\right.$ DNA, $75 \mu \mathrm{M} \mathrm{NaCl}, 75 \mu \mathrm{M}$ cacodylate $\mathrm{pH} 7,15 \mu \mathrm{M}$ EDTA, field pulse $\left.3.45 \times 10^{6} \mathrm{~V} / \mathrm{m}\right)$.

Here, since the width of transition is large, the perturbation caused by the electric field from the equilibrium state is small compared to poly [d(A-T)]. Therefore there is not much separation between the rise and decay time constants. Observed time constants for the main amplitude of B-A transition at both wavelengths are in the range of $\sim 5 \mu \mathrm{s}$.

Field jump experiments with 859 base pair restriction fragments showed that field pulses induce B-A transition in natural DNA. To confirm the results obtained with the 859 base pair restriction fragments and to check for any chain length dependence field jump experiments were conducted with plasmid DNA and $\lambda$ DNA, which are with defined chain length of 2,629 bp and 48,502 bp respectively. The width of the B-A transition in plasmid DNA and lambda DNA are found to be 
about 3.5 times higher than that in poly $[\mathrm{d}(\mathrm{A}-\mathrm{T})]$ and about 1.5 times higher than that in 859 base pair restriction fragments (table 4.1). Reaction amplitudes observed at 265 $\mathrm{nm}$ and $248 \mathrm{~nm}$ were not with enough magnitude for an explicit study of the time constants of the reaction. Analysis of the absorbance spectra of plasmid DNA and $\lambda$ DNA showed that at wavelengths around $300 \mathrm{~nm}$, the relative absorbance of A-form DNA to B-form DNA is large enough to follow the B-A transition. Therefore, experiments were conducted at $296 \mathrm{~nm}$ where high DNA concentrations can be used. The concentration of the DNA is selected in such a way that the uncorrected dichroism amplitude is less than $10 \%$ of the total light intensity.

In order to optimise the conditions for the experiment, threshold field strength for denaturation (Diekmann and Pörschke, 1982) was found out by conducting experiments at the two ethanol concentrations which are outside the of BA-transition, that is, one at $60 \% \mathrm{EtOH}$ and other at $80 \%$ ethanol. The threshold field strength for denaturation in 2629 bp plasmid DNA was found to be $\sim 40 \mathrm{kV} / \mathrm{cm}$ whereas in 7160 bp plasmid DNA and $\lambda$-DNA it was $\sim 35 \mathrm{kV} / \mathrm{cm}$. Therefore 34.5 $\mathrm{kV} / \mathrm{cm}$ was chosen as the optimal field strength to study the B-A transition in $2629 \mathrm{bp}$ plasmid DNA and $27.3 \mathrm{kV} / \mathrm{cm}$ was found optimal for 7160 bp plasmid DNA and $\lambda$ DNA.

\subsubsection{Experiments with 2629 bp plasmid DNA}

Field jump experiments were conducted with plasmid DNA at $296 \mathrm{~nm}$ and reaction amplitudes with sufficient magnitude appeared under magic angle conditions. The dependence of magic angle amplitude at $296 \mathrm{~nm}$ to the ethanol percentage is shown in figure 4.37. The dependence of reaction amplitude on ethanol percentage confirms that the observed process is B-A transition. The amplitude observed at the center of transition is sufficient for an accurate determination of reaction time constants. As in the case of poly $[\mathrm{d}(\mathrm{A}-\mathrm{T})]$, a small reaction amplitude is observed at ethanol percentages below the B-A transition range, which is assigned to some internal conformational change occurring within the B-helical structure upon the application of field pulse. 


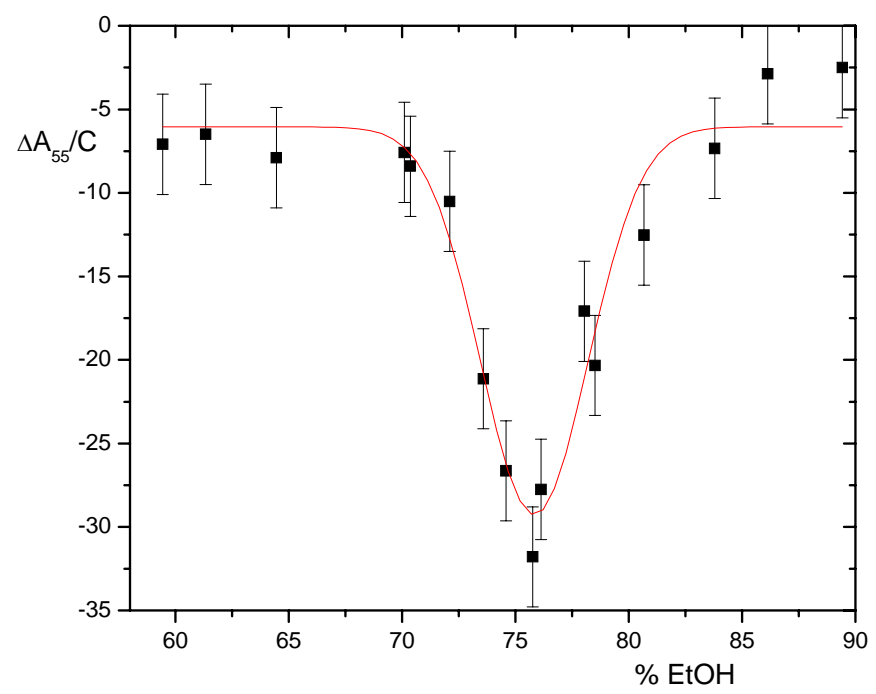

Figure 4.37. Relative magic angle amplitudes $\Delta \mathrm{A}_{55} / \mathrm{C}$ of plasmid DNA at $296 \mathrm{~nm}$ as a function of the ethanol content in $\%$ units $(\mathrm{v} / \mathrm{v})$, The line represents a Gaussian fit (center 75.84, width 4.74, offset -6.05 , height 23.22$)$, $\left(8^{\circ} \mathrm{C}, 80 \mu \mathrm{M}\right.$ plasmid DNA, 75 $\mu \mathrm{M} \mathrm{NaCl}, 75 \mu \mathrm{M}$ cacodylate $\mathrm{pH} 7,15 \mu \mathrm{M}$ EDTA; field pulse $3.45 \times 10^{6} \mathrm{~V} / \mathrm{m}$ ).

The magic angle decay transients of this sample showed a fast process with most of the amplitude ( $2 \mu$ s) and a slow process with small amplitude $(\sim 100$ $\mu \mathrm{s})$. These time constants are faster than that observed in poly [d(A-T)]. Magic angle rise time constants representing the main amplitude of B-A transition showed an increase with increase in ethanol percentage and an average value of $\sim 6 \mu$ s was observed at the center of transition (fig 4.38). Because of the large width of the transition, the magic angle amplitudes observed close to the initial and final ethanol ranges of B-A transition, where the equilibrium is more shifted either to the B-form or to the A-form, are not with enough magnitude for an accurate determination of time constants. 


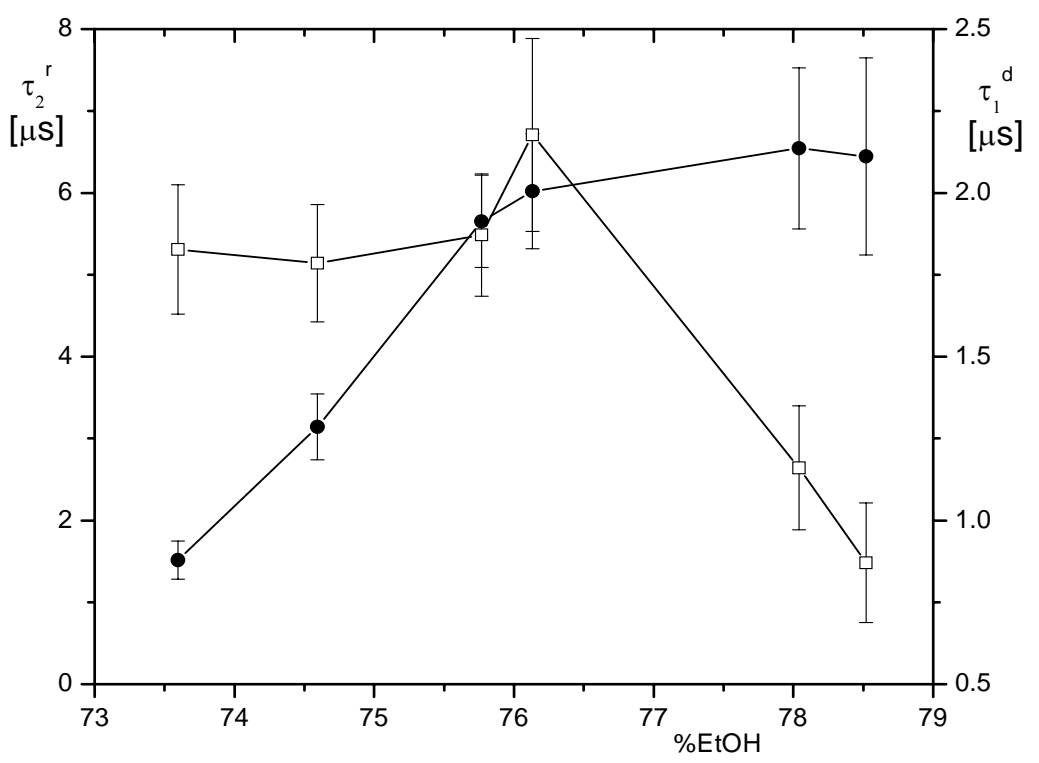

Figure 4.38 Magic angle time constants of the B-A-transition of plasmid DNA at 296 $\mathrm{nm}$ in the field free state $\left(\square, \tau_{1}{ }^{\mathrm{d}}\right.$, right scale) and of the $A-B$ transition under electric field pulses $\left(\bullet, \tau_{2}^{\mathrm{r}}\right.$, left scale) as a function of the ethanol content in $\%$ units $(\mathrm{v} / \mathrm{v})$, $\left(8^{\circ} \mathrm{C}, 80 \mu \mathrm{M}\right.$ DNA, $75 \mu \mathrm{M} \mathrm{NaCl}, 75 \mu \mathrm{M}$ cacodylate $\mathrm{pH}$ 7, $15 \mu \mathrm{M}$ EDTA, field pulse $\left.3.45 \times 10^{6} \mathrm{~V} / \mathrm{m}\right)$.

Polymers with GC base pairs have a strong tendency to undergo aggregation at high ethanol percentages. Moreover the high concentrations of natural DNA used for field jump experiments at wavelengths around $300 \mathrm{~nm}$ also promote aggregation. At $\sim 78 \%$, ethanol the dichroism decay time constants corrected to the state of water at $20^{\circ} \mathrm{C}$ shows an increase with increase in ethanol percentage, reaches a maximum at $\sim 84 \%$ ethanol and then decreases. This clearly shows that aggregation of DNA is occurring at high ethanol percentages (fig 4.39). 


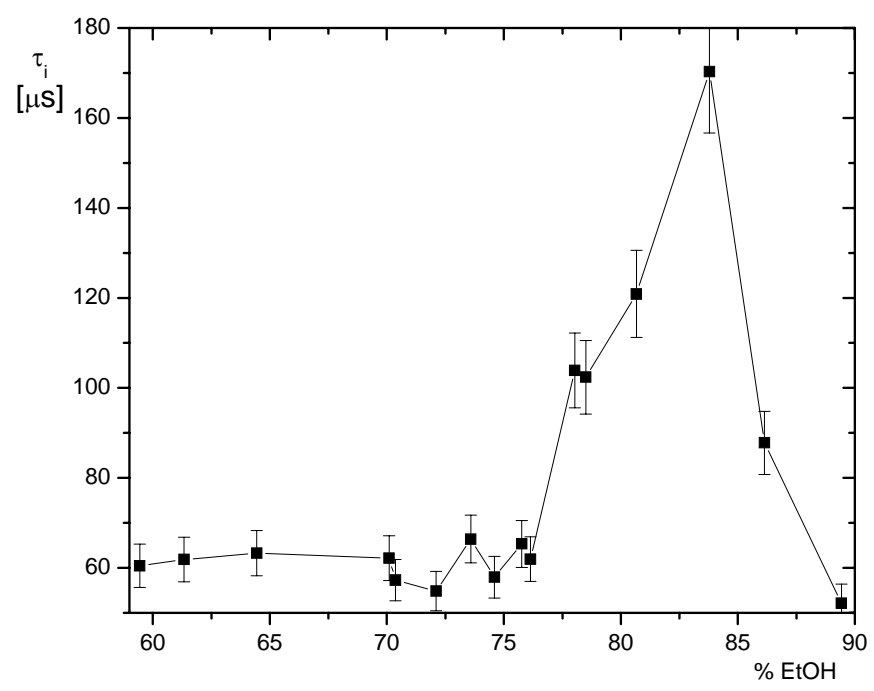

Figure 4.39 Integral dichroism decay time constants $\tau_{i}$ for plasmid DNA as a function of the ethanol content $(\mathrm{v} / \mathrm{v})$ corrected to the state of water at $20^{\circ} \mathrm{C} .(75 \mu \mathrm{M}$ $\mathrm{NaCl}, 75 \mu \mathrm{M}$ cacodylate $\mathrm{pH} 7,15 \mu \mathrm{M}$ EDTA; field pulse $\left.3.45 \times 10^{6} \mathrm{~V} / \mathrm{m}\right) \tau_{\mathrm{i}}$ was calculated from the parameters of the two exponential fit according to $\tau_{\mathrm{i}}=$ $\tau_{1} \cdot A_{1} /\left(A_{1}+A_{2}+A_{3}\right)+\tau_{2} \cdot A_{2} /\left(A_{1}+A_{2}+A_{3}\right)+\tau_{3} \cdot A_{3} /\left(A_{1}+A_{2}+A_{3}\right)$, where $\tau_{1}, \tau_{2}, \tau_{3}$ are the time constants and $A_{1}, A_{2}, A_{3}$ are the amplitudes of the fit to the dichroism decay.

\subsubsection{Experiments with 7160 bp plasmid DNA}

In order to confirm the observations with 2629 bp plasmid DNA and to check for any chain length dependence of B-A transition, field jump experiments were conducted on a plasmid DNA which is with a chain length of $7160 \mathrm{bp}$. Field jump experiments were conducted at $27.3 \mathrm{kV} / \mathrm{cm}$, which is below the threshold field strength for denaturation of this sample. Amplitudes representing the B-A transition appeared under magic angle condition. A small reaction amplitude which is about four times higher than the noise level is observed outside B-A transition range. The transients reflecting the $\mathrm{B} \rightarrow \mathrm{A}$ reaction showed a fast process $(\sim 2 \mu \mathrm{s})$ with most of the amplitude ( $\sim 80 \%$ of the total amplitude) and a slow process ( $100 \mu$ s) with a small amplitude ( $20 \%$ of the total amplitude). The main amplitude which represents $\mathrm{A} \rightarrow \mathrm{B}$ reaction showed a time constant of $\sim 6 \mu$ s at the center of transition. The absorbance changes during the field pulses and the time constants of the reaction 
transients observed with 7160 bp plasmid DNA are exactly similar to that observed in 2629 bp plasmid DNA.

\subsubsection{Experiments with $\lambda$ - DNA}

To check for any chain length dependence of B-A transition in natural DNA, field jump experiments were conducted with $\lambda$-DNA, which is with a definite chain length of 48,502 base pair. The width of B-A transition in $\lambda$-DNA is almost similar to that in plasmid DNA (table 4.1). The absorbance spectra of $\lambda$-DNA showed that the relative change of absorbance during the $\mathrm{B}$ to $\mathrm{A}$ transition is larger at wavelengths around $300 \mathrm{~nm}$ than at short wavelengths. The concentration of the DNA was selected in such a way that the uncorrected dichroism amplitude is less than $10 \%$ of the total light intensity at the standard field strength.

Reaction amplitudes appeared under magic angle conditions and the dependence of the amplitude on ethanol percentage clearly confirmed that the observed effect is B-A transition (fig 4.40). The magic angle amplitude showed a clear maximum close to the center of B-A transition, which has been determined independently by measurements of CD and absorbance difference spectra for different natural DNA fragments (table 4.1). As in the case of poly [d(A-T)] and plasmid DNA, at ethanol percentages below the B-A transition range, some reaction amplitude which is attributed to some internal conformational change within the B-helix upon the application of field pulse was observed. At high ethanol percentages, above $~ 85 \%$, precipitation of DNA is occurring. 


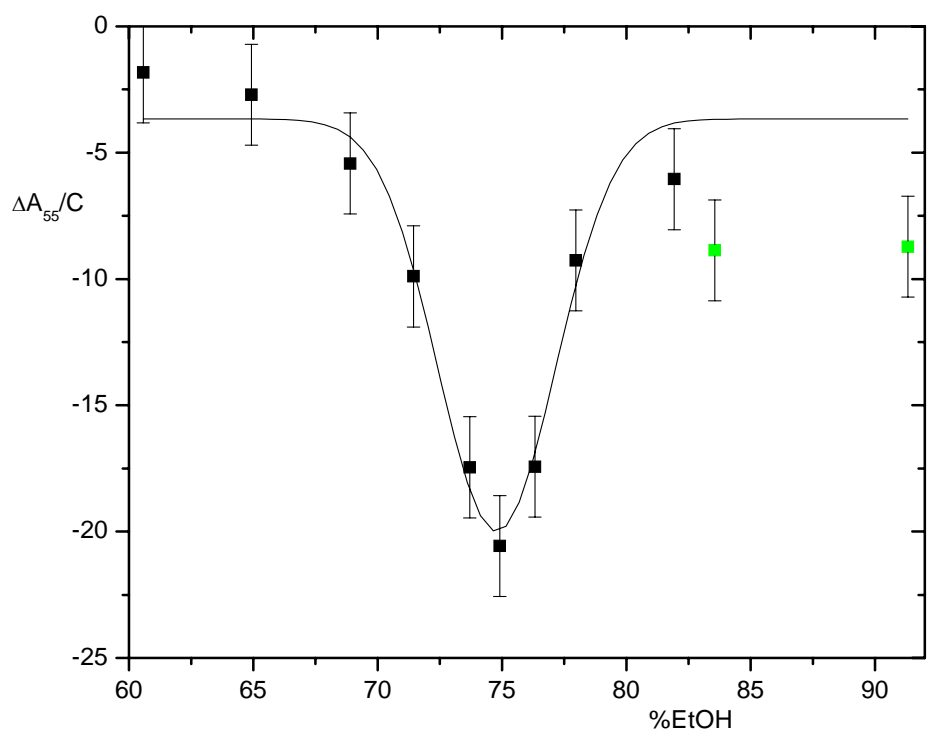

Figure 4.40. Relative magic angle amplitudes $\Delta \mathrm{A}_{55} / \mathrm{C}$ of $\lambda$-DNA at $296 \mathrm{~nm}$ as a function of the ethanol content in \% units (v/v), The line represents a Gaussian fit (center 74.79, width 4.72, offset -3.66, height 16.33), ( $8^{\circ} \mathrm{C}, 120 \mu \mathrm{M} \lambda$-DNA, $75 \mu \mathrm{M}$ $\mathrm{NaCl}, 75 \mu \mathrm{M}$ cacodylate $\mathrm{pH}$ 7, $15 \mu \mathrm{M}$ EDTA; field pulse $2.73 \times 10^{6} \mathrm{~V} / \mathrm{m}$ ).

The magic angle decay transients showed a fast process ( $2 \mu \mathrm{s})$ with most of the amplitude ( 75\% of the total amplitude) and a slow process ( $20 \mu \mathrm{s}$ ) with a small amplitude ( $~ 25 \%$ of the total amplitude). At the center of transition, the magic angle rise time constants which represents the main amplitude of the reaction showed a value of $\sim 9 \mu$ s (fig 4.41). As in the case of plasmid DNA, the transitions occurring at ethanol percentages close to the start and end regions of B-A transition are not with enough amplitude. Therefore, an accurate determination of time constants in those ethanol ranges is not possible. 


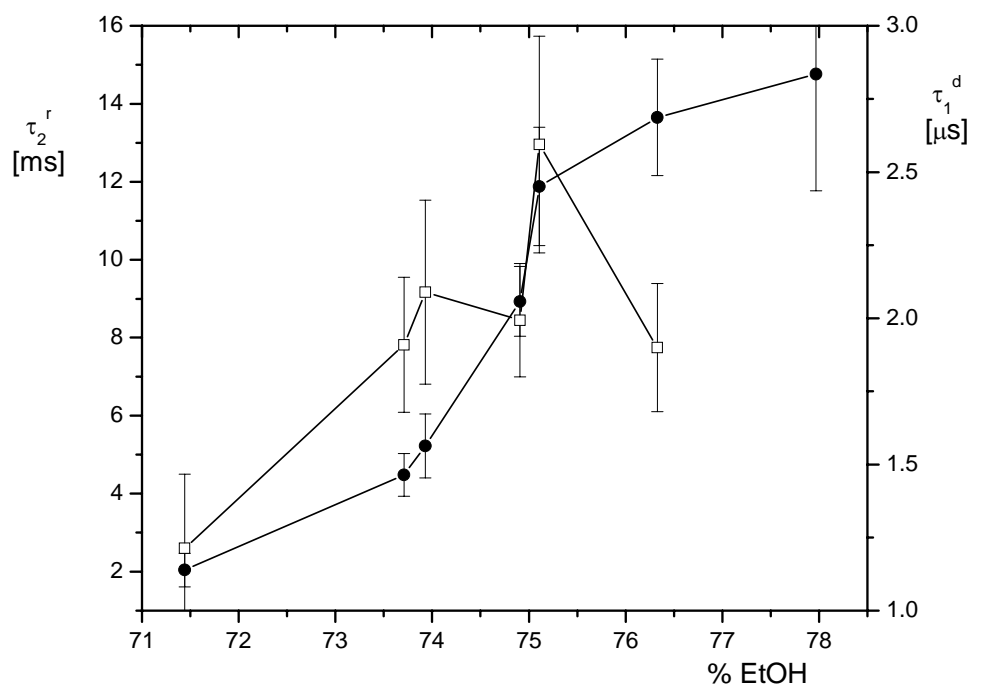

Figure 4.41 Magic angle time constants of the B-A-transition of lambda DNA at 296 $\mathrm{nm}$ in the field free state $\left(\square, \tau_{1}{ }^{\mathrm{d}}\right.$, right scale) and of the $A-B$ transition under electric field pulses $\left(\bullet, \tau^{\mathrm{r}}\right.$, left scale) as a function of the ethanol content in $\%$ units $(\mathrm{v} / \mathrm{v})$, $\left(8^{\circ} \mathrm{C}, 120 \mu \mathrm{M} \lambda\right.$-DNA, $75 \mu \mathrm{M} \mathrm{NaCl}, 75 \mu \mathrm{M}$ cacodylate $\mathrm{pH}$ 7, $15 \mu \mathrm{M}$ EDTA, field pulse $\left.2.73 \times 10^{6} \mathrm{~V} / \mathrm{m}\right)$.

The experiments on natural DNA with fragments of different chain length confirmed that at least in the studied range the B-A transition in DNA is independent of chain length.

Field jump experiments at wavelengths $296 \mathrm{~nm}$ and $298 \mathrm{~nm}$ with high concentration of DNA showed an increase in light intensity under field pulses at ethanol percentages outside the B-A transition range. In all cases the amplitude observed outside the B-A transition was only about four to five times higher than the noise level. In plasmid DNA, the observed change in light intensity did not show any dependence on ethanol percentage in an ethanol range of $~ 60 \%$ to $\sim 70 \%$ (fig 4.37). A change in absorbance of approximately $-6 \times 10^{-4}$ was observed in plasmid DNA where the concentration of the sample was $\sim 80 \mu \mathrm{M}$. The ethanol percentage of the sample was $64.45 \%$ and the applied field strength was $34.5 \mathrm{kV} / \mathrm{cm}$. Figure 4.42 shows the general nature of the observed effect. In lambda DNA, the change in absorbance observed at two different ethanol percentages, 60.6\% and 64.9\%, was approximately $-3 \times 10^{-4}$. The concentration of the sample was $\sim 120 \mu \mathrm{M}$ and the field strength used 
was $27.3 \mathrm{kV} / \mathrm{cm}$. The reaction amplitude observed outside the B-A transition is approximately $15 \%$ of the maximum B-A transition amplitude observed in natural DNA. The amplitudes observed in these changes are too small for an accurate determination of time constants. Magic angle decay transients showed a time constant of $\sim 1 \mu$ s and the magic angle rise transients showed a time constant of $\sim 3 \mu \mathrm{s}$.

The possibility that the observed increase in light intensity comes from the denaturation of double helix is discarded after considering the fact that denaturation of DNA is associated with an increase in absorbance. This was further confirmed by an analysis of the magic angle rise transients at field strengths above and below the threshold level for denaturation. At field strengths below the threshold denaturation field strength the observed effect is an increase light intensity. The magic angle rise transients at field strength $63.5 \mathrm{kV} / \mathrm{cm}$, which is above the threshold field strength for denaturation, showed the occurrence of two processes. The first process is an increase in light intensity, which is similar as that observed at low field strengths. It was then followed by a decrease in the light intensity. The observed decrease in light intensity is attributed to denaturation of the sample at this field strength. The occurrence of these two effects is observed in all studied cases at ethanol percentages below the B-A transition range with field strengths above the denaturation threshold. This confirmed that the observed increase in light intensity out side the B-A transition range during field pulse is not due to denaturation of the sample.

Field jump experiments conducted at $302 \mathrm{~nm}$ with poly [d(A-T)] fragments which was with a concentration of $\sim 160 \mu \mathrm{M}$ also showed changes similar to that observed in natural DNA. Experiments were done at ethanol percentages $62.7 \%$ and $64.5 \%$ and the field strength applied was $34.5 \mathrm{kV} / \mathrm{cm}$. Here the observed amplitude outside the B-A transition range is only about $2 \%$ of the maximum B-A transition amplitude. In poly [d(A-T)], even though the changes observed outside the B-A transition range appears to be similar to that in natural DNA, the current experimental data are insufficient to arrive at a final conclusion.

It is known that field pulses induce some stretching of DNA double helix and the small amplitude observed outside the B-A transition range is assigned to some internal conformational change occurring within the B-helical structure due to this stretching. 


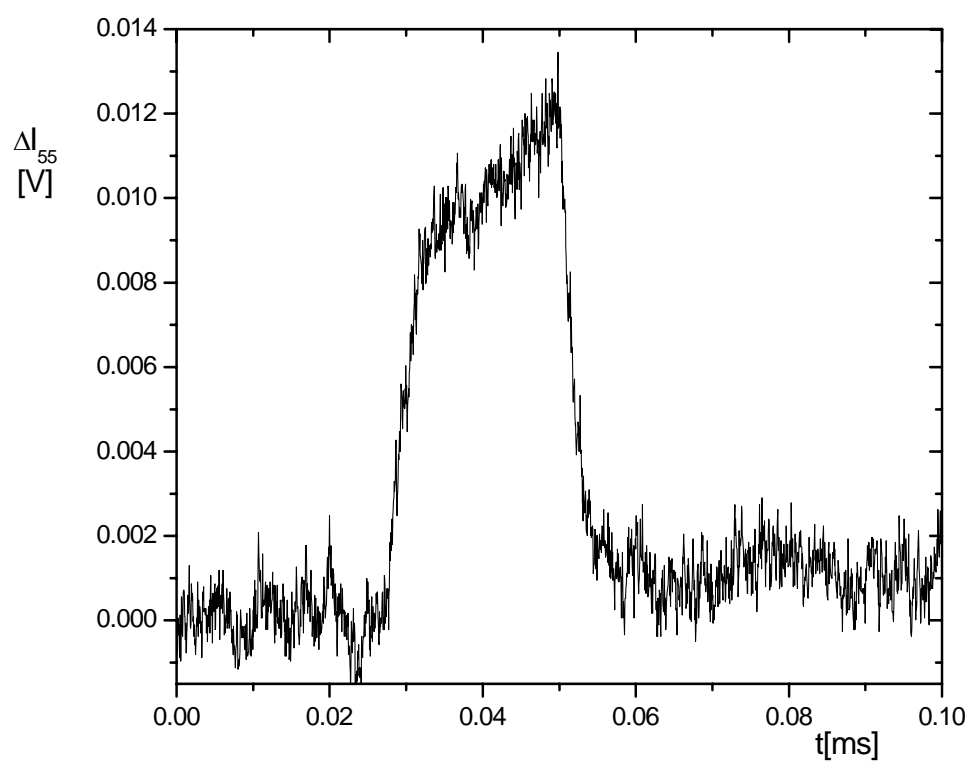

Figure 4. 42 Field induced change of the transmission $\Delta \mathrm{I}$ observed outside the $B-A$ transition range at $296 \mathrm{~nm}$ for plasmid DNA at polarizer orientations $\varphi=55^{\circ}$ with respect to the field vector. (64.45\% ethanol (v/v), $8^{\circ} \mathrm{C}, 80 \mu \mathrm{M}$ DNA, $75 \mu \mathrm{M} \mathrm{NaCl}, 75 \mu \mathrm{M}$ cacodylate $\mathrm{pH}$ 7, 15 $\mu \mathrm{M}$ EDTA; field pulse $\left.3.45 \times 10^{6} \mathrm{~V} / \mathrm{m}\right)$.

\begin{tabular}{|l|c|c|}
\hline Sample & $\begin{array}{c}\text { Wave length } \\
\text { (nm) }\end{array}$ & $\begin{array}{l}\text { \% of B-A transition } \\
\text { in field jump } \\
\text { experiment }\end{array}$ \\
\hline $\begin{array}{l}1500 \text { bp } \\
\text { Poly [d(A-T)] }\end{array}$ & 280 & $65 \% \pm 10 \%$ \\
\hline $\begin{array}{l}1500 \text { bp } \\
\text { Poly [d(A-T)] }\end{array}$ & 302 & $80 \% \pm 10 \%$ \\
\hline $\begin{array}{l}2629 \text { bp Plasmid } \\
\text { DNA }\end{array}$ & 296 & $20 \% \pm 10 \%$ \\
\hline Lambda DNA & 298 & $20 \% \pm 10 \%$ \\
\hline
\end{tabular}

Table 4.2 The extent of perturbation induced by field jump experiments 
The B-A reaction amplitude observed in natural DNA is smaller than that observed in poly $[\mathrm{d}(\mathrm{A}-\mathrm{T})]$. This shows that the perturbation from equilibrium state caused by the electric field pulses are smaller in natural DNA than in poly [d(A-T)]. The perturbation caused by the electric field from the equilibrium state can be found out by comparing the change in absorbance observed in the field jump experiment with that observed in absorbance difference spectra. Table 4.2 shows that electric field pulses induce a perturbation of approximately $70 \%$ from equilibrium in poly [d(A-T)] while the induced perturbation is only about $20 \%$ in natural DNA. In poly [d(A-T)] field pulses drives the reaction close to completion whereas in natural DNA only a part of the reaction is occurring.

The absorbance and thermodynamic parameters of the B-A transition of DNA obtained from field jump experiments with different samples are summarized in table 4.3. Table 4.3 is in agreement with table 4.1, where the absorbance data obtained from titration are given. 


\begin{tabular}{|c|c|c|c|c|c|c|c|}
\hline Sample & Buffer & solvent & $\begin{array}{l}\text { Concentrat } \\
\text { ion of the } \\
\text { sample }\end{array}$ & $\begin{array}{l}\text { Wave } \\
\text { length }\end{array}$ & $\begin{array}{l}\text { Maximum } \\
\text { magic angle } \\
\text { absorbance } \\
\text { change } \\
\text { observed in FJ } \\
\text { experiment }\end{array}$ & $\begin{array}{l}\text { Center of } \\
\text { transition } \\
\text { in FJ } \\
\text { experiment. }\end{array}$ & $\begin{array}{l}\text { Width of } \\
\text { transition } \\
\text { in FJ } \\
\text { experiment }\end{array}$ \\
\hline $\begin{array}{l}\text { poly } \\
{[\mathrm{d}(\mathrm{A}-\mathrm{T})]}\end{array}$ & 1/4 NCE7 & $\mathrm{EtOH}$ & $8.5 \mu \mathrm{M}$ & 280 & -0.0071 & $70.81 \%$ & $2.81 \%$ \\
\hline $\begin{array}{l}\text { poly } \\
{[\mathrm{d}(\mathrm{A}-\mathrm{T})]}\end{array}$ & 1/4 NCE7 & $\mathrm{EtOH}$ & $160 \mu \mathrm{M}$ & 302 & -0.031 & $70.43 \%$ & $3.21 \%$ \\
\hline $\begin{array}{l}\text { poly } \\
{[\mathrm{d}(\mathrm{A}-\mathrm{T})]}\end{array}$ & NCE 7 & $\mathrm{EtOH}$ & $8.5 \mu \mathrm{M}$ & 280 & -0.0058 & $68.98 \%$ & $1.63 \%$ \\
\hline $\begin{array}{l}\text { poly } \\
{[\mathrm{d}(\mathrm{A}-\mathrm{T})]}\end{array}$ & 1/4 NCE7 & TFE & $8.5 \mu \mathrm{M}$ & 280 & -0.0046 & $67.91 \%$ & $3.63 \%$ \\
\hline $\begin{array}{l}\text { Poly } \\
{[\mathrm{d}(\mathrm{A}-\mathrm{T})]}\end{array}$ & NCE 7 & TFE & $8.5 \mu \mathrm{M}$ & 280 & -0.0042 & $66.39 \%$ & $2.09 \%$ \\
\hline $\begin{array}{l}70 \text { bp } \\
\text { poly } \\
{[\mathrm{d}(\mathrm{A}-\mathrm{T})]}\end{array}$ & 1/4 NCE7 & $\mathrm{EtOH}$ & $8.5 \mu \mathrm{M}$ & 280 & -0.0016 & $70.45 \%$ & $0.63 \%$ \\
\hline $\begin{array}{l}120 \text { bp } \\
\text { poly } \\
{[\mathrm{d}(\mathrm{A}-\mathrm{T})]}\end{array}$ & 1/4 NCE7 & $\mathrm{EtOH}$ & $8.5 \mu \mathrm{M}$ & 280 & -0.0027 & $70.46 \%$ & $1.55 \%$ \\
\hline $\begin{array}{l}859 \text { bp } \\
\text { restrn. } \\
\text { Frgmnt. }\end{array}$ & $1 / 4$ NCE7 & $\mathrm{EtOH}$ & $5.25 \mu \mathrm{M}$ & 265 & -0.0012 & $74.53 \%$ & $6.34 \%$ \\
\hline $\begin{array}{l}859 \text { bp } \\
\text { restrn. } \\
\text { Frgmnt. }\end{array}$ & $1 / 4$ NCE7 & $\mathrm{EtOH}$ & $5.25 \mu \mathrm{M}$ & 248 & 0.0014 & $74.84 \%$ & $5.42 \%$ \\
\hline $\begin{array}{l}\text { plasmid } \\
\text { DNA }\end{array}$ & 1/4 NCE7 & $\mathrm{EtOH}$ & $80 \mu \mathrm{M}$ & 296 & -0.0025 & $75.84 \%$ & $4.74 \%$ \\
\hline $\begin{array}{l}\text { Lambda } \\
\text { DNA }\end{array}$ & 1/4 NCE7 & $\mathrm{EtOH}$ & $120 \mu \mathrm{M}$ & 298 & -0.0025 & $74.79 \%$ & $4.72 \%$ \\
\hline
\end{tabular}

Table 4.3 Parameters of the B-A transition obtained from the field jump experiments. 


\subsubsection{Field dependence of B-A transition}

Field jump experiments on poly $[\mathrm{d}(\mathrm{A}-\mathrm{T})]$ showed a decrease in the absorbance at $280 \mathrm{~nm}$ under electric field pulses whereas at $248 \mathrm{~nm}$ an increase in absorbance was observed. From the absorbance difference spectra (fig 4.1) it is clear that the absorbance of A-form is higher than that of B-form at $280 \mathrm{~nm}$ and at $248 \mathrm{~nm}$ the absorbance of B-form is higher than that of A-form DNA. This shows that the electric field pulses induce a reaction from the A to the B-form. The preference for the B-form in the presence of electric field indicates that B-helices have a higher effective dipole moment. The dipole moments are known to increase strongly with the length of DNA helices (Diekmann et al., 1982). The length increment per base pair for B-DNA (3.4 $\AA$ ) is much higher than that for A-DNA $(\sim 2.8 \AA)$. The fact that the contour length of DNA-helices in B-form is higher than that in A-form suggests dipolar stretching as the main driving force for the $\mathrm{A} \rightarrow \mathrm{B}$ reaction under field pulses.

A simple analysis of the transients observed under electric field pulses supported the above observation. The magic angle rise time transients reveal a special type of coupling (fig 4.43). A satisfactory fit requires two exponentials, where the amplitude of the first exponential is opposite to that of the second one. The figure clearly shows a delay at the start of the reaction. This delay can be explained based on the above proposed dipolar stretching theory. The A-B reaction can only be driven when the dipole exceeds a threshold level. This threshold level is achieved by ion polarization and rotation of the polymers into the direction of the field vector. This is not an instantaneous process, but requires some time. The time required for achieving this threshold depends on the state of the sample, that is, how far it is shifted from the equilibrium position. Ion polarization is not associated with any change of UV absorbance and any effect of polymer rotation on the absorbance is suppressed under magic angle condition. Thus these processes are not visible directly under magic angle conditions. However the influence of these processes is coupled to the A-Breaction, such that the whole process appears as a convolution product. The initial process of dipole development is without change of absorbance, but is reflected in the transient by coupling to the A-B reaction, which is associated with a relatively large change of the absorbance. The expected convolution product is in complete agreement with the observed transient. The first exponential reflects the rise of the dipole 
moment and the second one describes the A-B reaction at the given electric field strength.

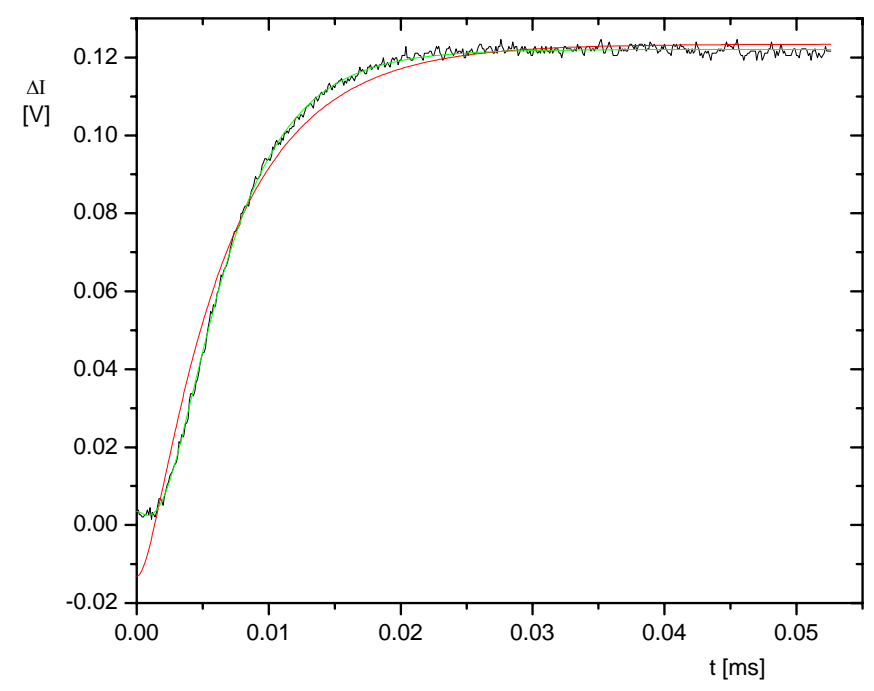

Figure 4.43. Magic angle rise curve of poly [d(A-T)] induced by a field pulse of $3.7 \times 10^{6}$ $\mathrm{V} / \mathrm{m}$. Single exponential fit $(6.17 \mu \mathrm{s})$ is represented by a red line and the double exponential $\left(\tau_{1}=1.69 \mu \mathrm{s}, \tau_{2}=4.38 \mu \mathrm{s}, \mathrm{A}_{1}=-85 \% \mathrm{~A}_{2}=185 \%\right)$ is by a green line. (70.4\% ethanol $(\mathrm{v} / \mathrm{v})$, $8^{\circ} \mathrm{C}, 8.5 \mu \mathrm{M}$ poly [d(A-T)], $75 \mu \mathrm{M} \mathrm{NaCl}, 75 \mu \mathrm{M}$ cacodylate $\mathrm{pH}$ 7, $15 \mu \mathrm{M}$ EDTA).

In order to confirm the proposed dipolar stretching theory and to find the dependence of magic angle and dichroism rise time constants on applied field strength, experiments were conducted at different field strengths with poly [d(A-T)] solutions at various percentages of ethanol. Poly $[d(A-T)]$ was chosen as the optimal probe to study the field dependence because of its comparatively larger magic angle amplitude than natural DNA.

Figure 4.44 shows that the observed rise time constants of both the orientation and reaction transients are of similar magnitude at an ethanol percentage $70.32 \%$ which is close to the center of transition. Therefore, the possibility of some coupling of orientation time constants to reaction time constants cannot be excluded. 


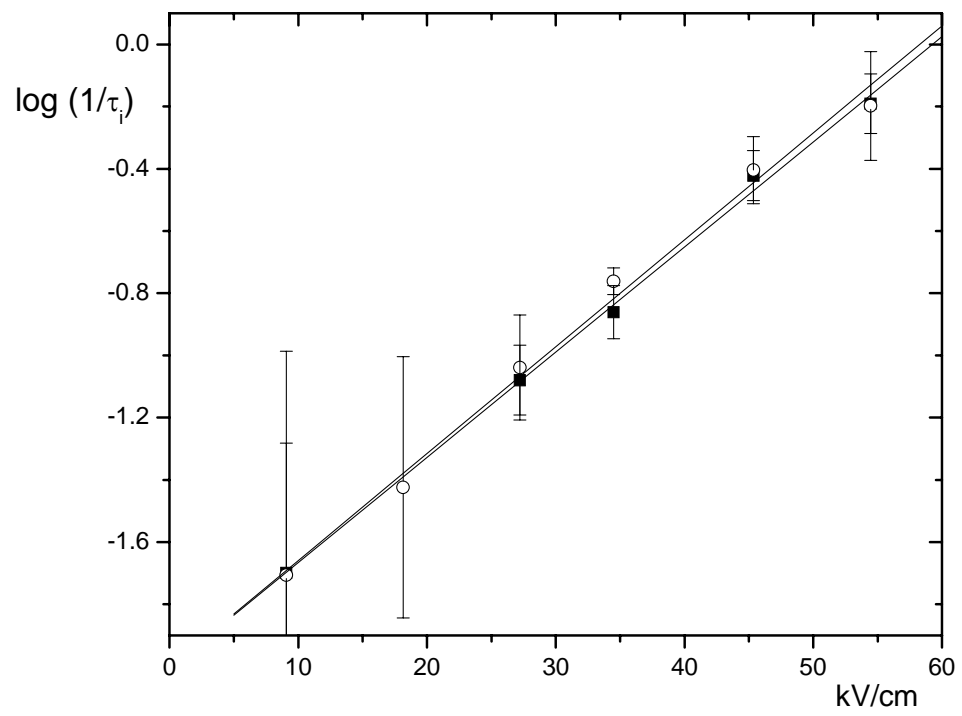

Figure 4.44. Magic angle rise integral time constant (open circles) and dichroism rise integral time constant (filled squares) of poly [d(A-T)] as a function of the field strength ( $70.32 \%$ ethanol (v/v), $8.5 \mu \mathrm{M}$ poly [d(A-T)], $75 \mu \mathrm{M} \mathrm{NaCl}, 75 \mu \mathrm{M}$ cacodylate $\mathrm{pH}$ 7, $15 \mu \mathrm{M}$ EDTA).

In order to have an explicit idea about the dependence of these time constants on field strengths, field jump experiments were performed on poly [d(A-T)] samples at different ethanol percentages. Figure 4.45 shows the dependence of reaction and orientation rise time constants on field strength at an ethanol percentage $68.69 \%$, which is more towards the equilibrium B-form and figure 4.46 shows the dependence at an ethanol percentage $72.40 \%$, which is towards the equilibrium Aform. At $68.69 \%$ ethanol, reaction rise times were faster than dichroism rise times and at $72.40 \%$ dichroism rise time constants were faster than reaction times.

As shown in figure 4.44, 4.45 and 4.46, the logarithm of the integral time constant of the magic angle rise and dichroism can be represented at a reasonable accuracy as a linear function of the electric field strength. This dependence is expected for reactions driven by an increase of a permanent dipole moment, when the orientation of molecules is close to saturation (Porschke, 1985). As shown in literature (Diekman et al., 1982), the induced dipole moment of polynucleotides is saturated at the field strengths used in the present experiments and, thus, the field induced effects of these polynucleotides are as expected for permanent dipoles. 


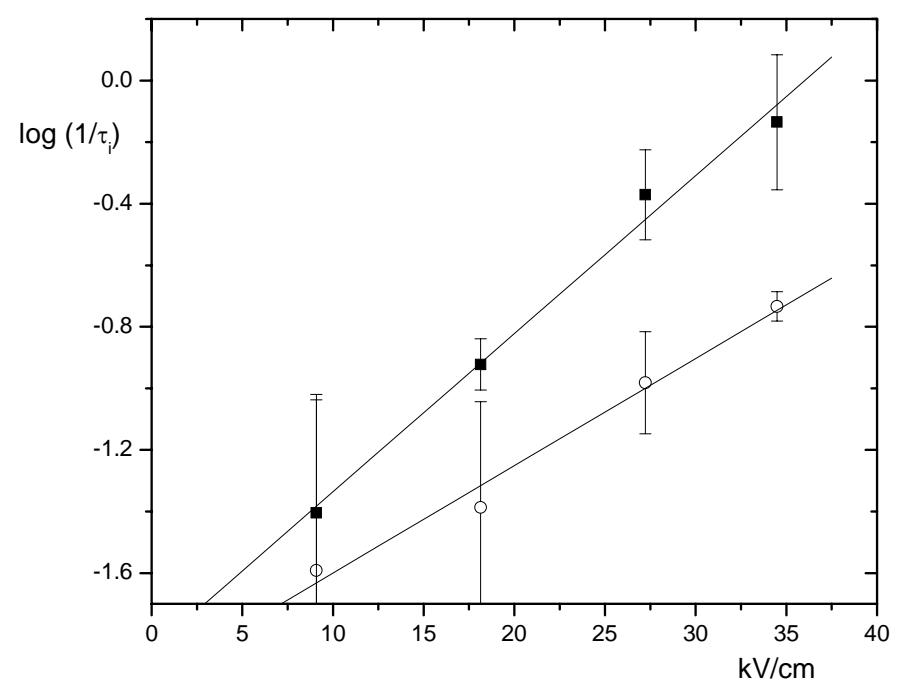

Figure 4.45. Magic angle rise integral time constant (open circles) and dichroism rise integral time constant (filled squares) of poly [d(A-T)] as a function of the field strength (68.69\% ethanol (v/v), $8.5 \mu \mathrm{M}$ poly [d(A-T)], $75 \mu \mathrm{M} \mathrm{NaCl,} 75 \mu \mathrm{M}$ cacodylate $\mathrm{pH}$ 7, $15 \mu \mathrm{M}$ EDTA).

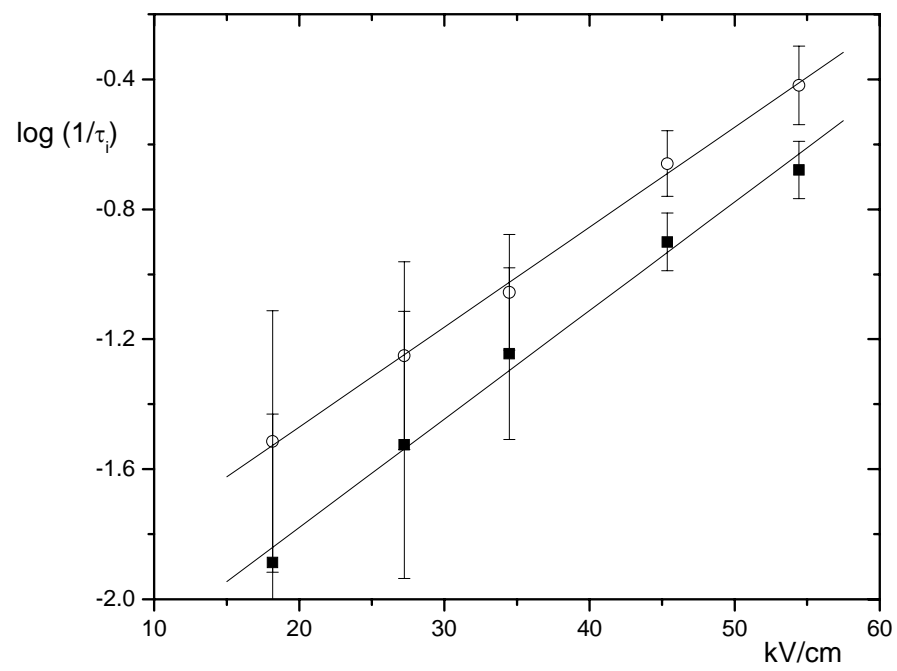

Figure 4.46. Magic angle rise integral time constant (open circles) and dichroism rise integral time constant ( filled squares) of poly [d(A-T)] as a function of the field strength (72.40\% ethanol (v/v), $8.5 \mu \mathrm{M}$ poly [d(A-T)], $75 \mu \mathrm{M} \mathrm{NaCl}, 75 \mu \mathrm{M}$ cacodylate $\mathrm{pH}$ 7, $15 \mu \mathrm{M}$ EDTA). 
The comparison of reaction and orientation time constants at different ethanol percentages revealed that at low ethanol percentages, reaction rise times are faster than dichroism rise times whereas at the center of transition similar times are observed for both process and at high ethanol percentages reaction rise times get slower than the dichroism time constant (fig 4.44, fig 4.45 and fig 4.46). In order to confirm these observations field jump experiments were conducted at a definite field strength with poly $[\mathrm{d}(\mathrm{A}-\mathrm{T})]$ samples at various ethanol percentages. Figure 4.47 shows the observed time constants and it clearly shows that at lower ethanol percentages reaction times are faster than dichroism times whereas at higher ethanol percentage reaction time are slower than dichroism times. Figure 4.47 further revealed that reaction rise time constants are strongly dependent on the ethanol percentages whereas comparatively smaller dependence is observed in the case of dichroism rise time constants.

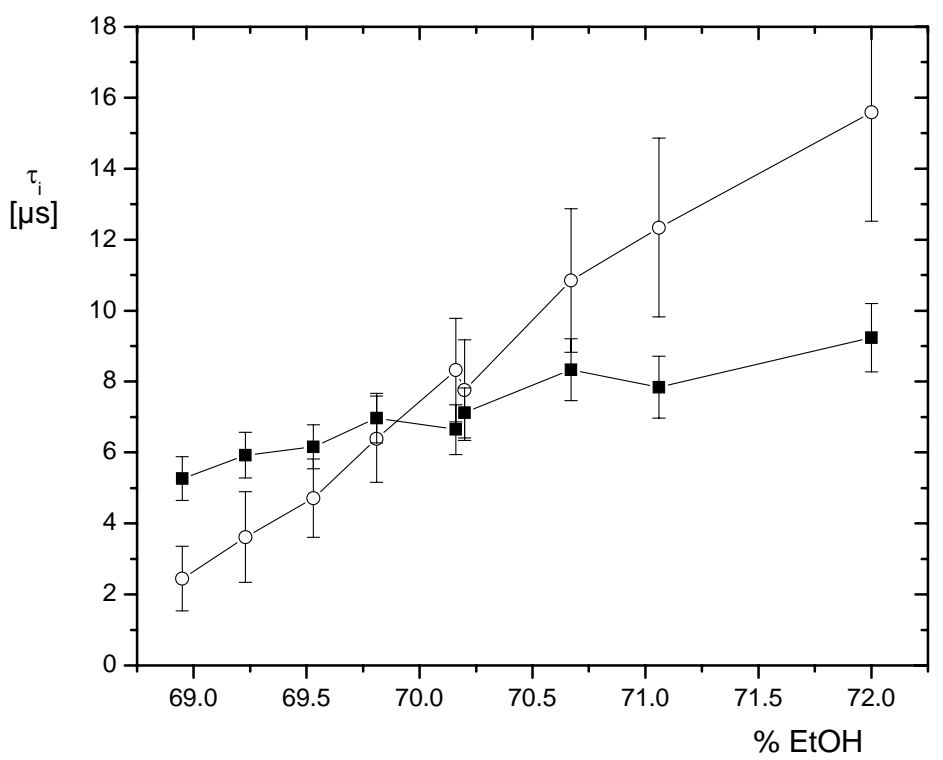

Figure 4.47. Magic angle rise integral time constant (open circles) and dichroism rise integral time constant (filled squares) of poly $[\mathrm{d}(\mathrm{A}-\mathrm{T})]$ as a function of ethanol \% in units (v/v), $(8.5 \mu \mathrm{M}$ poly [d(A-T)], $75 \mu \mathrm{M} \mathrm{NaCl}, 75 \mu \mathrm{M}$ cacodylate $\mathrm{pH}$ 7, $15 \mu \mathrm{M}$ EDTA, field pulse $\left.3.45 \times 10^{6} \mathrm{~V} / \mathrm{m}\right)$.

To arrive at a conclusion about the dependence of dichroism and reaction time constants on field strength and ethanol percentages, field jump experiments were performed on a poly [d(A-T)] fragment which was with an average chain length of 
100 bp. Figure 4.48 shows the dependence of rise time constants on field strength at an ethanol percentage of $70.60 \%$ which is close to the center of transition. In this case, it is clear that the magic angle rise times are slower by almost two to three times than the dichroism times. Comparison of time constants for this fragment at two different ethanol percentages, $69.02 \%$ and $69.78 \%$, which are more towards the equilibrium Bform, revealed that reaction time constants are approximately two times slower than dichroism time constants. This is as per expectation because it is known that the orientation of short fragments under field pulse is faster than that of long polymer. Again, analysis of the rise time constants of 120 bp sample at $34.5 \mathrm{kV} / \mathrm{cm}$ field strength with various ethanol percentages showed that the reaction rise time is almost three times slower than dichroism rise time (fig 4.49). The observed dichroism and reaction rise time constants of 70 bp fragments were compared at different ethanol percentages and in this case also it is found that reaction rise times are three times slower than dichroism rise times.

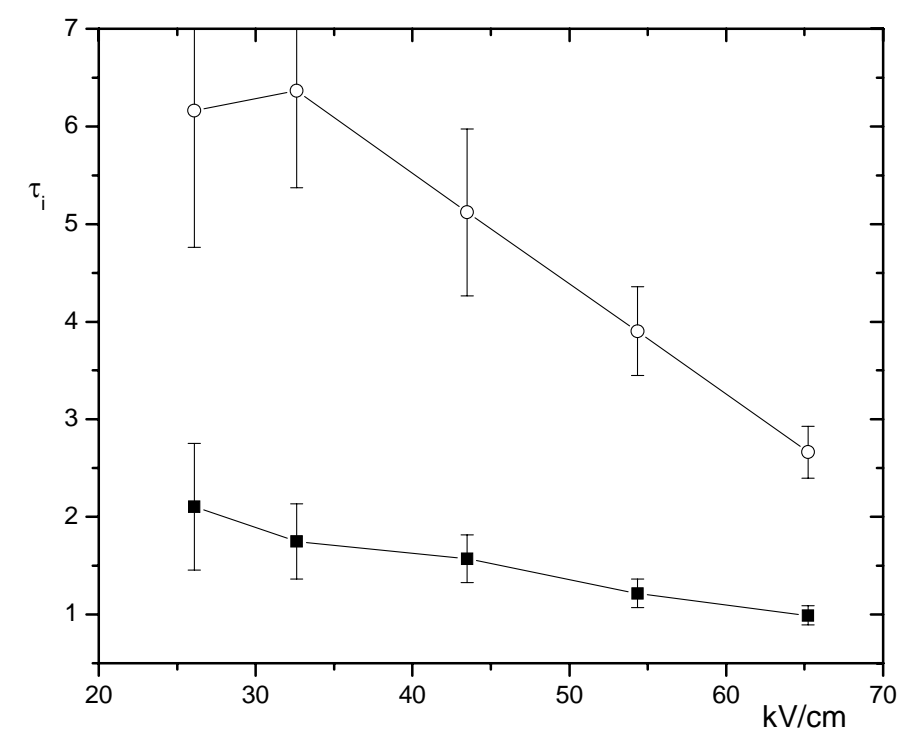

Figure 4.48. Magic angle rise integral time constant (open circles) and dichroism rise integral time constant (filled squares) of $100 \mathrm{bp}$ poly [d(A-T)] as a function of the field strength ( $70.60 \%$ ethanol (v/v), $8.5 \mu \mathrm{M}$ poly [d(A-T)], $75 \mu \mathrm{M} \mathrm{NaCl}, 75 \mu \mathrm{M}$ cacodylate $\mathrm{pH}$ 7, $15 \mu \mathrm{M}$ EDTA). 


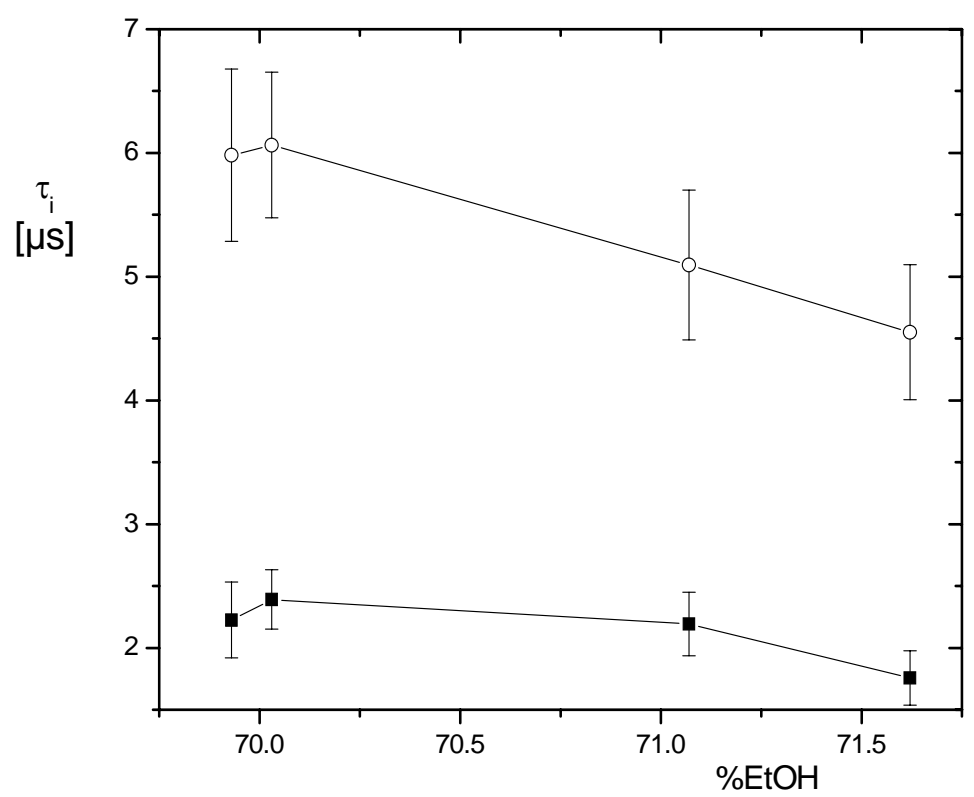

Figure 4.49. Magic angle rise integral time constant (open circles) and dichroism rise integral time constant (filled squares) of $120 \mathrm{bp}$ poly [d(A-T)] as a function of ethanol $\%$ in units (v/v), $(8.5 \mu \mathrm{M}$ poly [d(A-T)], $75 \mu \mathrm{M} \mathrm{NaCl}, 75 \mu \mathrm{M}$ cacodylate $\mathrm{pH} 7,15 \mu \mathrm{M}$ EDTA, field pulse $\left.3.45 \times 10^{6} \mathrm{~V} / \mathrm{m}\right)$.

Figure 4.45 and figure 4.47 shows that at lower ethanol percentages magic angle rise times of polymers with long chain lengths are faster than dichroism rise times. The dipolar stretching mechanism could not explain this observation because the observed reaction time is faster than the time required to achieve the threshold dipole moment, which is supposed to drive the reaction to completion. The alternative mechanism which can be suggested is the field induced dissociation of counterions using the polyelectrolyte theory developed by Manning (1977 a,b, 1979, 2001, 2002). During the application of field pulses the counterions associated with the DNA double helix will dissociate. Because of the higher charge density of A-form DNA than that of B-form DNA, the repulsive force experienced by the helix from the negatively charged phosphate groups is higher in A-form DNA. This destabilizes the A-form and the transition to the low energy B-form occurs. 
The above mentioned observations suggests that depending on the ethanol percentage two types of mechanism, dipolar stretching mechanism and field induced dissociation of counterion mechanism, can be proposed for the B-A transition of DNA under electric field pulse. With the present data it is difficult to conclude which of this mechanism is more predominant. In order to arrive at a final conclusion about the detailed mechanism of B-A transition under field pulses some more studies are required. 


\section{CHAPTER 5}

\section{DISCUSSION}

Franklin and Gosling (1953) observed the A and B forms of DNA during their first X-ray studies. Even after 50 years, the dynamics of this transition has not been characterized. This is remarkable since most other properties of the DNA double helix have been exhaustively investigated. Part of the problem is due to the fact that the analysis of B-A transition is not as easy as other type of reactions found in the DNA helices such as helix-coil transitions. In addition the B-A transition has not been such a focus of interest as other transitions of DNA. However, interest in B-A transition has been revived recently after the detection of A-form DNA in many protein-DNA complexes (Cheatham and Seitz, 1999; Jacobo-Molina et al 1993; Jones, et al., 1999; Lu, et al., 2000; Keifer, et al., 1998).

The B-A transition is associated with a large change in the absorbance spectrum. Thus it is not necessary to introduce any spectroscopic labels to follow the transition. Mixing of DNA solutions with ethanol can induce the B-A transition and it can be easily studied by following the absorbance changes at $248 \mathrm{~nm}$ or at $286 \mathrm{~nm}$. Therefore, stopped flow technique was selected as the first method to study the kinetics of this transition. However, the analysis turned out to be difficult because of several technical problems. One of them was caused by the difference in the density of the solutions, leading to dilution of the sample after mixing by convection. When these problems were as much under control as possible, optical signals expected for the B-A-transition were not observed (fig 4.11). The absence of any amplitude that could be assigned to B-A-transition shows that the reaction is complete during the mixing time of about $0.2 \mathrm{~ms}$.

The next alternative was the temperature jump technique. But the enthalpy change associated with B-A transition is very small and therefore the possibility of using temperature jump technique was discarded. For a solution with low salt concentration, the best method to follow kinetics is the electric field jump technique. This technique is not very popular, because reaction effects must be separated from 
orientation effects, which requires special attention (Porschke, 1996). Under these conditions NMR technique seem to be a reasonable alternative. But assignment of rates by NMR techniques is not trivial, when the time constants are in the $\mu$ s-time range. The DNA concentrations required for NMR-analysis are high and thus, aggregation would be a serious obstacle for any NMR analysis. It is known that multivalent cations can induce the B-A transition. Electric field pulses are known to induce dissociation of ion complexes. Therefore, it is expected that field pulses will drive the B-A equilibrium towards either B or A form by field induced dissociation of cations. Considering all these factors field jump technique was selected as the optimal method to follow the B-A transition.

\section{Selection of an optimal sample}

The B-A transition in DNA double helices is a cooperative process, with an estimated cooperative length in the range of 10 to 30 base pairs (Ivanov et.al, 1992). Optimal amplitudes are expected in the range of chain lengths above this cooperative length. Salmon sperm DNA was taken as the suitable sample because of its easy availability and low sample cost. But the reaction amplitude observed in field jump experiments was not with enough magnitude to follow the B-A transition. It is known that B-A transition is dependent on the GC content (Minchenkova et.al 1986). Thus, the width of the transition for homopolymers is expected to be lower than that for DNA with mixed sequence. The transition width of poly [d(A-T)] is $\sim 5$ times narrower than that of natural DNA (table 4.1). Polymers with G-C base pairs are expected to be less convenient than those with A-T base pairs because of the stronger tendency of G-C polymers for aggregation. Therefore, for initial studies poly [d(A-T)] was selected as the optimal model system to follow the dynamics of B-A transition. To study the B-A transition in natural DNA, 859 base pair restriction fragment was chosen as the best possible model because of its narrow B-A transition width (table 4.1).

\section{Separation of field induced effects}

Field pulses are known to induce both physical and chemical relaxation effects. In the present case B-A transition is coupled with the orientation effects. To 
have a proper understanding about these two different effects, they must be separated. Separation of these effects was done by the proper use of magic angle technique. Both the theoretical basis and the practice of the magic angle technique are well established (Porschke, 1996,2001). The successful separation of reaction effects from orientation effects can be demonstrated by the different spectrum of time constants (Fig. 4.13 4.18, 4.21, 4.33 and 4.35). The difference in the chain length dependence observed for reaction and orientation effects further confirmed the proper separation of these two effects. The dichroism decay time constants are strongly dependent on the chain length in exact agreement with expectations, whereas the time constants of the magic angle effect are almost independent of the chain length, as expected for reaction effects above the cooperative length. These results clearly demonstrate that the separation of reaction effects from orientation was successful.

\section{B-A transition}

The unique dependence of the magic angle amplitude on the ethanol content in all studied cases supports the assignment of the magic angle effect to B-A transition (Fig 4.14, 4.19, 4.23, 4.27, 4.31, 4.32, 4.37 and 4.40). In all cases the reaction amplitude showed a clear maximum close to the center of B-A transition, which has been determined independently by measurements of CD and absorbance difference spectra under the same experimental conditions (table 4.1 and table 4.3). Furthermore, the spectral signature of the magic angle effect is in agreement with the B-A-reaction and neither consistent with an orientation effect nor with any effect due to a helix-coil transition or aggregation as potential alternatives. Field jump experiments with poly $[\mathrm{d}(\mathrm{A}-\mathrm{T})]$ solutions showed a small decrease in light intensity, which is $\sim 3 \mathrm{mV}$, at $270 \mathrm{~nm}$. This is attributed to the denaturation of the sample under field pulses and plotted as a function of ethanol in figure 4.15. The figure clearly shows the absence of any dependence of the amplitude on ethanol percentage at this wavelength. Moreover, a reversal of reaction amplitude is observed at $248 \mathrm{~nm}$. These changes are in accordance with the absorbance difference spectra of B-A transition (fig 4.1). If the dependence of amplitude on ethanol percentage is due to any other processes like aggregation or helix-coil transition, it should be reflected at all wavelengths. 
CD and absorbance difference spectra showed that in a salt concentration four times higher than that of the standard concentration, the B-A transition was shifted towards $2 \%$ lower ethanol concentration and with TFE the transition occurred at 5\% lower alcohol concentration than that in ethanol (fig 4.8). In field jump experiments also these trends were observed and this further confirmed the attribution of the observed effect to B-A transition (fig 4.25, fig 4.27, table 4.3).

The width of the B-A transition in natural DNA is $~ 5$ times broader than that in poly $[\mathrm{d}(\mathrm{A}-\mathrm{T})]$ (Table 4.1). The absorbance difference spectra revealed that the B to A transition in natural DNA shows an increase in absorbance at $265 \mathrm{~nm}$ and a decrease in absorbance at $248 \mathrm{~nm}$ (fig 4.2). At these wavelengths the denaturation spectra of natural DNA also exhibits significant amplitude. So increasing the field strength to achieve a considerable perturbation from the equilibrium state to increase the B-A transition amplitude will lead to the occurrence of many side reactions. Therefore field jump experiments were conducted at field strengths below the threshold field strength for denaturation. The observed reaction amplitudes at wavelengths $248 \mathrm{~nm}$ and $265 \mathrm{~nm}$ are not with enough magnitude for an accurate determination of the time constants of the reaction. So it is concluded that, experiments conducted at field strengths, which is lower than the threshold field strength for denaturation was not sufficient to induce the B-A transition to a considerable extent.

It was known that the B-A transition width of DNA restriction fragments is narrower than that of other natural DNAs (Table 4.1). Therefore to study the B-A transition in natural DNA, DNA restriction fragments with a chain length of 859 base pair was chosen as the optimal probe. Reaction amplitudes, which correspond to B-A transition, are observed at $265 \mathrm{~nm}$ and $248 \mathrm{~nm}$ and they showed the characteristic dependence on the ethanol percentage (fig. 4.31 and 4.32). The observed reaction amplitudes are small compared to poly $[\mathrm{d}(\mathrm{A}-\mathrm{T})]$, but the characteristics of the changes observed at $248 \mathrm{~nm}$ and $265 \mathrm{~nm}$ confirmed the occurrence of B-A transition. This experiment showed that field pulses could induce B-A transition not only in poly $[\mathrm{d}(\mathrm{A}-\mathrm{T})]$ but also in natural DNA.

Analysis of the absorbance spectra of DNA showed that at wavelengths around $300 \mathrm{~nm}$, the relative absorbance of A-form DNA to B-form DNA is larger than that at $265 \mathrm{~nm}$ and $248 \mathrm{~nm}$. Moreover, field jump experiments with standard field strengths conducted at wavelengths around $300 \mathrm{~nm}$ demonstrated that even at a 
very high concentration of DNA, the observed amplitude at the parallel orientation of polarized light is within the $10 \%$ limit of the incident light intensity. As the concentration of DNA increases, the amplitude of B-A transition also increases and this can be used for the explicit determination of reaction time constants. Field jump experiments conducted on poly d[(A-T)] at $302 \mathrm{~nm}, 2629$ bp plasmid DNA at $296 \mathrm{~nm}$, 7160 bp plasmid DNA at $298 \mathrm{~nm}$ and $\lambda$-DNA at $298 \mathrm{~nm}$ gave reaction amplitudes with sufficient magnitude so that the determination of accurate time constants for B-A transition is possible. The dependence of reaction amplitudes on ethanol percentage confirmed that the observed effect is B-A transition.

During the application of field pulses, poly [d(A-T)] samples at $280 \mathrm{~nm}$ and natural DNA samples at $265 \mathrm{~nm}$ showed an increase in light intensity. This shows that A-form, which has a higher absorbance at this wavelength, gets converted to B-form, which is with a low absorbance. That is electric field stabilizes the B-form compared to the A-form.

Field jump experiments at wavelengths around $300 \mathrm{~nm}$ with DNA samples at high concentration showed some amplitude outside the B-A transition range. In all cases the amplitude observed outside the B-A transition was only about four to five times higher than the noise level. The possibility that the observed increase in light intensity comes from the denaturation of double helix is discarded after considering the fact that denaturation of DNA is associated with a decrease in light intensity. It is known that field pulses induce some stretching of DNA double helix and the small amplitude observed outside the B-A transition range is assigned to some internal conformational change occurring within the B-helical structure due to this stretching.

\section{Dichroism decay time constants}

The dichroism decay time constants reflect the rotational diffusion and provide a very sensitive measure of hydrodynamic dimensions. B-DNA and A-DNA differ in their hydrodynamic dimensions and this is reflected in their dichroism decay time constants (Fig. 4.22 and 4.24). The corrected dichroism decay time constants showed the expected decrease of hydrodynamic length upon the B-A transition. The gel electrophoresis of the 70 bp poly [d(A-T)] fragment showed a distribution of chain 
lengths between $\sim 60 \mathrm{bp}$ and $\sim 80 \mathrm{bp}$. In order to follow the decrease in hydrodynamic dimensions during the $\mathrm{B} \rightarrow \mathrm{A}$ transition the chain length of the fragment should be calibrated to a finite value. This calibration of chain length was done using the corrected integral dichroism decay time constant of the B-form, based on a rise per base pair of $3.4 \AA$, and an effective chain length of 76 base pairs was obtained for this fragment. Using this value of chain length and the dichroism decay time constant measured for A-form, an effective rise per base pair of $3.0 \AA$ is obtained for the Aform. These calculations were based on the worm like chain model with a persistence length of $1000 \AA$ found for DNA at low salt concentrations.

The dichroism decay transients of poly [d(A-T)] with 1500 bp cannot be interpreted at the same accuracy because of its broad spectrum of time constants. The slowest process remains almost constant over the transition range, suggesting that there is almost no change in the overall dimensions. This may be due to a change in the persistence length upon the B-A transition and/or aggregation of the A-form. Any change in the persistence length has a minor influence on the results for the 70 and 120 bp samples, because their contour length is smaller than the persistence length.

Polymers with GC base pairs have a strong tendency to undergo aggregation at high ethanol percentages. Moreover the high concentrations of natural DNA used for field jump experiments at wavelengths around $300 \mathrm{~nm}$ also promote aggregation. With natural DNA, at 78\% ethanol the dichroism decay time constants shows an increase with increase in ethanol percentage, reaches a maximum at $\sim 84 \%$ ethanol and then decreases. This clearly shows that aggregation of DNA is occurring at high ethanol percentages (fig 4.39). Therefore under present conditions it is difficult to have a clear picture of the reduction in hydrodynamic dimensions of natural DNA during the $\mathrm{B} \rightarrow \mathrm{A}$ transition.

\section{B-A time constants}

The time constants for B-A transition are determined for different samples. The relatively high amplitude observed at the magic angle for poly [d(A-T)] polymer with a chain length of $\sim 1500 \mathrm{bp}$ indicate that the field pulses can drive the reaction close to completion and the time constants do not represent relaxation processes any more. This is also indicated by the fact that the time constants observed in the presence 
of the electric field ( $\mathrm{A} \rightarrow \mathrm{B}$ reaction) are different from those in the field free state ( $\mathrm{B} \rightarrow \mathrm{A}$ reaction) (Fig. 4.17, 4.20, 4.26 and 4.28). The transients reflecting the $\mathrm{B} \rightarrow \mathrm{A}$ reaction show a fast process $(\tau=\sim 10 \mu \mathrm{s})$ with most of the amplitude and a slow process ( $\tau=\sim 100 \mu$ s) with a small amplitude. Both the slow and fast amplitudes are associated with amplitudes showing a spectral characteristic consistent with the B-A transition and not consistent with a helix-coil transition or a change of the aggregation state.

The time constants representing the main amplitude of the $\mathrm{B} \rightarrow \mathrm{A}$ reaction decreases with increasing ethanol content. This is because the rate of the $B \rightarrow A$ reaction increases with increase in ethanol percentage. The opposite direction is observed for the $\mathrm{A} \rightarrow \mathrm{B}$ reaction, which occurs in the presence of electric field. The time constants for the opposite processes are equivalent at $~ 71 \%$ ethanol, shifted from the mid-point of the B-A-equilibrium towards the domain of the A-DNA. This is due to the fact that the field pulses accelerate the $\mathrm{A} \rightarrow \mathrm{B}$ reaction. Under the present experimental conditions, the field strength applied causes a large perturbation from the equilibrium state and therefore the forward and backward time constants differ in their magnitude. A reduction in the field strength to reduce the perturbation will result in a decrease in the change in amplitude making an accurate determination of time constants difficult. If the process would be followed without large perturbations, the time constants would be equivalent at any given point of the transition.

It is known that apart from ethanol, TFE also can induce the B-A transition (Minchenkova et al. 1986). If the same state of transition is considered, the B-A transition time constants obtained for poly [d(A-T)] in TFE solutions (fig 4.28) are similar to that observed in ethanol. This data shows that irrespective of the solvent used to reduce the water activity, the time constants of the B-A transition remained the same.

Reaction rates of polyelectrolytes are usually strongly dependent on the ionic strength. Thus, the B-A reaction should be analyzed at different salt concentrations. However, limitations imposed both by the experimental system and by the method preclude an analysis over a wide range of ionic strengths. Experiments were done at two different concentrations of $\mathrm{Na}^{+}, 75 \mu \mathrm{M}$ and $300 \mu \mathrm{M}$. The time constants of the B-A transients (fig 4.17 and fig 4.26) are in close agreement at both salt concentrations. Thus, the dependence of the time constants on the ionic strength is relatively small, if the same state of transition is considered. In order to have an 
explicit idea about the dependence of B-A reaction time constants on ionic strength, the analysis should be extended to a wider range of ionic strengths.

In a cooperative transition, for chain lengths above the cooperative length, the time constants should be independent of the chain length. The average reaction unit is defined by the cooperative length, which has been estimated for the B-Atransition to be 10-30 bp (Ivanov et al., 1992). Therefore, for chain lengths above the cooperative length, these time constants do not reflect a reaction over the full length of the polymer. The time constants for the B-A transition of $70 \mathrm{bp}, 120 \mathrm{bp}$ and 1500 bp samples of poly $[\mathrm{d}(\mathrm{A}-\mathrm{T})]$ are very close to each other.

The large amplitude observed for B-A transition of poly [d(A-T)] at 302 $\mathrm{nm}$ increased the sensitivity of the measurements, which made the determination of the reaction time constants more precise (fig 4.18). The concentration of poly [d(AT)] used for the field jump experiments at $302 \mathrm{~nm}$ is approximately 20 times higher than that used at $280 \mathrm{~nm}$. The time constants observed for the main amplitude for B-A transition in the field free and field on conditions are similar at both concentrations (fig 4.17 and fig 4.20). This shows that B-A transition is independent of the concentration of the probe.

Experiments with 859 bp DNA restriction fragment showed that electric field could induce B-A transition in natural DNA under well-defined conditions. Here the amplitudes are almost five times lower than that in poly $[\mathrm{d}(\mathrm{A}-\mathrm{T})]$, but the dependence of amplitude and time constants on ethanol percentages are same as that in poly $[\mathrm{d}(\mathrm{A}-\mathrm{T})]$. The extent of perturbation from the equilibrium state caused by electric field pulses are smaller in this case than in poly $[\mathrm{d}(\mathrm{A}-\mathrm{T})]$ and therefore the time constants observed for the $\mathrm{B} \rightarrow \mathrm{A}$ and $\mathrm{A} \rightarrow \mathrm{B}$ reactions are more or less similar. The time constants which represents the main amplitude of the B-A transition at both these wavelengths are in the range of $\sim 5 \mu \mathrm{s}$.

The experiments with 2629 bp plasmid DNA at 296 nm, 7160 bp plasmid DNA at $298 \mathrm{~nm}$ and $\lambda$-DNA at $298 \mathrm{~nm}$ confirmed the observations with 859 base pair restriction fragments and showed that the time constants of B-A transition is independent of chain length. In these cases, the time constant representing the main amplitude of the $\mathrm{B} \rightarrow \mathrm{A}$ reaction showed a value of $\sim 3 \mu$ s whereas the value observed for the $\mathrm{A} \rightarrow \mathrm{B}$ reaction time constants is $\sim 7 \mu \mathrm{s}$. The width of $\mathrm{B}-\mathrm{A}$ transition in natural DNA is broader than that in poly $[\mathrm{d}(\mathrm{A}-\mathrm{T})]$. Because of the large width of the 
transition, the magic angle amplitudes observed close to the initial and final ethanol regions of B-A transition, where the equilibrium is more shifted either to the B-form or to the A-form, are not with enough magnitude for an accurate determination of time constants.

The direction of the magic angle effect measured for various samples at different wavelengths clearly shows that electric field pulses induce a reaction from the A-form to the B-form. The preference for the B-form in the presence of electric fields indicates that B-helices have a higher effective dipole moment. The dipole moments are known to increase strongly with the length of DNA helices (Diekmann et al., 1982). The length increment per base pair for B-DNA (3.4A) is much higher than that for A-DNA $(\sim 2.8 \AA)$. These parameters imply that a dipolar stretching mechanism can be proposed for the field induced B-A transition. An analysis of the reaction transients under field pulses (fig 4.43) revealed that dipolar stretching could be the driving mechanism for the A to B transition. According to this mechanism the A to B reaction can only be driven when the dipole exceeds a threshold level. This threshold level is achieved by ion polarization and rotation of the polymers into the direction of the field vector. But field jump experiments at ethanol percentages around 69\%, which are more towards the B-form showed that orientation time constants are slower than the reaction time constants (fig 4.45 and 4.47). The dipolar stretching mechanism could not explain this observation because the observed reaction time is faster than the time required to achieve the threshold dipole moment, which is supposed to drive the reaction. The alternative mechanism which can be suggested is the field induced dissociation of counterions using the polyelectrolyte theory developed by Manning (1977 a,b, 1979, 2001, 2002). During the application of field pulses the counterions associated with the DNA double helix will undergo a homogenous dissociation. It is known that the charge density of A-form DNA is higher than that of B-form DNA. Therefore A-form DNA experiences a higher repulsive force from the negatively charged phosphate groups than B-form DNA. This destabilizes the A-form and under field pulses the helix prefers B-form, which is with a lower charge density than A-form. These observations suggests that depending on the ethanol percentage of the sample the mechanism which drives the A to B reaction under field pulse can be different. With the present experimental data it is difficult to arrive at a final conclusion about the extent of contribution of these mechanisms to the field induced B-A transition. 
The experimental data clearly show that the B-A- reaction proceeds with time constants of $\sim 5$ to $10 \mu$ s. Compared to the predictions by molecular dynamics (Chetham et al., 1996; Yang and Petit, 1996; Sporus et al., 1998; Stefl and Koca, 2000; Dornberger et al., 2001) this is unexpectedly slow. The activation barriers indicated by the experimental results are also larger than expectations based on x-ray structures, which were interpreted to represent a continuum of structures (Dickerson and Ng, 2001; Ng and Dickerson, 2002) between B-and A-DNA.

The experimental results on B-A transition showed a wide difference from predictions. There is a possibility for the occurrence of some potential side reaction in solution, which slows down the B-A transition. One reason for such retardation may be coupling with an aggregation reaction. A strong argument against this interpretation is provided by the dichroism decay time constants reflecting rotational diffusion, which is a very sensitive indicator of aggregation. The values obtained for the 70 bp and 120 bp fractions do not show any pertinent extent of aggregation under the conditions of the present experiments. Moreover, even after increasing the concentration of poly $[\mathrm{d}(\mathrm{A}-\mathrm{T})]$ by twenty times, the time constants remained the same. Another potential side reaction is field-induced denaturation of the double helix. The experimental conditions were selected to reduce the extent of this reaction to a minimum. Any residual field induced denaturation is not expected to affect the BA-reaction, because the cooperative length of the B-A-transition is much shorter than that of the helix-coil transition. Moreover the field strength was adjusted such that it is below the threshold field strength, which is necessary for denaturation.

The time constants observed for the B-A-transition should be compared with those observed previously for various related processes of nucleic acids. Simple stacking reactions in single stranded nucleic acids were observed in the time range from about 10 ns to $1 \mu \mathrm{s}$, depending on the base and the sugar residue (Porschke, 1977). Stacking of bases connected by a simple methylene-chain proved to be much faster (Porschke, 1978). Thus the sugar-phosphate chain seems to impose restrictions on the dynamics of base stacking. The relaxation time of double helix unzipping ("fraying” of helix ends) is $\sim 0.2 \mu$ s (Porschke, 1977). Stacking rearrangements in simple RNA loops (Menger et al., 2000) have been observed in the time range from 5 to $40 \mu$ s. These time constants demonstrate the level of activation barriers, which are expected to be in the same order of magnitude as those of the B-A-transition. From 
this point of view, the time constants observed in the present investigation, are consistent with previous observations.

The information on the dynamics of the B-A transition is not complete. The study should be extended to a greater extend to have a full insight into the internal dynamics of the helices. One limitation of the current investigation is the low ionic strength used in the present set of experiments. Current data show that the dependence on ionic strength is relatively small, which seems to be due to a rather small change of electrostatic repulsion during the B-A reaction. However this conclusion should be confirmed by measurements at higher salt concentrations. There are some indications for B-A transitions at high salt in the literature, but these cases are not nearly as well documented as those in the low salt regime.

Nucleic acids play a key role in the molecular processes associated with life. Therefore it is important to have an insight into the structural details of these molecules. DNA is a dynamic molecule. To have a complete understanding about the structural and functional characteristics of a dynamic molecule, a clear insight about the dynamics of its transitions between different conformations is necessary. The B-A transition represents the internal dynamics of DNA double helices. Most interpretations of the dynamics of DNA chains are based on the assumption of high rates for internal conversions between conformations. But the present study shows that B-A transition is a slower process than expected. Therefore, all interpretations based on the fast kinetics of internal dynamics of DNA double helices should be reconsidered. 


\begin{abstract}
Although the transition from the B-DNA double helix to the A-form is essential for biological function, as shown by the existence of the A-form in many protein-DNA complexes, the dynamics of this transition has not been resolved yet. The current study presents the first experimental data on the dynamics of B-A transition using a special electric field jump technique.

The B-A transition is associated with large spectral changes. The reduction of relative humidity drives the transition of B-form DNA to A-form and this can be generated in solution by the addition of ethanol. For the analysis of the kinetics of this transition, the stopped flow technique appeared to be the optimal method. Stopped flow experiments in which the B-A transition is induced by mixing DNA samples with ethanol is complete within the dead time of the instrument, showing that the reaction is faster than $\sim 0.2 \mathrm{~ms}$.

The possibility of using many other techniques were considered, but they were unacceptable due to one or other reason. Finally, electric field jump technique was tried to resolve the kinetics of the B-A transition. Electric field pulses are known to induce both physical and chemical reaction effects and the separation of these effects was carried out by the proper use of magic angle technique.

Poly $[d(A-T)]$ was established as the favourable model system, because of its relatively narrow transition width and also of a spectral signature allowing separation of potential side reactions. Electric field jump experiments were conducted on poly $[\mathrm{d}(\mathrm{A}-\mathrm{T})]$ samples and reaction amplitudes, which correspond to B-A transition, appeared under magic angle condition. The observed absorbance changes are consistent with the absorbance difference spectra measured for B-A transition. The absence of any amplitude outside the B-A transition range and the different nature of the amplitude observed at wavelengths $280 \mathrm{~nm}, 270 \mathrm{~nm}$ and $248 \mathrm{~nm}$, confirmed the successful separation of field induced orientation effect from reaction effect and the assignment of the observed effect to B-A transition. The time constants observed in the case of poly [d(A-T)] with 1500 bp are in the range of $10 \mu \mathrm{s}$. An additional process with time constants of $\sim 100 \mu \mathrm{s}$ is also observed which might be due to nucleation. Experiments were done on fragments with chain lengths 70 bp and
\end{abstract}


120 bp and similar time constants as those in 1500 bp are observed. These experiments showed that the time constants of B-A transition are independent of the chain length $\mathrm{N}$ of the sample for $\mathrm{N} \geq 70 \mathrm{bp}$.

One major drawback of the experiments with poly $[\mathrm{d}(\mathrm{A}-\mathrm{T})]$ is that the observations are restricted to the case of A-T base pairs only. In order to check for any dependence of the kinetics of B-A transition on G-C content, field jump experiments were conducted on salmon sperm DNA and $\lambda$-DNA samples at various ethanol percentages in the B-A transition range. But the reaction amplitudes appeared at $265 \mathrm{~nm}$ and $248 \mathrm{~nm}$ were not with sufficient magnitude for an accurate determination of time constants. The width of the B-A transition in natural DNA is almost 5 times broader than that in poly $[\mathrm{d}(\mathrm{A}-\mathrm{T})]$ and therefore the extent of perturbation from the equilibrium state upon the application of field pulses are smaller in natural DNA than in poly [d(A-T)]. However, it was known that when compared to other natural DNAs, DNA restriction fragments have a relatively narrow transition width. Field jump experiments were conducted on 859 bp DNA restriction fragments and reaction amplitude with sufficient magnitude appeared at $248 \mathrm{~nm}$ and $265 \mathrm{~nm}$. The observed time constants for the main amplitude of B-A transition at both wavelengths are in the range of $\sim 5 \mu \mathrm{s}$.

Analysis of the absorbance spectra of DNA revealed that the relative absorbance of A-form DNA to B-form DNA is higher at wavelengths around $300 \mathrm{~nm}$ than that at $265 \mathrm{~nm}$ or $280 \mathrm{~nm}$. This revealed the possibility of studying the B-A transition in DNA at wavelengths around $300 \mathrm{~nm}$ where a high concentration of DNA can be used. Field jump experiments conducted on poly [d(A-T)], 2629 bp plasmid DNA, 7160 bp plasmid DNA and $\lambda$-DNA at wave lengths in the range $296 \mathrm{~nm}$ to 302 $\mathrm{nm}$ gave reaction amplitudes with sufficient magnitude so that the determination of accurate time constants for B-A transition is possible. The time constants of the B-A transition and its dependence on ethanol percentage for poly [d(A-T)] samples at high concentration are in close agreement with that at low concentration which shows that B-A transition is independent of the concentration of the sample. The experiments with plasmid DNAs and $\lambda$-DNA confirmed the observations with 859 base pair restriction fragments and confirmed that the time constants of B-A transition is independent of chain length $\mathrm{N}$ of the sample for $\mathrm{N} \geq 859 \mathrm{bp}$. In natural DNA the time 
constant representing the main amplitude of the $\mathrm{B} \rightarrow \mathrm{A}$ reaction showed a value of $\sim 3$ $\mu$ s whereas the value observed for the $\mathrm{A} \rightarrow \mathrm{B}$ reaction time constants is $\sim 7 \mu \mathrm{s}$.

The direction of the magic angle effect measured at different wavelengths showed that electric field pulses stabilize the B-form compared to the A-form. Analysis of the reaction transients under field pulses revealed that depending on the ethanol percentage two mechanisms, the dipolar stretching mechanism and field induced dissociation of counter ion mechanism, can be proposed for the field induced B-A transition of DNA. It is obvious that some more studies should be done in order to arrive at a final conclusion about the percentage of contribution of these mechanisms to the reaction at different ethanol percentages.

The present study provides the first experimental data on the kinetics of B-A transition. The experiments clearly show that the B-A transition of DNA proceeds with time constants of $\sim 5$ to $10 \mu \mathrm{s}$. In comparison to the predictions by molecular dynamics this is unexpectedly slow. B-A transition represents the internal dynamics of the DNA double helices. Most interpretations of the dynamics of DNA chains are based on the assumption of a high rate for internal conversions between conformations. The experimental data show that the B-A transition is a slower process than expected and a significant activation barrier exists between these two clearly separated helical conformations. Therefore, all interpretations based on the fast kinetics of internal dynamics of DNA double helices should be reconsidered. 


\section{ABBREVIATIONS}

$\AA \quad$ Angstrom

A Absorbance

$\mathrm{A}_{\mathrm{ll}} \quad$ Absorbance with light polarized parallel to the field vector

$\mathrm{A}_{\perp} \quad$ Absorbance with light polarized perpendicular to the field vector

A-T Adenine-Thymine

AMP Adenosin monophosphate

ATP Adenosin-5'-triphosphate

${ }^{\circ} \mathrm{C} \quad$ Degree Celsius

CD Circular dichroism

Cm Centimeter

DNA Deoxyribonucleic acid

$\mathrm{D}_{\mathrm{r}} \quad$ Rotational diffusion coefficient

E $\quad$ Electric field strength

EtOH Ethanol

EDTA Ethylenediamminetetraacetic acid

FJ Field jump

G-C Guanine-Cytosine

$k \quad$ Boltzmans constant

$\mathrm{kV} \quad$ Kilovolt

$\mathrm{mM} \quad$ Millimolar

mm Millimeter

ms Millisecond

NMR Nuclear Magnetic Resonance

PC Personal Computer

RNA Ribonucleic acid

T Temperature

TEMED N,N,N',N'-tetramethylethylenediamide

TFE 2,2,2- Trifluoro ethanol

Tris Tris-hydroxymethyl-aminomethane

UV Ultraviolet

V Volt

$\mathrm{v} / \mathrm{v} \quad$ volume to volume 


\begin{tabular}{ll}
$\alpha$ & Polarizability \\
$\varepsilon$ & Molar extinction coefficient \\
$\varepsilon_{\mathrm{L}}$ & Molar extinction coefficient of left circularly polarized light \\
$\varepsilon_{\mathrm{R}}$ & Molar extinction coefficient of right circularly polarized light \\
$\phi$ & Orientation function \\
$\eta$ & Coefficient of viscosity \\
$\varphi$ & Angle \\
$\lambda$ & Wavelength \\
$\mu$ & Micro \\
$\mu \mathrm{s}$ & Microsecond \\
$\mu \mathrm{M}$ & Micromole \\
$\rho$ & Density \\
$\tau$ & Time constants \\
$\tau_{\mathrm{i}}$ & Integral time constant \\
$\tau_{1}^{\mathrm{r}}$ & Magic angle rise first time constant \\
$\tau^{\mathrm{r}}{ }_{2}$ & Magic angle rise second time constant \\
$\tau_{1}^{\mathrm{d}}$ & Magic angle decay first time constant \\
$\tau_{1}^{\mathrm{d}}{ }_{2}$ & Magic angle decay second time constant \\
$\tau_{\mathrm{s}}^{\mathrm{d}}$ & Magic angle decay solo time constant \\
$\nu$ & Kinematic Viscosity \\
$\xi$ & Reduced dichroism \\
\hline &
\end{tabular}




\section{SPECIFICATIONS}

The term poly $[d(A-T)]$ in the whole text is specifically used for the poly [d(A-T)] polymer which is with a chain length of $\sim 1500 \mathrm{bp}$. The other two poly [d(A-T)] fragments used in experiments were always prefixed with their measured average chain length.

The term Natural DNA in the text stands for all DNA samples, except poly [d(A-T)] fragments, used in the experiments. 


\section{REFERENCES}

1. Anderson,C.F. and Record,M.T.Jr. (1982) Annu. Rev. Phys. Chem., 33, 191222.

2. Anderson,C.F. and Record,M.T.Jr. (1990) Annu. Rev. Biophys. Biophys. Chem., 19, 423-465.

3. Arnott,S. Fuller,W. Hodgson,A. and Prutton,I. (1968) Nature, 220, 561-564.

4. Arnott,S. and Hukins,D.W.L. (1972) Biochem. Biophy.Res., 47, 1504-1510

5. Arnott,S. and Selsing,E. (1974) J.Mol.Biol., 88, 509-521.

6. Arnott,S. and Selsing,E. (1975) J.Mol.Biol., 98, 265-269.

7. Beabealashvily,R.S., Ivanov,V.I., Minchenkova,L.E. and Savochkina,P.L. (1972) Biochem.Biophys.Acta, 259, 35-40.

8. Bernasconi, C.F. (1976) Relaxation Kinetics, Academic Press New York.

9. Bloomfield,V.A., Crothers,D.M., and Tinoco,I.Jr., (2000) Nucleic AcidsStructures, Properties and Functions, University Science Books California.

10. Brahms,J. and Mommateers,M.F. J.Mol.Biol., 10, 73 (1964)

11. Cech,T.R. (1987) Sceince, 236, 1532-1539.

12. Chargaff,E. (1950) experimenta, 6, 201-209.

13. Chargaff,E. (1951) Fed. Proc., 10, 654-659.

14. Cheatham,T.E. and Kollman,P.A. (1996) J.Mol.Biol., 259, 434-444.

15. Cheatham,G.M.T. and Steitz,T.A. (1999) Science, 286, 2305-2309.

16. Creighton,T.E., (1984) Proteins, Structure and Molecular Properties., W.H. Freeman and company, pp 187-189.

17. Crick, F. (1970) Nature, 227, 561-563. 
18. Cohen,S.S. Hofner,N., Jansen,M., Moore,M. And Raina,A. (1967) Proc. Nat.Acad.Sci. USA, 57, 721-728.

19. Cooper, P.J. and Hamilton,L.D. (1966) J.Mol.Biol., 16, 562-563.

20. DeMaeyer,L.C.M. (1969) Methods in Enzymology, XVI, 80-118

21. DeMaeyer,L.C.M. (1974) Techniques of Chemistry, Wiley Interscience, VI, part II,

22. Dickerson, R.E.(1992) Methods Enzymol., 211, part A, 67-110

23. Dickerson,R.E. Bansal,M., Calladine,C.R., Diekmann,S., Hunter,W.N., et al (1989) J. Mol. Biol., 205, 787-791.

24. Dickerson,R.E. and Ng,H.L. (2001) Proc. Natl Acad. Sci. USA, 98, 6986-6988.

25. Diekmann,S., Hillen,W., Morgeneyer,B., Wells,R.D., and Porschke,D. (1982) Biphys. Chem, 15, 263-270.

26. Diekmann,S., Hillen,W., Jung,M., Wells,R.D., and Porschke,D. (1982) Biphys. Chem, 15, 157-160.

27. Dornberger,U., Spackova,N., Walter,A., Gollmick,F.A., Sponer.J. and Fritzsche,H. (2001) J. Biol. Struct. Dyn., 19, 159-172.

28. Dourlent,M., Hogrel,J.F., Helene,C. (1974) J.Am.Chem.Soc., 96, 3398-3406

29. Eigen,M. and DeMaeyer,L. (1963) Technique of Organic Chemistry VIII part II. Wiley, New York, pp 895-1054.

30. Florentiev,V.L. and Ivanov,V.I. (1972) Nature, 228, 519-522.

31. Franklin,R.E and Gosling, R. (1953) Nature, 171, 740-741.

32. Frank-kamenteskii,M.D. and Lazurkin,Y.S. (1974) Annual Rev. Biophys. Bioengineering, 3, 127-150. 
33. Frederq,E., Houssier,C., (1973) Electric dichroism and electric birefringence., Clarendon Press, New York.

34. Fuchs,E., Millette,R.L., Zilling.W. and Walter,G. (1967) Eur.J. Biochem., 244, 413-424.

35. Fuller,W., Wilkins,M.H.F., Wilson,H.R., Hamilton,L.D., and Arnott.S. (1965) J. Mol. Biol., 12, 60-80.

36. Girod,J.C., Johnson,W.C.Jr., Huntington,S.K. and Maestre,M.F. (1973) Biochemistry, 12, 5092-5096.

37. Gratzer,W.D. and Richards,E.G. (1971) Biopolymers, 10, 2607.

38. Grunhagen,H.H., (1974) Dissertation, Universitat Braunschweig, Germany

39. Guschalbauer,W., Chantot,J.F., and Thiele,D. (1990) J. Biomol. Struct. Dyn., 8, 491-511.

40. Hagerman, P.J. (1986) Nature, 321, 449-450.

41. Hillen,W. and Wells,R.D. (1980) Nucl. Acids. Res., 8, 5427-5431.

42. Hoffmann,G.W. (1971) Rev. Sci. Instrum., 42, 1643-1647.

43. Hseih,C.H., and Griffith,J.D. ( 1988) Cell, 52, 535-544.

44. Htun,H., and Dahlberg,J.E. ( 1988) Sceince, 241, 1791-1796.

45. Ivanov,V.I., and Minyat, E.E.(1981) Nucl. Acids. Res., 9, 4783-4798.

46. Ivanov,V.I., Minchenkova,L.E., Schyolkina,A.K.and Poletayev,A.I. (1983) Biopolymers, 12, 89-110.

47. Ivanov,V.I., Minchenkova,L.E., Minyat,E.E., Frank-kamentskii,M,D. and Schyolkina, A.K.(1974) J. Mol.Biol., 87, 817-833.

48. Ivanov,V.I., Minchenkova,L.E., Minyat,E.E., and Schyolkina,A.K.(1983) Cold Spring Harbor Symp.Quant.Biol., 47, 243-250. 
49. Ivanov,V.I., Krylov,D. Y. and Minyat, E.E.(1985) J.Biomol. Struct. Dyn., 3, 4356.

50. Ivanov,V.I., Karapetyan,A.T., Minyat,E.E. and Sagy,J. (1993) Mol.Biol., 27, 1150-1156.

51. Ivanov,V.I., and Krylov,D.Y. (1992) Methods Enzymol., 211, 111-127.

52. Ivanov,V.I. and Minchenkova,L.E. (1995) Mol.Biol., 6, 780-788.

53. Jacobbo-Molina,A., Ding,J., Nanni,R.G., Clark,A.D.Jr., Lu,X., Tantillo,C., Williams,R.L., Kramer,G., Ferris,A.L., Clark,P., Hizi,A., Hughes,S.H. and Arnold,E. (1993) Proc. Natl. Acad. Sci. USA., 90, 6320-6324.

54. Johnson, W.C. Jr., and Tinoco, I. Jr. (1969) Biopolymers, 7, 727.

55. Jones,S., van Heyningen,P., Berman,H.M. and Thornton,J.M. (1999) J.Mol.Biol., 287, 877-896.

56. Kiefer,J,R., Mao,C., Braman,J.C. and Beese,L.S. (1998) Nature, 391, 304-307.

57. Koo,H.S., and Crothers,D.M. ( 1988) Proc. Natl. Acad. Sci. USA., 85, 17631767.

58. Krylov,D.Y., Makarov,V.L. and Ivanov,V.I. (1990) Nucleic acids Res., 18, 759761.

59. Lane,A.N., Ebel,S. and Brown,T. (1993) Eur. J. Biochem., 215, 297-306.

60. Langridge,R., Wilson,H.R., Hooper,C.W., Wilkins,M.H.F., and Hamilton,L.D. (1960 a) J. Mol. Biol., 2, 19-37.

61. Langridge,R., Marvin,D.A., Seeds,W.E., Wilson,H.R. and Hamilton,L.D. (1960 b) J. Mol. Biol., 2, 38-64.

62. Lilley,D.M.J. ((1989) Chem. Soc. Rev., 18, 53-83.

63. Lu,X.J., Shakked,Z. and Olson,W.K. (2000) J. Mol. Biol., 287, 877-896. 
64. Manning,G.S. (1977 a) Biophy.Chem., 7, 95-102.

65. Manning,G.S. (1977 b) Biophy.Chem., 7, 189-192.

66. Manning,G.S. (1979) Accts. Chem. Res., 12, 443-449.

67. Manning,G.S. (2001) Macromolecules., 34, 4650-4655.

68. Manning,G.S. (2002) Biophy.Chem., 101, 461-473.

69. Marvin.D.A., Spencer.M., Wilkins,M.H.F., and Hamilton,L.D. (1961) J. Mol. Biol., 3, 547-565.

70. Menger,M., Eckstein,F. and Porschke,D. (2000) Biochemistry, 39, 4500-4507.

71. Meselson,M and Stahl,F.W. (1957) Proc. Natl. Acad. Sci. USA., 44, 671-682.

72. Minchenkova,L.E., Schyolkina,A.K., Chernov,B.K. and Ivanov,V.I. (1986) J.Biomol.Struct, Dyn. 4, 397-409.

73. Minyat,E.E., $\quad$ Ivanov,V.I., $\quad$ Kritzyn,A.M., $\quad$ Minchenkova,L.E., $\quad$ and Schyolkina,A.K., (1979) J. Mol. Biol., 128, 547-565.

74. Mirkin,S., Lyamichev,V., Kumarev.V., Kobzev,V., Nosikov,V. and Vologodskii,A. (1987) J.Biomol.Struct, Dyn., 5, 79-88.

75. Mohr,S.C., Sokolov,N.V.H.A., He.C. and Setlow,P. (1991) Proc. Natl. Acad. Sci. U.S.A., 88, 77-81.

76. Morris,D.R. (1973) Polyamines in Normal and Neoplastic Growth., Raven press New York pp. 111-122.

77. Nara-Inui,H., Akutsu,H. And Kyogoku,Y. (1985) J. Biochem., 98, 629-636.

78. Ng,H.L. and Dickerson,R.E. (2002) Nucleic Acids Res., 30, 4061-4067.

79. Onsager,L. (1934) J.Chem.Phys., 2, 599.

80. Porschke,D.(1974) Biophys. Chem., 1, 381-386.

81. Porschke,D.(1976) Biophys. Chem., 4, 383-394.

82. Porschke,D.(1978) Biopolymers, 17, 315-323. 
83. Porschke,D.(1979) Nucleic Acids Res., 6, 883-898.

84. Porschke,D.(1985) Annu. Rev. Phys. Chem., 36, 159-178.

85. Porschke,D.(1985) Mol. Biol. Biochem. Biophys., 24, 191-218.

86. Porschke,D. and Jung, M (1985) J. Biomol.Struct.Dyn., 2, 1173-1184.

87. Porschke,D. and Obst,A.(1991) Rev. Sci. Instrum., 62, 818-820.

88. Porschke,D.(1996) Ber.Bunsenges. Phys. Chem., 100, 715-720.

89. Porschke,D.(2001) Protein-Ligand interactions: Hydrodynamics and Calorimetry. A practical Approach., Oxford University Press, Oxford, UK, pp $197-221$.

90. Potaman,V.N., Bannikov,Y.A., and Shlyachtenko,L.S. (1980) Nucleic Acids Res., 8, 635-642.

91. Rajagopal,P., and Feigon,J. (1989) Nature, 339, 637-640.

92. Rosenberg,M., Seeman,N.C., Day,R.O., and Rich,A. (1976) J.Mol.Biol., 104, $145-167$.

93. Samejima,T., Hashizume,H., Imahori,K., Fujii,I., and Miura,K. (1968) J.Mol.Biol., 34, 39.

94. Saenger,W. (1984) “Principles of Nucleic acid structure”. Springer-Verlag, New York.

95. Seeman,N.C., Rosenberg,M., Suddath,F.L., Kim,J.J. and Rich,A. (1976) J.Mol.Biol., 104, 109-144.

96. Sinden,R.R., (1994) DNA Structure and Function, Academic Press.

97. Sharp,P.A. (1987) Sceince, 235, 766-771.

98. Sprecher,C.A., Basse,W.A. and Johnson,W.C.Jr. (1979) Biopolymers, 18, 10091019. 
99. Sprous,D., Young,M.A. and Beveridge,D.L. (1998) J. Phys. Chem. B, 102, 4658-4667.

100. Stefl,R. and Koca,J. (2000) J. Am. Chem. Soc., 122, 5025-5033.

101. Sundquist,W.I., and Klug,A. (1989) Nature, 342, 825-829.

102. Tolostorukov,M.Y., Ivanov,V.I., $\quad$ Malenkov,G.G., Jernigapin,R.L., and Zhurkin,V.B. (2001) Biophys. J., 81, 3409-3421.

103. Tonomura,B., Nakatani,H., Ohnishi,M., Yamaguchi-Ito,J. and Hiromi.K. (1978) Anal. Biochem., 84, 370-383.

104. Tunis-Schneider,M.J.B. and Maestre,M.F. (1970) J.Mol.Biol., 52, 521-543.

105. Vargason,J.M., Henderson,K., Ho,P.S. (2001) Pro.c Natl. Acad. Sci. U.S.A., 98, 7265-7270

106.Vorlickova,M., Sedlacek,P., Kypr,J. and Sponar,J. (1982) Nucleic Acids Res., 10, 6969-6979.

107. Vorlickova,M. and Kypr,J. (1985) J. Biomol. Struct. Dyn., 3, 67-83.

108. Wachsman, W.and Antony, D.D. (1980) Biochemistry, 19, 5981-5986.

109. Watson,J.D. and Crick,F.H.C. (1953) Nature, 171, 737-738.

110. Wells,R.D., and Harvey,S.C. (1987) Unusual DNA structures, Springer, New York.

111. Wells,R.D., Collier,D.A., Hanvey,J.C., Shimizu,M., and Wohlrab,F. (1988) FASEB J., 2, 2939-2949.

112. Wien,M. (1931) Phys.Z., 32, 545.

113. Wilkins,M.H.F., and Randall,J.T. (1953) Biochim. Biophys. Acta., 10, 192.

114. Wilkins,M.H.F., Stocker,A.R., and Wilson,H.R. (1953) Nature, 171, 738-740.

115. Wissbrun,K.F. and Patterson,A. (1958) J. Polym. Sci., 33, 235-247.

116. Xu,Q., Shoemaker,R.K. and Braunlin,W.H. (1993) Biophys. J., 65, 1039-1049. 
117. Yamakawa,H. and Fuji,M. (1973) Macromolecules, 6, 407-415.

118. Yang,L and Pettitt,B.M. (1996) J.Phys.Chem., 100, 2564-2566.

119. Young,D.V. and Srinivasan,P.R. (1974) J. Bacteriol., 117, 1280.

120. Zamenhof,S., Brawerman,G., and Chargaff,E. (1952) Biochim. Biophys. Acta., 9,402-405. 


\section{Acknowledgement}

I sincerely thank my Supervisor, Prof. Dr. Dietmar Pörschke for the excellent guidance and encouragement offered throughout my stay at Max Plank Institute for Biophysical Chemistry, Göttingen. I admire the patience he exercised while dealing often with my scientific queries and for inspiring myself to the hidden problems of biophysics.

I am grateful to Prof. Dr. J. Troe who agreed to be my doctoral referent during my research.

I would like to express my sincere thanks to Mr. Jürgen Wawrzinek for the assistance he offered whenever required and for providing a pleasant working atmosphere in the lab.

Words are inadequate to express my heartfelt thanks to my friends Saju, Mahesh, Venketesh, Shiva, and Vinesh for their unstinted support that often pulled me out of my bad times.

My largest debt of gratitude is owed to my parents, brothers and sister in law whose love, faith and inspiration shaped my career that keeps me going fine.

Finally I would like to acknowledge Deutschen Forschungsgesellschaft (DFG) and Max-Planck Society for the generous financial support. 


\section{Lebenslauf}

Davis Jose

16-01-1977: $\quad$ geboren in Palai, Indien

Staatsangehörigkeit : indisch

1982-1992: $\quad$ Besuch der Mittelschule in Kottayam,Indien

1992-1994: $\quad$ Studium an der Mahatma Gandhi University, Kottayam,Indien

Pre-Degree (physics, Chemistry and Biology)

1994-1997 : $\quad$ Studium an der Mahatma Gandhi University, Kottayam, Indien Bachelor of Science (Chemistry)

1997-2000 : $\quad$ Studium an der Mahatma Gandhi University, Kottayam, Indien Master of Science (Chemistry)

Seit ab 2001 : $\quad$ Doktorand an der Abteilung für Biomolecular Dynamics der MPI for Biophysical Chemistry unter der Anleitung von Prof. Dr. D.Pörschke.

Davis Jose

15.03.05 

